\author{
Universidade de São Paulo \\ Instituto de Física
}

\title{
INCORPORAÇÃO DO ESPALHAMENTO COMPTON NO MODELO DE TBC MODIFICADO
}

\author{
Daniel Cruz Torres
}

Orientador: Prof. Dr. Paulo Roberto Costa

Dissertação de mestrado apresentada ao Instituto de Física para a obtenção do título de Mestre em Ciências

Banca Examinadora:

Prof. Dr. Paulo Roberto Costa (IFUSP)

Prof. Dr. Sergio Luiz Morelhão (IFUSP)

Prof. Dr. Ricardo Andrade Terini (IEE-USP) 


\section{FICHA CATALOGRÁFICA \\ Preparada pelo Serviço de Biblioteca e Informação do Instituto de Física da Universidade de São Paulo}

\section{Torres, Daniel Cruz}

Incorporação do espalhamento Compton no modelo de TBC modificado. São Paulo, 2015.

Dissertação (Mestrado) - Universidade de São Paulo. Instituto de Física. Departamento de Física Nuclear

Orientador: Prof. Dr. Paulo Roberto Costa

Área de Concentração: Física Médica

Unitermos: 1. Física médica; 2. Espalhamento Compton; 3. Klein-Nishina; 4. Simulação computacional. 
Aos meus pais, Evandro e Maria Emília, irmãos, amigos, e em especial à minha esposa Sheila 


\section{Agradecimentos}

A lista de pessoas as quem que devo meus agradecimentos não caberia em poucas palavras, quiça em várias, porém no pouco espaço que tenho quero que todas elas saibam que são os mais sinceros agradecimentos

Aos meus pais, Evandro e Maria Emília por terem me criado, mesmo com todas as dificuldades, me dando todo o que eu necessitava.

Em especial, à minha mãe, que além do seu companheirismo e bons exemplos, sempre esteve do meu lado no percurso desta vida.

As meus irmãos, Dalmo e Mário, que se não tivesem nascido meus irmãos assim se teriam tornado por escolha, pois são os companheiros que tenho tido por toda vida.

Às minhas irmãs Mariana e Luisa, e sobrinhas Amanda, e Malu, por me deixarem, ainda que um pouco à contragosto, falar tanto sobre assuntos relacionados à física

Ao meu orientador Paulo Costa, por ter me ajudado, principalmente nas horas difíceis.

À professora Elisabeth Yoshimura, que com suas inspiradoras aulas duante a graduação, criou em mim o gosto pela área de física das radiações.

À todos os colegas e amigos da Dosimetria que me inspiraram, foram companheiros nas horas de festa e também nas horas em desânimo. Dentre eles alguns ajudaram diretamente neste trabalho, Josilene Cerqueira, Leandro Mariano, Alejandro Heyner. Sem sua ajuda este trabalho não teria chegado ao seu fim.

Ao amigo Jonatas Cesar, por ter sido o primeiro colaborador na análise dos dados.

Aos amigos Leonardo Jeronimo e Leila Lobato, pelas muitas e muitas horas de estudos em grupo, que me ensinaram física e companheirismo.

Aos amigos Jessé Américo, Leandro Biondo, Rafael Rossi e Everton Medeiros por me aturar nas minhas lamúrias, e serem meus amigos de copo e de cruz.

Ao meu professor de Jiu Jitsu, Adriano Silva, que me ensinou, pelo exemplo, que para se conseguir alguma coisa é preciso não só querer, mas querer muito.

Por fim, gostaria de agradecer à minha esposa Sheila, por além de ter me suportado nas dificuldades e ser minha companheira nas alegrias, mas por carregar em seu ventre um ser, que ainda mesmo antes de vir ao mundo já é a razão do meu viver. 


\section{SUMÁRIO}

1 INTRODUÇÃO

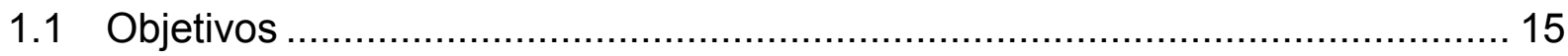

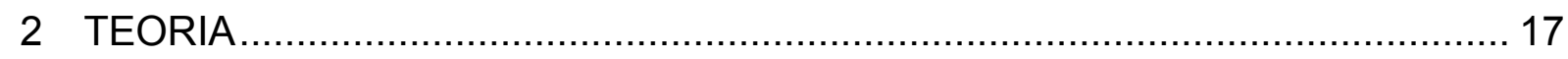

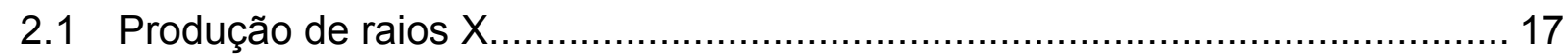

2.2 Interação de partículas carregadas rápidas com a matéria............................. 18

2.3 Interação de fótons com a matéria. ............................................................ 23

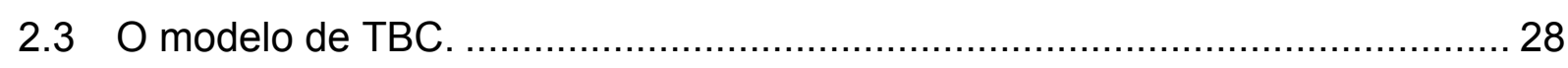

2.4 O modelo de TBC Modificado.................................................................... 31

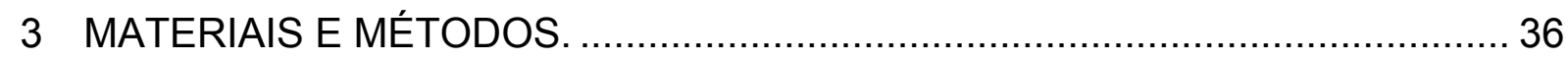

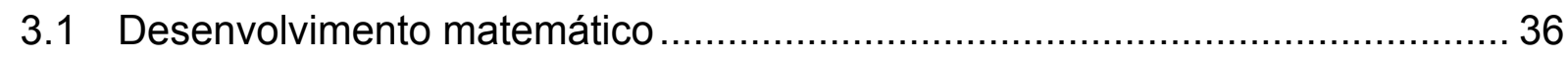

3.2 Escolha da geometria e das propriedades físicas da barreira espalhadora. .... 38

3.3 Cálculo do número de fótons espalhados................................................. 41

3.4 Aparato experimental utilizado nas medições para validação do modelo

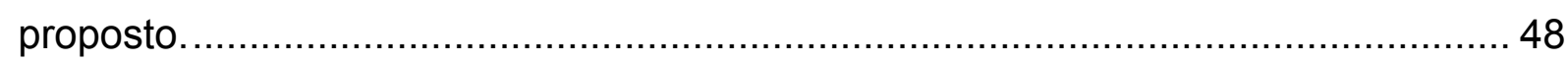

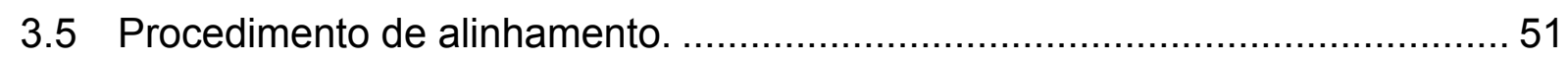

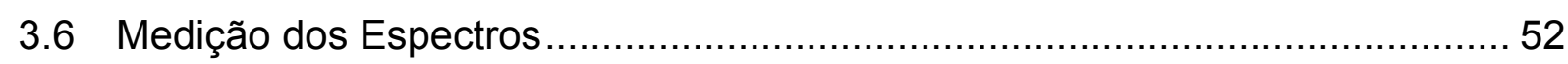

3.7 Métricas usadas para comparações entre espectros medidos e cálculados... 56

3.8 Validação do modelo de TBC modificado para filtração adicional de $15 \mathrm{mmAl} . .57$

3.9 Calibração da amplitude dos espectros calculados ........................................ 62

4 RESULTADOS

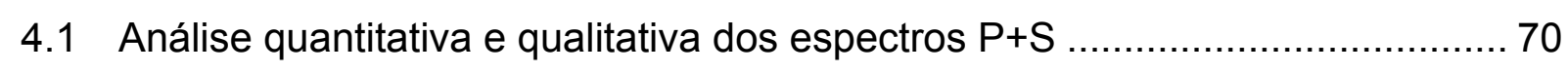

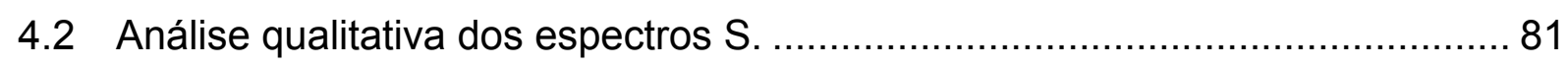

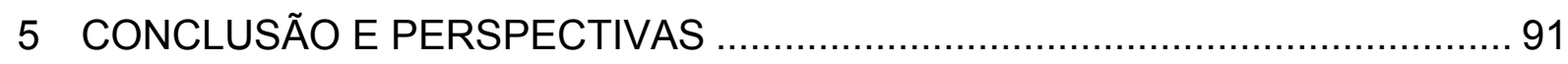

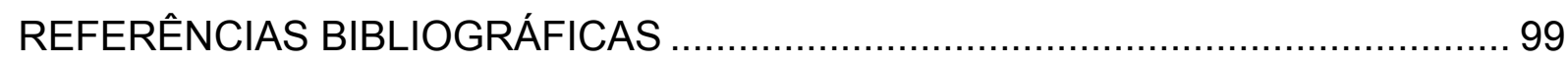




\section{LISTA DE FIGURAS}

Figura 1 - Esquema simplificado da aceleração de elétrons no tubo de raios $X$ em direção ao alvo. Pela interação dos elétrons com material do alvo há a emissão de fótons em todas as direções (Adaptado de Oppelt, A.).

Figura 2 - O parâmetro de impacto b é a menor distância entre a trajetória da partícula incidente e o alvo cuja interação irá provocar espalhamento. (Adaptado de Podgosrsak, E.B.)..... 19

Figura 3 - Diagrama simplificado dos níveis de energia para o átomo de tungstênio. (Adaptado de Oppelt, A.)

Figura 4 - Poder de freamento mássico total, por colisão e por radiação, para o tungstênio, e para energias que vão além das usadas em medicina diagnóstica. Apenas uma pequena parte das interações emite radiação, e por isso, apenas cerca de $1 \%$ da energia aplicada no feixe de elétrons do tubo de raios $X$ se converte efetivamente em fótons de raios $X$

Figura 5 - Esquema simplificado do efeito fotoelétrico, o fóton incidente é completamente absorvido pelo átomo, que por sua vez ejeta um elétron. Posteriormente a vacância deixada pelo elétron ejetado é preenchida pela transição um elétron de uma das camadas superiores, com a emissão de um fóton característico. (Adaptado de Oppelt, A.)

Figura 6 - Esquema simplificado da cinemática do espalhamento Compton. (Adaptado de Oppelt, A.)

Figura 7 (a) Espectro de raios X utilizando $100 \mathrm{kV}$, e (b) Região de interesse para cálculo de áreas abaixo de cada pico característico'. 34

Figura 8 - Geometria de detecção utilizada nos experimentos para determinação dos espectros transmitidos por materiais utilizados, e adotada para incorporação da função de correção para o efeito Compton.

Figura 9 - Forma da barreira usada no modelo matemático para simulação de espalhamento Compton, com elemento de volume em detalhe. O cálculo do espalhamento Compton é feito para cada uma das células (voxels), o conjuntos de células forma a grade usada para discretização da barreira (Adaptado de Pfenniger and Friedli)

Figura 10 - Livre caminho médio do fóton no acrílico para ocorrência de interação Compton. Fótons com energias entre 20 e $150 \mathrm{keV}$ que percorrem distâncias menores que $6 \mathrm{~cm}$ no acrílico apresentam baixa probabilidade de realizarem espalhamento secundário.

Figura 11 - Comparação entre o coeficiente de atenuação total e apenas por interação Compton para o acrílico na faixa de energias utilizada em radiologia diagnóstica

Figura 12 - Visão em duas dimensões da dependência em relação à geometria para o cálculo do espalhamento Compton em cada célula. 
Figura 13 - Fluxograma do programa computacional que implementa o modelo matemático usado para o cálculo do espalhamento Compton.

Figura 15 - Aparato experimental que permite representar a geometria apresentada esquematicamente na Figura 12: Barreira de acrílico em primeiro plano, espectrômetro e câmara de ionização ao fundo.

Figura 16 - Aparato experimental que permite representar a geometria apresentada esquematicamente na Figura 12: Tubo de raios $X$ ao fundo, e a barreira de acrílico.

Figura 17 - Na mesma imagem estão a câmara de ionização e o espectrômetro, já montados $e$ alinhados para as medições.

Figura 18 - Imagem do digitalizador computadorizado de radiografias, com seu respectivo image plate posicionado para leitura. (Adaptado de Mariano)

Figura 19: Equipamento de imageamento digital (IP) posicionado atrás do espectrômetro e da câmara de ionização para a aquisição de imagens, estas imagens foram usadas para centralização destes equipamentos em relação ao feixe de raios $X$.

Figura 20 - Exemplo de uma das imagens radiográficas utilizadas para alinhamento do arranjo experimental. Pode-se observar a parte traseira do espectrômetro e a barreira para espectros primários. ....... 52

Figura 21 - Representação esquemática do aparato experimental usado nas medições de espectros transmitidos mais espalhados pela barreira, $P+S$.

Figura 22 - Representação esquemática do aparato experimental usado nas medições de espectros espalhados pela barreira, $S$

Figura 23 - Espectros medidos (linhas azuis) e calculados (linhas verdes) referentes às tensões de 50, 80, 110 e $150 \mathrm{kV}$ aplicadas ao tubo de raios X. A filtração adicional considerada na simulação e adotada no procedimento experimental foi de $15 \mathrm{~mm}$ de Al.

Figura 24 - Diagrama de fluxo mostrando o funcionamento do programa que calcula os parâmetros para ajuste dos espectros.

Figura 25 - Superfície formada pelo cálculo do indicador de forma $\delta 2$ aplicado aos diversos valores do fator exponencial B (cm), e da constante multiplicativa A (adimensional), para espectro primário com tensão de $150 \mathrm{kV}$.

Figura 26 - Na figura da esquerda está um dos espectros primários apresentados na Figura 23 à direita, ajuste feito neste espectro primário, usando $B=1,06$ e $A=1$.

Figura 27 - Reta de calibração da amplitude dos espectros calculados, obtida por regressão linear a partir do conjunto de todos os valores de kerma no ar total medido/kerma no ar total calculado. Os dados considerados são os dos espectros de feixes atenuados pela barreira incluindo o espalhamento.

Figura 28 - Exemplo de comparação entre espectros de espalhamento medido e calculado. Os espectros representam o feixe espalhado pela barreira de acrílico de $20 \mathrm{~mm}$ à $2 \mathrm{~m}$ da fonte e para tamanho de campo de $39,5 \mathrm{~cm}$ de raio.

Figura 29 - Espectros P+S. Raio do campo $39,5 \mathrm{~cm}$, distância da barreira $2 \mathrm{~m}$, e espessura $20 \mathrm{~mm} . . .70$ 
Figura 30 - Espectros P+S. Raio do campo 27,5 cm, distância da barreira $2 \mathrm{~m}$, e espessura $20 \mathrm{~mm}$.... 71

Figura 31 - Espectros P+S. Raio do campo 18,2 cm, distância da barreira $2 \mathrm{~m}$, e espessura $20 \mathrm{~mm}$..... 71

Figura 32 - Variação no tamanho de campo para espectros $P+S$, barreira de $20 \mathrm{~mm}$ de espessura à 2 $m$ da fonte de raios $X$.

Figura 33 - Valores de figura de mérito $\delta 2$ para espectros medidos com diferentes tamanhos de campo. Feixes $P+S$. Barreira de acrílico de $20 \mathrm{~mm}$ espessura à $2 \mathrm{~m}$ da fonte. 73

Figura 34 - Espectros P+S. Raio do campo $39,5 \mathrm{~cm}$, distância da barreira $2 \mathrm{~m}$, e espessura $20 \mathrm{~mm}$.... 74

Figura 35 - Espectros P+S. Raio do campo 39,5 cm , distância da barreira $2 \mathrm{~m}$, e espessura $24 \mathrm{~mm} . .75$

Figura 36 - Espectros P+S. Raio do campo $39,5 \mathrm{~cm}$, distância da barreira $2 \mathrm{~m}$, e espessura $44 \mathrm{~mm}$...... 75

Figura 37 - Razão entre valores de kerma no ar medidos e calculados considerando diferentes espessuras da barreira. Foram utilizados espectros $P+S$, para tamanho de campo de $39,5 \mathrm{~cm}$ à uma distância de $2 m$. 76

Figura 38 - Valores de $\delta 2$, considerando diferentes espessuras da barreira. Foram utilizados espectros P+S. Tamanho do campo de 39,5 cm e uma distância de $2 \mathrm{~m}$. 77

Figura 39 - Espectros P+S. Raio do campo $39,5 \mathrm{~cm}$, distância da barreira $2 \mathrm{~m}$, e espessura $44 \mathrm{~mm}$...... 78

Figura 40 - Espectros P+S. Raio do campo 39,5 cm , distância da barreira 2,87 m, espessura $44 \mathrm{~mm}$. . 78

Figura 41 - Espectros P+S. Raio do campo 39,5 cm , distância da barreira 4,34 m, espessura 44mm... 79

Figura 42 - Variação na distância da barreira, para espectros $P+S$. Tamanho de feixe de $39,5 \mathrm{~cm}$. Barreira com $44 \mathrm{~mm}$ de espessura. 80

Figura 43 - Variação na distância da barreira pelo $\delta 2$, fótons de espectros $P+S$. Tamanho de feixe de $39,5 \mathrm{~cm}$. Barreira com $44 \mathrm{~mm}$ de espessura. 81

Figura 44 - Espectros S.Raio do campo $39,5 \mathrm{~cm}$, distância da barreira $2 \mathrm{~m}$, espessura $20 \mathrm{~mm}$...........82

Figura 45 - Espectros S. Raio do campo $27,5 \mathrm{~cm}$, distância da barreira $2 \mathrm{~m}$, e espessura $20 \mathrm{~mm}$.........82

Figura 46 - Espectros S. Raio do campo 18,2 cm, distância da barreira $2 \mathrm{~m}$, e espessura $20 \mathrm{~mm}$...........83

Figura 47 - Valores de figura de mérito $\delta 2$ para espectros medidos com diferentes tamanhos de campo. Feixes espalhados pela barreira de acrílico $20 \mathrm{~mm}$ de espessura à $2 \mathrm{~m}$ da fonte. 83

Figura 48 - Espectros S. Raio do campo $39,5 \mathrm{~cm}$, distância da barreira $2 \mathrm{~m}$, espessura $20 \mathrm{~mm}$.............85

Figura 49 - Espectros S. Raio do campo $39,5 \mathrm{~cm}$, distância da barreira $2 \mathrm{~m}$, e espessura $24 \mathrm{~mm}$..........8 85

Figura 50 - Espectros S. Raio do campo $39,5 \mathrm{~cm}$, distância da barreira $2 \mathrm{~m}$, espessura $44 \mathrm{~mm}$...........8 86

Figura 51 - Valores de $\delta 2$ considerando diferentes espessuras da barreira. Foram utilizados espectros $S$ para tamanho de campo de 39,5 cm e uma distância de $2 \mathrm{~m}$ 86

Figura 52 - Espectros S. Raio do campo $39,5 \mathrm{~cm}$, distância da barreira $2 \mathrm{~m}$, e espessura $44 \mathrm{~mm}$..........87 Figura 53 - Espectros S. Raio do campo 39,5 cm , distância da barreira 2,87 m,e espessura $44 \mathrm{~mm}$.....88

Figura 54 - Espectros S. Raio do campo 39,5 cm , distância da barreira 4,34 m,e espessura $44 \mathrm{~mm}$.....88

Figura 55 - Variação com a distância da barreira, espectros S, pela figura de mérito $\delta 2$. Tamanho de feixe de $39,5 \mathrm{~cm}$. Barreira com $44 \mathrm{~mm}$ de espessura 
Figura 56: Razão dos valores de kerma no ar para os espectros $P+S$ para todas as configurações de medições. A linha vermelha indica o valor ideal da razão, 1. As linhas pontilhadas indicam os valores máximos $e$ mínimos obtidos. As incertezas não foram incluídas na figura para maior clareza 


\section{LISTA DE TABELAS}

Tabela 1 - Características do tubo de raios X usado nas medições (adaptado de Gonzales). 49

Tabela 2 - Parâmetros usados tanto nas medições de espectros $P$, quanto na sua simulação com uso do Modelo de TBC Modificado. Os valores de tensão, corrente e tempo foram aplicados no tubo de raios .57

Tabela 3 - Parâmetros de correção encontrados por maximização. No parâmetro A a maior incerteza é de $1 \%$ e para o parâmetro $B$ a maior incerteza é de $0,1 \%$.

Tabela 4 - Figura mérito dada por divisão entre os valores de kerma no ar medido e calculado, para os pares de espectros primários utilizados par a verificação do ajuste descrito na equação (45). 63

Tabela 5 - Dados obtidos nas medições para a variação com o tamanho do campo. São apresentados os valores de kerma no ar e as respectivas técnicas radiográficas utilizadas em cada conjunto de medições $S$ e $P+S$. As incertezas associadas aos valores de kerma no ar foram estimadas em no máximo 10,3\% ${ }^{53}$. Espessura da barreira de $20 \mathrm{~mm}$ e distância da barreira de $2 \mathrm{~m}$.

Tabela 6 - Dados obtidos nas medições, para a variação com a espessura da barreira. São apresentados os valores de kerma no ar e as respectivas técnicas radiográficas utilizadas em cada conjunto de medições $S$ e P+S. Com tamanho de campo de 39,5 cm e distância da barreira de $2 \mathrm{~m}$. As incertezas associadas aos valores de kerma no ar foram estimadas em $10,3 \%{ }^{53}$ 68

Tabela 7 - Dados obtidos nas medições para a variação com a distância da barreira. São apresentados os valores de kerma no ar e as respectivas técnicas radiográficas utilizadas em cada conjunto de medições $S$ e P+S. Com tamanho de campo de 39,5 cm e espessura da barreira de $20 \mathrm{~mm}$. As incertezas associadas aos valores de kerma no ar foram estimadas em $10,3 \%^{53}$ 


\section{RESUMO}

No último século, houve grande avanço no entendimento das interações das radiações com a matéria. Essa compreensão se faz necessária para diversas aplicações, entre elas o uso de raios $X$ no diagnóstico por imagens. Neste caso, imagens são formadas pelo contraste resultante da diferença na atenuação dos raios $X$ pelos diferentes tecidos do corpo. Entretanto, algumas das interações dos raios $X$ com a matéria podem levar à redução da qualidade destas imagens, como é o caso dos fenômenos de espalhamento. Muitas abordagens foram propostas para estimar a distribuição espectral de fótons espalhados por uma barreira, ou seja, como no caso de um feixe de campo largo, ao atingir um plano detector, tais como modelos que utilizam métodos de Monte Carlo e modelos que utilizam aproximações analíticas. Supondo-se um espectro de um feixe primário que não interage com nenhum objeto após sua emissão pelo tubo de raios $X$, este espectro é, essencialmente representado pelos modelos propostos anteriormente. Contudo, considerando-se um feixe largo de radiação $X$, interagindo com um objeto, a radiação a ser detectada por um espectrômetro, passa a ser composta pelo feixe primário, atenuado pelo material adicionado, e uma fração de radiação espalhada. $A$ soma destas duas contribuições passa a compor o feixe resultante. Esta soma do feixe primário atenuado, com o feixe de radiação espalhada, é o que se mede em um detector real na condição de feixe largo. O modelo proposto neste trabalho visa calcular o espectro de um tubo de raios $X$, em situação de feixe largo, o mais fidedigno possível ao que se medem em condições reais. Neste trabalho se propõe a discretização do volume de interação em pequenos elementos de volume, nos quais se calcula o espalhamento Compton, fazendo uso de um espectro de fótons gerado pelo Modelo de TBC, a equação de Klein-Nishina e considerações geométricas. Por fim, o espectro de fótons espalhados em cada elemento de volume é somado ao espalhamento dos demais elementos de volume, resultando no espectro total espalhado. O modelo proposto foi implementado em ambiente computacional MATLAB ${ }^{\circledR}$ e comparado com medições experimentais para sua validação. O modelo proposto foi capaz de produzir espectros espalhados em diferentes condições, apresentando boa conformidade com os valores medidos, tanto em termos quantitativos, nas quais a diferença entre kerma no ar calculado e kerma no ar medido é menor que $10 \%$, quanto qualitativos, com fatores de mérito superiores a $90 \%$.

Palavras-chave: Espalhamento Compton , Klein-Nishina, simulação computacional. 


\begin{abstract}
The understanding of the interactions between radiation and matter advanced considerably in the last century. This understanding was needed by several applications, such as the use of X-rays in diagnostic imaging. In diagnostic applications, the image is created by the contrast resulting from the X-ray attenuation by the different body tissues. However, some interactions between the X-rays with the matter may reduce the quality of the images obtained in diagnostic imaging, as is the case of the scattering phenomenon. There are several modeling approaches to estimate the spectral distribution of photons scattered through a barrier, as in the case of a broad beam hitting a spectrometer detector. For instance, there are approaches that use Monte Carlo methods and approaches that use analytical approximations. Assuming a primary spectrum that does not interact with any object after its issuance by the $X$-ray tube, this spectrum is essentially represented by the previously proposed models. However, considering a broad beam of X-rays interacting with an object, the radiation to be detected by a spectrometer is now composed of the primary beam attenuated by the added material, and a scattered radiation fraction. The sum of these two contributions becomes part of the resulting beam. This sum of attenuated primary beam with the scattered radiation beam is what is measured in a real detector in broad beam condition. The model proposed in this work aims to simulate the spectrum of an x-ray tube in wide beam situation, the most reliable possible to what is measured in real conditions. In this work we propose the discretisation of the volume of interaction into small volume elements, which are used to calculate the Compton scattering. The spectrum of the photon spreading in each volume element is added to other volume elements, resulting in the spectrum of the whole barrier. The proposed model was implemented in MATLAB $^{\circledR}$, a computational environment. We evaluate the model by comparing the computational results with results from physical experiments. The model we propose was capable of creating accurate distribution of the spectrum spreading, under different conditions and in different experiments. The model results were close to the results obtained by experimental evaluation, both quantitatively, such as the difference smaller than $10 \%$ between the simulated air kerma and the measured air kerma obtained in the experimental evaluation, and qualitatively.
\end{abstract}




\section{INTRODUÇÃO}

Em 1895, ao fazer experimentos com raios catódicos, o alemão W. C. Roentgen notou que raios emitidos de seu tubo experimental tinham a notável capacidade de atravessar diferentes materiais, como placas de diferentes metais, papel e diversos líquidos ${ }^{1}$. O pesquisador notou que se tratava de raios diferentes dos já conhecidos raios catódicos, por não sofrerem desvios aparentes por campo magnético e por apresentarem grande capacidade de penetração.

Diante dessas características peculiares, Roentgen utilizou sua própria mão, e a mão de sua esposa para testar seus resultados. Ao perceber que os ossos podiam ser vistos em contraste ao restante do tecido, concluiu que o tecido ósseo absorvia parcialmente esses raios. Para identificar tais efeitos, Roentgen denominou-os de Raios X, sendo esse termo utilizado em seu artigo intitulado On a new kind of rays ${ }^{2}$, em que discorre sobre seus achados, além de constar a radiografia da mão da sua esposa.

Essa descoberta teve impacto imediato na comunidade científica, pois, entre várias possibilidades, estava a possibilidade de visualização do corpo a partir de uma ferramenta não invasiva. Ou seja, foi possível, então, "ver o interior do corpo sem cortá-lo".

Este evento foi o precursor do início do uso dos raios $X$ na medicina diagnóstica. $O$ desenvolvimento do uso dos raios $X$ foi imenso desde então e, ainda nos dias atuais, é usado em um grande número de aplicações, desde a medicina diagnóstica, difração de raios $X$ e até mesmo o tratamento de doenças. Este último é o caso da teleterapia, onde se usam feixes de raios $X$ de alta energia em tratamentos contra o câncer.

No último século, muito se avançou no entendimento das interações das radiações com a matéria. Essa compreensão se fez necessária para melhorar a capacidade de uso dos raios $X$ para diagnóstico. A imagem diagnóstica é formada pela diferença de atenuação entre os diferentes tecidos e materiais encontrados no corpo humano. A diferença na atenuação ocorre devido às possibilidades de ocorrerem diferentes tipos de interações da radiação ionizante e o material, e diferentes probabilidades de interação variando-se, por exemplo, o número atômico do material. As possíveis interações serão explicadas no Capítulo 2 da presente 
dissertação. Algumas dessas interações podem degradar a qualidade da imagem ${ }^{3}$. Este é o caso do espalhamento Compton, que pode introduzir ruído na imagem.

A fim de reduzir a degradação provocada pelos fenômenos de espalhamento, foram propostos diversos métodos ${ }^{4}$. Estes podem ser divididos em duas grandes categorias: Os métodos de estimativa, onde se procura quantificar o número de fótons espalhados, para posteriormente subtrai-los da imagem, e os chamados métodos de rejeição, que tem como objetivo impedir que os fótons espalhados alcancem o detector. Neste último caso se usa abordagens tais como, colimadores, espaçamentos com material de baixa atenuação (air gap) e, principalmente, a grade antiespalhamento. Este é um dispositivo colocado entre o paciente e o detector de imagem que tem por finalidade absorver os fótons secundários gerados por eventos Compton na interação do feixe de raios $X$ com o paciente.

Estimativas de espectros de feixes de raios $X$ são úteis como ferramentas para planejamentos de experimentos, quantificação de doses em pacientes e planejamentos de proteção radiológica ${ }^{5}$. Podem, também, ser usadas no desenvolvimento de métodos de redução dos efeitos da radiação espalhada em imagens médicas ${ }^{6}$.

Muitas abordagens têm sido difundidas com o objetivo de estimar a distribuição espectral no plano detector. Entre elas, destacam-se as relacionadas a modelos de aproximação analíticas ${ }^{7}$, simulações baseadas no método de Monte Carlo $^{8,9}$, métodos empíricos ${ }^{10}$ e modelos semi-empíricos ${ }^{11}$.

Entre os métodos semi-empíricos de estimativa de espectros de raios $\mathrm{X}$ está o Modelo $\mathrm{TBC}^{12}$, que usa ajustes de dados experimentais para obter parâmetros para determinação de espectros de Bremsstrahlung e da radiação característica provenientes da interação de elétrons com materiais comumente encontrados em alvos de tubos de raios $X$. Posteriormente foi proposto o modelo de TBC Modificado $^{13}$, que introduz uma generalização em relação ao modelo de TBC. Ambos os modelos serão descritos em detalhes no Capítulo 2.

O Modelo de TBC Modificado, contudo, prevê a produção de espectros de raios $\mathrm{X}$ somente no eixo central do feixe de radiação (feixe estreito) e, desta forma, não prevê fenômenos que ocorrem em maior destaque quando se utilizam feixes largos, mais próximos dos utilizados na prática clínica. Dentre estes fenômenos, o espalhamento Compton destaca-se pela importância que tem na qualidade das 
imagens e na previsão do comportamento dos espectros após atravessarem objetos macroscópicos.

Neste trabalho, o modelo de TBC Modificado foi revisto, tendo sido incluídas equações que incorporam os fenômenos de espalhamento Compton no espectro transmitido por um material de baixo número atômico. A geometria adotada simula a presença de um material macroscópico que modifica o feixe de raios $X$ incidente devido à atenuação e aos eventos relacionados ao espalhamento Compton.

Obteve-se uma formulação para o modelo de TBC modificado capaz de estimar um espectro de raios $X$ não só como um feixe estreito, mas em situação de feixe largo, e com a presença de uma barreira composta por um material de número atômico baixo. Além disso, foi avaliada a sensibilidade do modelo em função da tensão aplicada ao tubo de raios $X$, da largura do feixe e de diferentes espessuras de uma barreira de acrílico. Os resultados da modelagem matemática foram comparados às medições experimentais realizadas nas dependências do Laboratório de Dosimetria das Radiações e Física Médica do IF/USP.

\subsection{Objetivos}

- Derivação de uma equação para correção dos espectros calculados pelo Modelo de TBC modificado considerando os fótons provenientes do espalhamento Compton e que atingem um detector;

- Validação do modelo pela comparação com resultados experimentais;

- Teste de sensibilidade do modelo através da avaliação das modificações no espectro resultante em função de alterações na geometria do feixe e/ou no espectro incidente.

O presente trabalho apresenta a descrição das atividades realizadas a fim de cumprir com os objetivos propostos. Essas atividades incluem a formalização da teoria, execução da metodologia e apresentação dos resultados e conclusões.

No capítulo 2 define-se a teoria pertinente à este trabalho, onde se trata da produção de raios $X$, da interação dos diferentes tipos de radiações com a matéria, e do espalhamento Compton. Ainda neste capítulo o modelo de TBC é descrito, bem como o Modelo de TBC Modificado. 
O capítulo 3 , inicialmente, trata do desenvolvimento matemático para inclusão do efeito Compton no Modelo de TBC Modificado. Posteriormente, passa à descrição dos equipamentos e procedimentos usados para as medições experimentais usadas para validação do modelo.

No capítulo 4 são apresentados os resultados do presente trabalho. A validação do modelo de espalhamento Compton adicionado no Modelo de TBC Modificado foi feita por comparação entre espectros calculados e os espectros resultantes das medições descritas no capítulo 3. Por fim, as conclusões e perspectivas são apresentadas no capítulo 5. 


\section{TEORIA}

\subsection{Produção de raios $X$}

A radiação $X$ é produzida, por exemplo, em tubos de raios $X$ pelo bombardeamento de elétrons em um alvo de um material de elevado número atômico e alto ponto de fusão ${ }^{15}$. A disposição convencional de um tubo de raios $\mathrm{X}$ é a de ânodo e cátodo dispostos frente a frente, dentro de um recipiente (tubo) sob vácuo. Cátodo e ânodo, também chamado de alvo, são submetidos a uma diferença de potencial que acelera os elétrons provenientes do cátodo até que estes atingem o alvo e, por interação destes elétrons com o material do alvo, são emitidos os raios $\mathrm{X}$. A fonte de elétrons (cátodo) é constituída, em geral, de um filamento helicoidal de tungstênio de diâmetro variando entre $0,2 \mathrm{~mm} \mathrm{e} 0,3 \mathrm{~mm}^{16}$.

Os elétrons são ejetados do cátodo por emissão termoiônica. Para isto, o filamento do cátodo é aquecido pela passagem de uma corrente elétrica fazendo com que os elétrons da banda de condução adquiram energia suficiente para que se desliguem do metal. Estes elétrons são, então, acelerados pela diferença de potencial em relação ao cátodo. A Figura 1 mostra um esquema simplificado dos eletrodos do tubo de raios $\mathrm{X}$.

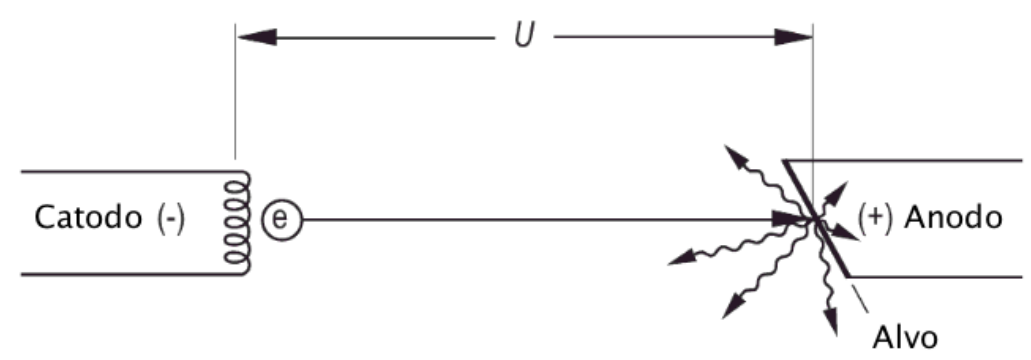

Figura 1 - Esquema simplificado da aceleração de elétrons no tubo de raios $\mathrm{X}$ em direção ao alvo. Pela interação dos elétrons com material do alvo há a emissão de fótons em todas as direções (Adaptado de Oppelt, A. ${ }^{14}$ ). 


\subsection{Interação de partículas carregadas rápidas com a matéria.}

Pode-se dividir as interações de partículas carregadas com a matéria em interações de partículas carregadas leves e de partículas carregadas pesadas. As pesadas são prótons, partículas alfa, ou mesmo íons. As partículas leves são elétrons e pósitrons. Neste trabalho, é mais relevante a revisão conceitual de interações de feixes de elétrons com a matéria, pois é a que ocorre no tubo de raios $X$ para a produção de fótons ${ }^{15}$.

Uma partícula carregada tem seu campo elétrico, que interage com a nuvem eletrônica dos átomos do alvo e com os núcleos destes átomos. As interações com o núcleo podem resultar em produção de radiação e, em geral, incorrem em grande deposição de energia cinética da partícula carregada. Dado que a probabilidade (seção de choque) de interação com o núcleo é muito pequena, estas interações ocorrem com menor frequência ${ }^{15}$.

As interações com os elétrons da nuvem eletrônica resultam em menor deposição de energia por parte da partícula carregada, e são mais prováveis (maior secção de choque). Deste modo a partícula carregada sofre um grande número de interações até que dissipe toda sua energia cinética. Um elétron de $1 \mathrm{MeV}$, por exemplo, sofre cerca de 1000 interações com elétrons da nuvem eletrônica até que dissipe toda sua energia cinética ${ }^{15}$.

O parâmetro usado para descrever a perda gradual de energia ao longo do caminho por parte de uma partícula carregada é o poder de freamento, ou Stopping Power. O poder de freamento é dividido em poder de freamento por colisão, que representa a perda de energia por interação com a nuvem eletrônica dos átomos do alvo, e poder de freamento por radiação, que se dá por interação com o núcleo do átomo.

Os valores do poder de freamento são medidos experimentalmente para vários materiais, e podem ser representados na forma da equação de Bethe ${ }^{57}$.

$$
-\left\langle\frac{d E}{d x}\right\rangle=K z^{2} \frac{Z}{A} \frac{1}{\beta^{2}}\left[\frac{1}{2} \ln \frac{2 m_{e} c^{2} \beta^{2} \gamma^{2} T_{\max }}{I^{2}}-\beta^{2}\right]
$$

Onde $K=4 \pi N_{A} r_{e}^{2} m_{e} c^{2}$, e $\beta=\frac{v}{c}$ 
Em geral usa-se o poder de freamento mássico:

$$
S \equiv \frac{d E}{\rho d x}
$$

Onde $\frac{d E}{d x}$ representa a energia média depositada no material por unidade de caminho da partícula, e $\rho$ é a densidade do material que compõe este meio.

As interações das partículas carregadas leves e pesadas podem ser divididas em três categorias de acordo com o seu parâmetro de impacto em relação ao raio médio do átomo. O parâmetro b pode ser observado na Figura 2.

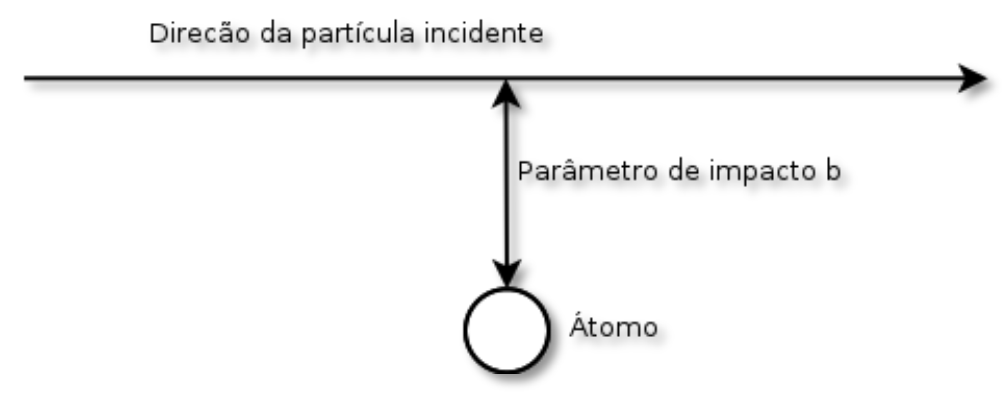

Figura 2 - O parâmetro de impacto b é a menor distância entre a trajetória da partícula incidente e o alvo cuja interação irá provocar espalhamento. (Adaptado de Podgosrsak, E.B. ${ }^{15}$ )

Classificação dos tipos de interações conforme o parâmetro de impacto:

1. Para $b \ll a$, onde a é o raio médio do átomo, ocorrem interação elástica da partícula com o núcleo do átomo, e também interação inelástica, com emissão de radiação de freamento, ou Bremsstrahlung;

2. Interação com o orbital eletrônico do átomo, situação em que $b \approx a$, ou colisão dura (hard colision), com emissão de fótons de radiação característica;

3. Interação com a camada eletrônica, porém com b >> a, ou colisão suave (soft colision).

\section{Bremsstrahlung}

As interações de partículas carregadas com o núcleo do átomo produzem radiação de freamento, ou Bremsstrahlung, devido à mudança na direção que estas partículas carregadas sofrem ao interagir com o potencial elétrico do núcleo. A radiação de freamento pode ser entendida no contexto do eletromagnetismo clássico, que prevê a emissão de um fóton devido à mudança de direção e momento da partícula carregada incidente. 


\section{Colisão dura}

Quando o parâmetro de impacto b, é da ordem do raio médio do átomo, ou seja $b \approx a$, a partícula carregada pode sofrer uma interação com um elétron desta camada eletrônica, fazendo com que este elétron orbital seja ejetado da camada eletrônica, e a camada eletrônica do átomo fique em um estado excitado de energia. Para que as interações do tipo colisão dura, ocorram é necessário que a energia cinética da partícula incidente seja maior que a energia do nível orbital atômico do elétron. Depois da interação, a partícula incidente e o elétron continuam seus caminhos de interações, porém não com toda a energia que a partícula incidente possuía antes da interação, pois parte desta energia foi utilizada para alterar o estado de energia do elétron orbital. Para voltar ao estado fundamental de energia, o átomo em estado excitado de energia emite um fóton ou um elétron Auger, que são vias concorrentes de desexcitação, quando um outro elétron decai para a vaga deixada na eletrosfera.

A emissão de radiação eletromagnética (fótons) pelo átomo que está em um estado excitado de energia é característica deste átomo, de acordo com as regras dadas pela mecânica quântica ${ }^{15}$. Por isto, dá-se o nome de radiação característica. Os níveis de energia dos estados são representados pelos números quânticos $n, I, j$ e $m_{j}$, onde:

- $\quad n$ é o número quântico principal.

- I é o número quântico relacionado ao momento ângular.

- j é o número quântico relacionado ao momento magnético.

- $m_{j}$ é o número quântico relacionado de spin.

Algumas transições de níveis de energia podem ser possíveis, e outras não. Transições de elétrons de qualquer camada para a camada $\mathrm{K}$ resultam na emissão de fótons das chamadas linhas $K$ do espectro. Estas transições, quando se dão da camada $\mathrm{L}$ para a camada $\mathrm{K}$ produzem as linhas $K_{\alpha}$ no espectro, quando se dão da camada $\mathrm{M}$ para a camada $\mathrm{K}$ produzem as linhas $K_{\beta}$ no espectro, e assim sucessivamente. Além de algumas transições, e portanto linhas espectrais, não serem possíveis, da mecânica quântica se sabe que a probabilidade de emissão é diferente para cada linha. As linhas espectrais $K_{\alpha}$ e $K_{\beta}$ características do tungstênio, que é o material do alvo do tubo de raios $X$ usado neste trabalho, poderão ser 
observadas em muitos dos espectros de energia apresentados nos próximos capítulos. Na Figura 3 pode-se ver os valores das energias de ligação, e séries de transições para o tungstênio.

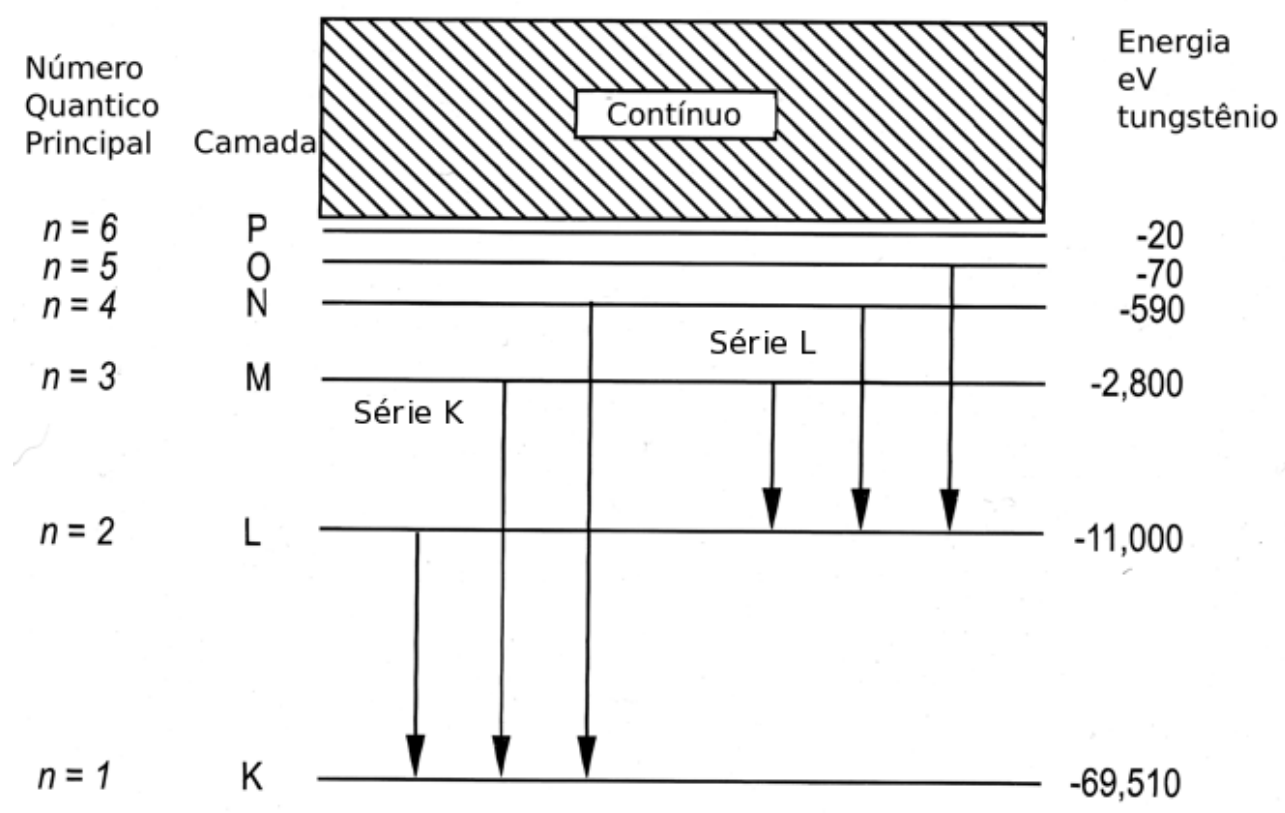

Figura 3 - Diagrama simplificado dos níveis de energia para o átomo de tungstênio. (Adaptado de Oppelt, A. $^{16}$ )

De forma concorrente à emissão de fótons de raios $X$ característicos, o efeito Auger é a emissão de um elétron, ou de uma cascata de elétrons, pelo átomo em estado excitado de energia, ao invés de emissão de fótons. Este efeito possui menor probabilidade de ocorrência que a emissão de fótons característicos.

No caso do tubo de raios $\mathrm{X}$, as partículas carregadas do feixe são elétrons, e para as energias usadas em medicina diagnóstica, a maior parte das interações ocorrem pelo processo de colisão dura. Então, a maior parte da energia do feixe de elétrons acelerado dentro do tubo é dissipada no alvo pelo seu aquecimento, e não na produção de raios $X$, que representa menos de $1 \%$ da dissipação de energia. Isto faz com que o desafio de engenharia envolvida na confecção de tubos de raios $X$ seja complexo.

\section{Colisão suave}

Quando o parâmetro de impacto, $b$, é muito maior do que o raio médio do átomo, $a$, a interação se dá com o átomo como um conjunto, ocorrendo pequena transferência de energia cinética para este átomo. Após este tipo de interação a 
partícula carregada perde pouco da sua energia cinética por interação eletrostática, e o átomo alvo fica, em geral, ionizado, polarizado, ou somente adquire uma pequena quantidade de energia cinética. No caso do tubo de raios $X$ onde se acelera elétrons contra um alvo, os elétrons do feixe mudam de trajetória, por transferência de momento e energia.

O poder de freamento mássico é simbolizado geralmente pela letra $S$, e é usado para situações em que o caminho é percorrido em um meio de dada densidade. A unidade do poder de freamento mássico fica então $\mathrm{MeV} . \mathrm{g} / \mathrm{cm}^{2}$.

O poder de freamento total, equação (3), é composto pela soma do poder de freamento por colisão e por radiação. Na Figura 4 pode-se ver a relação entre o poder de freamento por colisão e por radiação, para um feixe de elétrons que interage com tungstênio, que é o material geralmente usado nos ânodos (alvos) dos tubos de raios $X$.

$$
S_{\text {tot }}=S_{\text {col }}+S_{\text {rad }}
$$

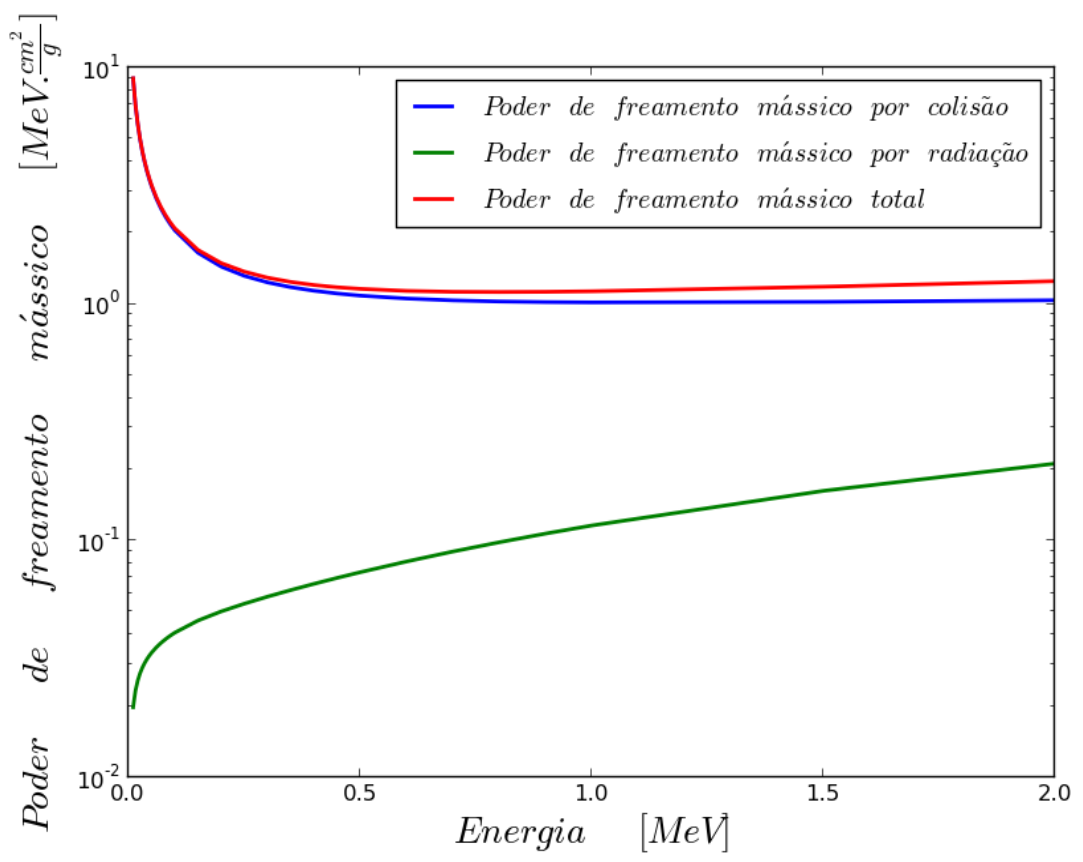

Figura 4 - Poder de freamento mássico total, por colisão e por radiação, para o tungstênio, e para energias que vão além das usadas em medicina diagnóstica. Apenas uma pequena parte das interações emite radiação, e por isso, apenas cerca de $1 \%$ da energia aplicada no feixe de elétrons do tubo de raios $X$ se converte efetivamente em fótons ${ }^{17}$ de raios $X$. 


\subsection{Interação de fótons com a matéria.}

Fótons são classificados como radiação indiretamente ionizante e depositam energia no material absorvedor em processos indiretos. Primeiramente a energia é transferida para uma partícula carregada leve (em geral elétrons). Em seguida esta partícula carregada leve deposita energia no meio. Dependendo da energia do fóton incidente e do número atômico do absorvedor, o fóton pode interagir com o átomo do absorvedor como um todo, com o núcleo, ou com elétrons da camada eletrônica do absorvedor. Como resultado da interação do fóton, tem-se uma partícula carregada ou um fóton espalhado ou ambos.

São sete os possíveis tipos de interação de fótons com a matéria ${ }^{15}$.

- Fotodesintegração

- Produção de tripletos

- Espalhamento Thomson

- Espalhamento Rayleigh

- Produção de pares

- Efeito fotoelétrico

- Espalhamento Compton

Nas energias usadas em medicina diagnóstica, até $150 \mathrm{keV}$, os únicos efeitos importantes são o efeito fotoelétrico, espalhamento Compton e os espalhamentos Thomson e Rayleigh.

O espalhamento Thomson se dá pela interação do fóton incidente, com um elétron fracamente ligado da eletrosfera atômica, e é descrito no contexto da eletrodinâmica clássica. $O$ fóton incidente provoca uma vibração ressonante no elétron, devido à força eletrostática. $O$ elétron, que está em vibração ressonante, por sua vez reemite um fóton, porém em direção diferente do incidente. Esta interação é chamada elástica, pois o fóton é reemitido pelo átomo com a mesma energia do fóton incidente, porém em direção diferente.

O espalhamento Rayleigh, assim como o espalhamento Thomson, é um espalhamento elástico, pois o fóton espalhado tem o mesmo comprimento de onda do incidente. A interação do tipo Rayleigh ocorre entre um fóton e o átomo como um 
todo pois, neste caso, o comprimento de onda do fóton incidente é maior que o raio médio deste átomo. Nesta interação, o fóton incidente interage com um átomo como um todo, que o espalha em outra direção. Não há transferência de energia para o meio, mas o átomo da interação recebe uma transferência de momento devido à conservação de momento linear na interação.

O efeito fotoelétrico tratado aqui é a interação entre fóton incidente e um elétron fortemente ligado da camada eletrônica do átomo, com maior probabilidade das camadas $\mathrm{K}$ e L. No efeito fotoelétrico o fóton incidente interage com um elétron que pertence a uma das camadas mais próximas do núcleo, este fóton desaparece, e o elétron da interação é ejetado do átomo. O elétron que é ejetado após interação, fica com energia cinética igual à diferença entre a energia do fóton incidente, e a energia do orbital.

$$
E_{\text {cinética }}=h v-E_{\text {ligação }}
$$

Após a interação por efeito fotoelétrico, o orbital onde estava o elétron que interagiu fica em estado de vacância, sendo imediatamente preenchido por um elétron da camada imediatamente superior, ou mesmo de uma camada de maior energia. Consequentemente há a emissão de um fóton característico, ou seja, com a energia característica daquela camada. O processo de emissão de fótons característicos é análogo à emissão de fótons característicos por interação de partículas carregadas com a nuvem eletrônica do átomo. Na Figura 5 pode-se ver uma representação simplificada de uma interação por efeito fotoelétrico.

Pode ocorrer a desexitação também por uma emissão de um elétron Auger, ou mesmo de uma cascata de elétrons Auger. A emissão desses elétrons é menos provável que a emissão de fótons característicos.

A emissão de fótons característicos compõe as várias linhas espectrais. Essas linhas espectrais são chamadas linhas $K_{\alpha}, K_{\beta}$ e assim sucessivamente, de acordo com as camadas eletrônicas envolvidas no decaimento. 


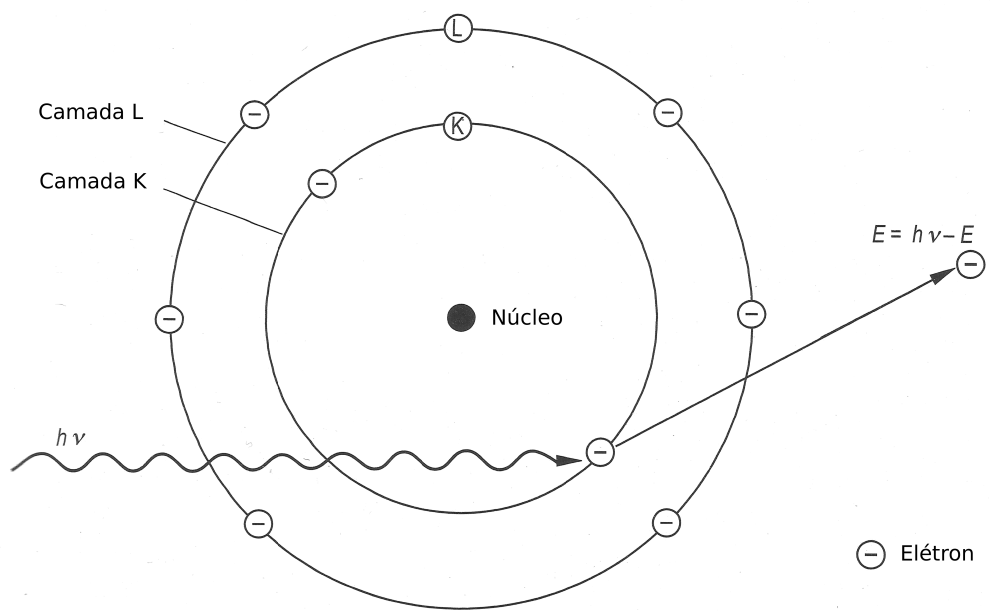

Figura 5 - Esquema simplificado do efeito fotoelétrico, o fóton incidente é completamente absorvido pelo átomo, que por sua vez ejeta um elétron. Posteriormente a vacância deixada pelo elétron ejetado é preenchida pela transição um elétron de uma das camadas superiores, com a emissão de um fóton característico. (Adaptado de Oppelt, A. ${ }^{16}$ )

A interação entre um fóton e um elétron fracamente ligado resultando no espalhamento de ambas partículas é chamada de efeito Compton. O fóton que emerge desta interação é ejetado com energia menor do que a energia do fóton incidente. Esta diferença de energia é recebida pelo elétron, na forma de energia cinética. Em medicina diagnóstica, esta é a interação de maior importância, no sentido de ser um fator de degradação do contraste nas imagens diagnósticas, por isto, no âmbito deste trabalho, é a interação entre fóton e o material absorvedor/espalhador que foi calculada.

A representação esquemática da cinemática do espalhamento Compton pode ser vista na Figura 6. 


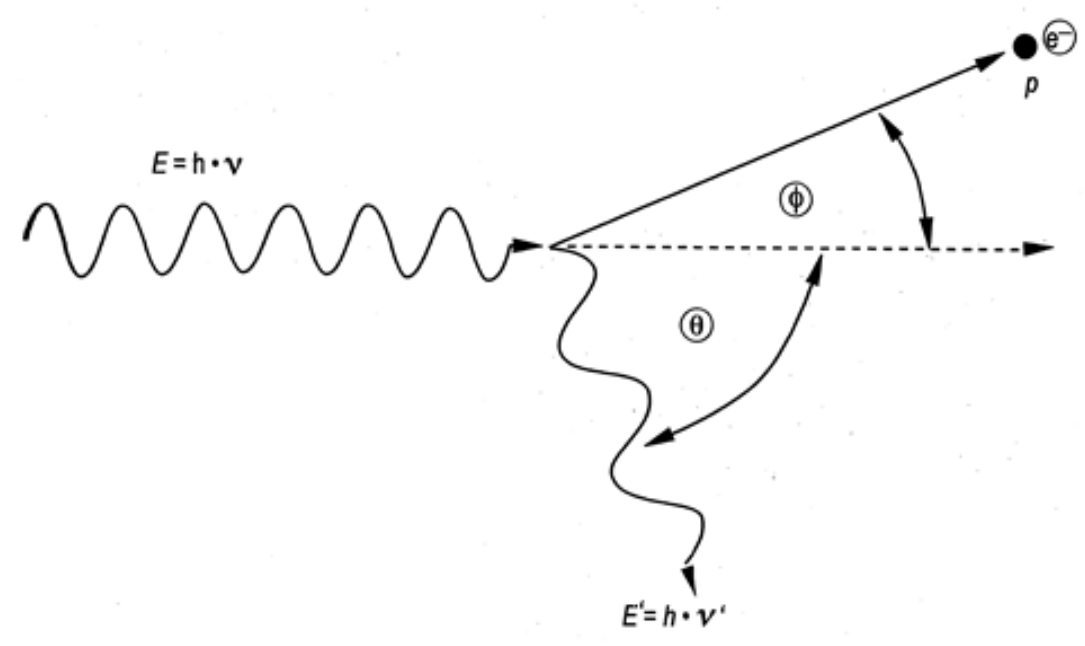

Figura 6 - Esquema simplificado da cinemática do espalhamento Compton. (Adaptado de Oppelt, A. ${ }^{16}$ )

Das leis de conservação do momento e da geometria do processo de espalhamento, se obtém.

$$
\begin{gathered}
\frac{E}{c}=\frac{E^{\prime}}{c} \cos \theta+p \cos \phi \\
p^{2}=\frac{E^{2}+E^{\prime 2}-2 E E^{\prime} \cos \theta}{c^{2}}
\end{gathered}
$$

Da conservação da energia, obtém-se.

$$
m c^{2}+E=E^{\prime}+m c^{2}+K_{e}
$$

Como a energia e o momento se conservam simultaneamente, chega-se fórmula de Compton, que descreve a diferença em energia entre o fóton incidente e espalhado.

$$
E^{\prime}=\frac{E}{1+\left(\frac{E}{m c^{2}}\right)(1-\cos \theta)}
$$


Não há mudança na energia para fótons espalhados na direção do fóton incidente, ou seja, para $\theta \rightarrow 0, E^{\prime}=E$. A maior mudança na energia ocorre com $\theta=180^{\circ}$.

\section{Seção de Choque de Klein-Nishina.}

A seção de choque é uma grandeza usada para calcular a probabilidade de uma determinada interação ocorrer ${ }^{1}$, tendo unidade de área e normalmente designada pela letra grega $\sigma$. A probabilidade da interação é dada pela seção de choque $\sigma$ dividida pela área do feixe. Para se obter o número de interações, multiplica-se esta probabilidade pelo número de átomos existentes na região de interação, e também pelo número de fótons que compõe o feixe.

$$
\Delta N=\sigma \frac{N_{\text {feixe }}}{A_{\text {feixe }}} N_{\text {alvo }}
$$

Onde $\Delta N$ é o número total de interaçães, $A_{\text {feixe }}$ é a área do feixe, $N_{\text {feixe }}$ é o número de partículas que compõe o feixe, e $N_{a l v o}$ é o número de átomos iluminados presentes no alvo.

Em geral, são utilizadas as seções de choque diferenciais, em função do ângulo de espalhamento ou da energia. Para calcular a probabilidade, neste último caso, é necessário integrar o valor da seção de choque no seu intervalo de energia, ou ângulo sólido, ou ambos.

A seção de choque para o espalhamento Compton é dada pela equação de Klein-Nishina ${ }^{18}$. Nesta equação, o elétron é considerado não ligado aos orbitais eletrônicos do átomo. A seção de choque de Klein-Nishina é dada pela equação:

$$
\frac{d \sigma(E, \theta)}{d \Omega}=\frac{r_{0}^{2}}{2}\left(1+\frac{\alpha(1-\cos \theta)^{2}}{\left(1+\cos ^{2} \theta\right)[1+\alpha(1-\cos \theta)]}\right) \frac{1+\cos ^{2} \theta}{[1+\alpha(1-\cos \theta)]}
$$

Onde $\theta$ é o ângulo do fóton espalhado, em relação à direção do feixe incidente, $r_{0}$ é o raio clássico do elétron e $\alpha=\frac{E}{m_{e} c^{2}}$, com $m_{e} c^{2}$ sendo a energia de repouso do elétron. 
A equação de Klein-Nishina usa a aproximação de elétrons não ligados à camada eletrônica do átomo. Para que se incorpore à esta equação o fato de os elétrons estarem presos na camada eletrônica, é usada a função de espalhamento incoerente ${ }^{18}, S(q, Z)$ que é adotada como uma correção à equação de Klein-Nishina:

$$
\frac{d \sigma(E, \theta)}{d \Omega}=\frac{d \sigma_{K N}(E, \theta)}{d \Omega} S(p, Z)
$$

Onde $\frac{d \sigma_{K N}(h v, \theta)}{d \Omega}$ é a equação de Klein-Nishina, e $S(p, Z)$ é a função de espalhamento incoerente, que depende do número atômico do meio e do fator $p$, que representa a magnitude do momento transferido para o elétron.

Os valores de $S(p, Z)$ podem ser calculados usando a aproximação introduzida por Baró et. al. ${ }^{19}$ que usa parâmetros obtidos por ajustes dos valores teóricos, calculados usando as aproximações de Hartree-Fock ${ }^{20}$

\subsection{O modelo de TBC.}

Um dos primeiros modelos teóricos conhecidos para o cálculo de espectros de raios $X$ foi o desenvolvido por Kulenkampff ${ }^{21}$ e Kramers $^{22}$ sintetizado na equação (12).

$$
N(E) d E=C Z(T-E)
$$

Onde $N(E) d E$ é o número de fótons de raios $\mathrm{X}$ produzidos com energia entre $E$ e $E+d E$ para cada elétron incidente, $Z$ é o número atômico do alvo, $T$ é a energia cinética do elétron e $C$ é uma constante. Embora esse modelo tenha sido amplamente usado, verificou-se que a atenuação dos fótons pelo próprio material do alvo não é considerada, além de não levar adequadamente a resultados experimentais, quando aplicado a baixos ângulos.

Posteriormente, Soole ${ }^{23,24}$ desenvolveu um modelo de cálculo de espectros de raios $X$ emergentes de um alvo de tungstênio corrigido pela sua atenuação através da teoria quântica da radiação. Birch e Marshall ${ }^{25}$ estenderam o trabalho de Soole e obtiveram bons resultados através de ajustes de parâmetros que concordam com medições experimentais. 
Foram, também, desenvolvidos métodos para o cálculo de espectros de raios $X$ através do da aplicação da transformada de Laplace a curvas de atenuação ${ }^{26,27}$. Esta metodologia vem sendo aplicada ainda atualmente para o cálculo analítico de espetros de raios $\mathrm{X}$ em diferentes aplicações clínicas ${ }^{28}$.

O Modelo de $\mathrm{TBC}^{12}$ (um anacronismo relacionando os nomes dos autores originais do modelo, Tucker, Barnes e Chacraborty) é uma extensão das ideias de Birch e Marshall, refinando os modelos de produção de raios $\mathrm{X}$, Bremsstrahlung e característico. Esse modelo é capaz de quantificar o espectro de raios $X$ através de equações que consideram os fenômenos de sua produção. Apesar da exatidão da reprodução dos espectros, o modelo apresenta deficiências na quantificação de suas grandezas em termos metrológicos, já que o espectro obtido é dado em unidades arbitrárias.

O modelo de TBC é um modelo semi-empírico que permite a implementação computacional de suas equações, e é capaz de reproduzir com precisão os espectros gerados pelo alvo de tungstênio ou de uma combinação tungstênio/rênio do tubo de raios $X$. Os cálculos utilizam os seguintes parâmetros de entrada do usuário: tensão $[\mathrm{kVp}]$, corrente $[\mathrm{mA}]$, tempo de exposição [s] e espessura do filtro adicional [mm Al].

Para a produção de raios $X$ pelo processo de Bremsstrahlung, o Modelo considera o poder de freamento dos elétrons incidentes no anodo, uma função que fornece a quantidade de fótons produzidos pelos elétrons nas interações, a atenuação dos fótons produzidos pelo material do alvo, e a filtração do tubo.

O poder de freamento para os elétrons incidentes no ânodo, pode ser modelado na forma da equação (13)

$$
\frac{1}{\rho} \frac{d T}{d x}=A_{m}+B_{m} e^{-T C_{m}}\left[\mathrm{keVm}^{2} \mathrm{~kg}^{-1}\right]
$$

Em que $A_{\mathrm{m}}, B_{\mathrm{m}}$ e $C_{\mathrm{m}}$ são parâmetros de ajuste e $T$ é a energia cinética dos elétrons ao atingirem $o$ alvo.

A função que fornece a quantidade de fótons com energia $E$ produzida por elétrons com energia $T, B(E, T)$, pode ser modelada pela equação paramétrica (14). 


$$
B(E, T)=\left\{\begin{array}{rr}
{\left[A_{0+} A_{1} T\right]\left[1+B_{1}\left(\frac{E}{T}\right)+B_{2}\left(\frac{E}{T}\right)+B_{2}\left(\frac{E}{T}\right)+B_{3}\left(\frac{E}{T}\right)\right]} & s e E \leq T \\
0 & \text { seE }>T
\end{array}\right.
$$

Nesta equação, $A_{0}, A_{1}, B_{1}, B_{2}, B_{3}$ e $B_{4}$ são parâmetros de ajuste a dados experimentais originalmente obtidos por outros autores.

Por fim, a atenuação dos fótons produzidos pelo material do alvo e a filtração do tubo (inerente e adicional), é calculada na equação (15).

$$
F(E, T)=e^{-\left[\mu_{w}(E) d_{w}+c d_{m}\right]}=e^{-\left[\frac{\mu_{W}(E)\left(T_{0}^{2}-T^{2}\right)}{\rho C(T) t g \theta}+\mu_{m}(E) d_{m}\right]}
$$

Na equação (15), $\mu_{w}(E)$ é o coeficiente de atenuação linear para o material alvo, $\mu_{m}(E)$ é o coeficiente de atenuação linear do material específico de referência da filtração do tubo (em geral de alumínio), $d_{m}$ é a filtração com equivalência de atenuação do tubo, $\theta$ é o ângulo de inclinação do ânodo e $C(T)$ é obtido a partir da constante de Thomson-Widdington ${ }^{29}$.

Com isso, o modelo de TBC propõe a equação (16) para determinar o espectro de Bremsstrahlung produzido por um alvo de tungstênio do tubo de raios $\mathrm{X}$ :

$$
N^{B}\left(E, T_{0}\right) d E=\frac{\sigma_{0} Z^{2}}{A} \frac{d E}{E} \int_{E}^{T_{0}} \frac{B(E, T)}{T} F(E, T)\left(\frac{1}{\rho} \frac{d T}{d x}\right)
$$

Nesta equação, $T$ é a energia cinética dos elétrons incidentes no alvo de tungstênio, $T_{0}$ é a energia máxima (inicial) dos elétrons, que é numericamente igual ao valor de tensão máxima de operação do tubo de raios $X, E$ é a energia do fóton produzido, $Z$ é o número atômico do material do alvo, $A$ é a massa atômica dos átomos do alvo e $\sigma_{0}$ é a constante da estrutura fina.

Em adição, Tuker et.al. ${ }^{12}$ propuseram a seguinte equação para o cálculo da radiação característica:

$$
N^{C}\left(E_{i}, T_{0}\right) d E=A_{K}\left(\frac{T_{0}}{E_{K}}-1\right)^{n_{k}} f\left(E_{i}\right) \int_{0}^{R_{a}} J\left(\frac{x}{R}\right) e^{-\mu_{w}\left(E_{i}\right) x / \operatorname{sen} \theta} d x
$$


Onde $f\left(E_{i}\right)$ é fração dos fótons de energia $E_{i}$ emitidos pelo alvo de tungstênio, $A_{K}$ e $n_{k}$ são parâmetros do modelo utilizado para o ajuste aos dados experimentais, $R_{a}$ é a distância em que a energia cinética média dos elétrons é igual à $E_{K}$ eJ $\left(\frac{x}{R}\right)$ é definido como:

$$
J\left(\frac{x}{R}\right)= \begin{cases}\left(\frac{3}{2}\right)\left[1-\left(\frac{x}{R}\right)^{2}\right] & \text { se } x \leq R \\ 0 & \text { se } x>R\end{cases}
$$

O modelo pode ser sintetizado como a soma das contribuições relacionadas ao Bremsstrahlung e à radiação característica:

$$
N\left(E, T_{0}\right)=N^{B}\left(E, T_{0}\right)+N^{C}\left(E, T_{0}\right)
$$

O Modelo de TBC foi extensivamente testado e comparado com outros modelos computacionais de geração de espectros de raios $X^{30,31}$, bem como com avaliações experimentais $^{32,33}$ e modelos usando o método Monte Carlo ${ }^{34,35}$. Na maioria dos casos representou de forma adequada os espectros de raios $\mathrm{X}$ utilizados na faixa de energias aplicadas para produção de imagens diagnósticas ${ }^{36}$. Além disso, os autores produziram, anos mais tarde, uma versão do modelo adaptada para a produção de espectros utilizados na faixa de energias utilizadas em mamografia ${ }^{37}$. Outros modelos para cálculo analítico de espectros de raios $X$ foram, também, publicados e têm sido extensivamente utilizados pela comunidade científica $^{38}$.

O Modelo de TBC vem sendo utilizado como importante ferramenta para cálculo de espectros e utilizado em aplicações, desde a metrologia de instrumentos utilizados em controle de qualidade ${ }^{39,40}$, até a determinação de propriedades de filtração de feixes ${ }^{41}$ e técnicas de blindagem de salas radiológicas ${ }^{42}$ e de Medicina Nuclear $^{43}$.

\subsection{O modelo de TBC Modificado.}

No modelo de TBC Modificado ${ }^{13}$ foi introduzida uma generalização do modelo de TBC originalmente proposto. Esta generalização considera a forma de onda 
gerada por equipamentos comerciais de raios X. Além disso, foram incorporadas as variações na forma espectral resultantes da adição de diferentes materiais atenuando o feixe de raios $X$, e representando de espectros em uma unidade radiométrica, o kerma no ar.

O desenvolvimento do método foi constituído de:

I - Calibração do componente Bremsstrahlung usando um ajuste polinomial.

II - Calibração da contribuição característica, considerando a fração da radiação característica em comparação com o componente de Bremsstrahlung.

A função calibração para contribuição Bremsstrahlung foi definida como:

$$
C^{B}(V, f)=\frac{A_{1}(f)+A_{2}(f) V+A_{3}(f) V^{2}}{\int_{0}^{E_{\max }} N^{B}(E) E_{t r}\left[\frac{\mu}{\rho}(E)\right]_{a r} d E}
$$

Na equação (20), $V$ é a tensão aplicada ao tubo (em [kV]), $f$ é a espessura da filtração total na saída do tubo de raios $X$ (espessura equivalente em $\mathrm{mmAl}$ correspondentes ao vidro do tubo, óleo isolante, janela da cúpula protetora do tubo e filtro adicional), $E_{\max }$ é a energia máxima com que um fóton do espectro pode ser produzido (numericamente igual a máxima energia dos elétrons ao atingirem o anodo e à tensão aplicada ao tubo), $E_{t r}$ é a energia média transferida para os elétrons do meio, $\left[\frac{\mu}{\rho}(E)\right]_{a r}$ é o coeficiente de atenuação mássico para o ar.

Os parâmetros de ajuste $A_{1}(f), A_{2}(f)$ e $A_{3}(f)$ foram modelados como funções Lorentzianas.

$$
A_{i}(f)=y_{i}+\frac{2 a_{i}}{\pi} \frac{w_{i}}{4\left(f-f_{i}\right)^{2}+w_{i}^{2}}
$$

Os valores de $y_{i}, a_{i}, w_{i}$ e $f_{i}$ com seus índices correspondentes $i=1,2$ ou 3 são parâmetros obtidos a partir de medições experimentais do kerma no ar [Gy] por unidade de produto corrente-tempo [ $\mathrm{mAs}]$ para diferentes tensões e filtros. Portanto, 
o componente Bremsstrahlung em unidades de kerma no ar por $m A s$ para uma dada diferença de potencial e filtração total $f$ pode ser definido como:

$$
N^{B, V, f}(E)=C^{B}(V, f) N^{B}(E, f) E\left[\frac{\mu}{\rho}(E)\right]_{a r}
$$

Para a calibração das linhas características em unidades de kerma no ar por $m A s$, os autores mediram espectros adquiridos em 80, 90, 100, 120, $150 \mathrm{kV}$.

Esses espectros corrigidos foram separados em porções relacionadas ao Bremsstrahlung e à radiação característica. Portanto, considerando $S_{c}$ como a área sob picos característicos, $S_{B}$ a área sob da porção Bremsstrahlung e $S_{T}$ a área abaixo do espectro completo, a razão entre a porção de raios $X$ da contribuição característica e a total pode ser definida como:

$$
R=\frac{S_{C}}{S_{T}}=\frac{S_{T}-S_{B}}{S_{T}}=1-\frac{S_{B}}{S_{T}}
$$

A dependência de $\mathrm{R}$ em relação à tensão aplicada também foi modelada usando uma função Lorentziana:

$$
R(V)=R_{0}+\frac{2 A_{r}}{\pi} \frac{w_{r}}{4\left(V-V_{C}\right)^{2}+w_{r}^{2}}
$$

$\mathrm{Na}$ equação (24) $A_{r}, R_{0}, w_{r}$ e $V_{C}$ são parâmetros de ajuste. Portanto, considerando $E_{K}$ como cada uma das linhas características $\mathrm{K}$ do material do ânodo, a função de calibração para a componente relativa à radiação característica foi definida como:

$$
C^{C}(V, l)=R(V) \frac{\int_{0}^{E_{\max }} N_{C}^{B, V, l}(E) d E}{\sum_{k} N^{C}\left(E_{k}\right) E_{k}\left[\frac{\mu}{\rho}\left(E_{k}\right)\right]_{a r}}
$$

Usando a equação (25), o espectro característico calibrado pode ser escrito como:

$$
N_{c}^{C, V, l}\left(E_{k}\right)=C^{c}(C, l) N^{c}\left(E_{k}, l\right) E_{k}\left[\frac{\mu}{\rho}\left(E_{k}\right)\right]_{a r}
$$


Para os cálculos da radiação característica necessita-se do valor do rendimento fracionário $l$. Assim, uma abordagem puramente empírica foi aplicada posteriormente pelos autores ${ }^{44,49}$ para o cálculo da razão de áreas dos espectros entre a contribuição Bremmstrahlung e Característica em função da tensão aplicada $V$, que variava entre 80 e $150 \mathrm{kV}$. Para isso, a área total de cada espectro, como mostrado na Figura $7(a)$, foi calculada utilizando a função de integração de áreas presente no software Origin 8.0 (OriginLab, Co.). Além disso, as áreas individuais de cada um dos quatro picos do espectro, $C_{k}(V)$, foi calculado. Esse cálculo considerou a subtração das áreas correspondentes de Bremsstrahlung abaixo de cada pico. Essa região foi estimada como uma área trapezoidal, como mostra a Figura 7(b).

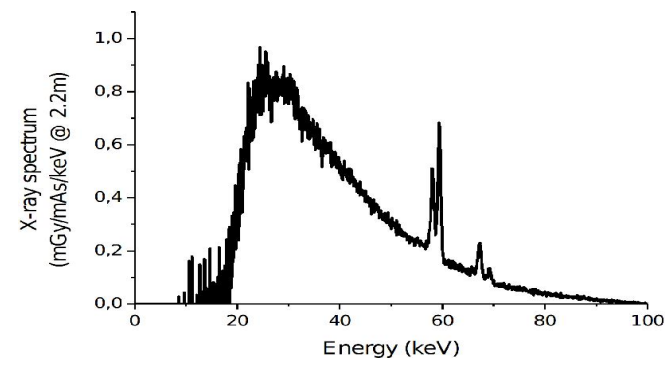

(a)

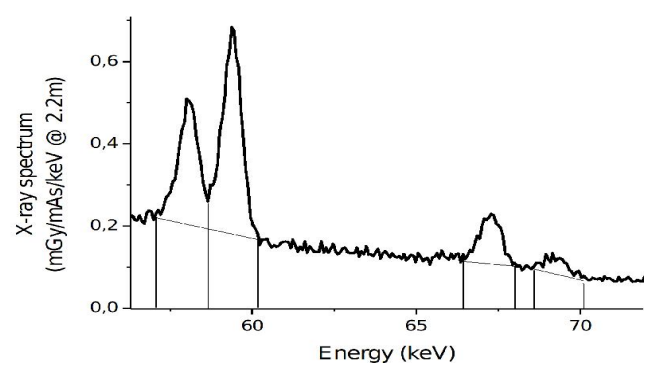

(b)

Figura 7 (a) Espectro de raios X utilizando 100 kV, e (b) Região de interesse para cálculo de áreas abaixo de cada pico característico ${ }^{49,45}$.

Assim, a função a razão entre espectros caraterístico e total foi calculada ${ }^{44}$ como:

$$
R=\frac{S_{C}}{S_{T}}
$$

Onde $S_{C}$ representa as áreas abaixo dos picos característicos, e $S_{T}$ representa a área abaixo do espectro completo. Com os valores de $R$ obtidos, realiza-se um ajuste Lorentziano que fornecerá as constantes necessárias para o cálculo. Dessa forma, se obtém o fator de calibração, $C^{C}(V, l)$, equação (25), e o espectro característico calibrado $N_{C}^{V, l}$.

Finalmente, o espectro ${ }^{13}$ gerado por um alvo de tungstênio do tubo de raios $\mathrm{X}$, alimentado por uma alta tensão $V$, e filtrado por uma espessura $f$ de um material de referência é expresso pela equação (28): 


$$
N^{V, f}\left(E, T_{0}\right)=N^{B, V, f}\left(E, T_{0}\right)+N^{C, V, f}\left(E, T_{0}\right)
$$

Onde o termo $N^{B, V, f}\left(E, T_{0}\right)$ é a componente de Bremsstrahlung e termo $N^{C, V, f}\left(E, T_{0}\right)$ a componente de espectro característico.

Outros modelos de geração de espectros usando métodos semi-empíricos são propostos na literatura. Bath e Pattison ${ }^{45}$, analisam o modelo de TBC original, proposto por Tucker et. al ${ }^{12}$ e o modelo proposto por Birch ${ }^{25}$ por comparação com espectros medidos experimentalmente. Bissonette e Schreiner ${ }^{31}$ também comparam estes dois modelos usando parâmetros tais como tensão equivalente, filtração de alumínio a ângulo do anodo. Por fim, Costa et. al ${ }^{13}$ propõe o Modelo de TBC modificado, e valida seus resultados por meio de comparações com espectros experimentais.

O modelo de TBC original ${ }^{12}$ e o modelo de Birch $^{25}$ se assemelham por considerar espectros gerados para tubos de potencial constante, enquanto que 0 modelo de TBC modificado amplia o modelo original inclusive para diferentes formas de onda. Os resultados das comparações prévias ${ }^{26,27}$ mostraram que o modelo de TBC original produziu espectros mais próximos dos experimentais que modelo de Birch $^{26}$, além de apresentar algumas outras vantagens sobre este modelo ${ }^{27}$. Os resultados de Costa et. al ${ }^{13}$ também apontam o modelo de TBC modificado como uma boa representação dos dados medidos. 


\section{MATERIAIS E MÉTODOS.}

Os modelos de TBC apresentados anteriormente, tanto o original quanto 0 modificado, são capazes de prever a distribuição energética de fótons de raios $X$ produzidos por alvos de tungstênio ou tungstênio/rênio somente no eixo central do feixe de raios X. Em outras palavras, os modelos foram elaborados para representar espectros obtidos em condições de feixe estreito. Contudo, muitas das aplicações práticas de feixes de raios $X$, seja para a produção de imagens ${ }^{46}$, seja para caracterização de materiais em termos de sua atenuação à radiação $X^{47,48}$, utilizam feixes largos de radiação. Desta forma, a proposta principal do presente trabalho foi rever as equações que definem o modelo de TBC modificado para incluir, neste, a condição de feixe largo, como uma generalização, visando a ampliação das possibilidades de suas aplicações.

Supondo-se um espectro primário que não interage com nenhum objeto após sua emissão pelo tubo de raios $X$, este espectro é, essencialmente representado pelos modelos propostos anteriormente. Contudo, considerando-se um feixe largo de radiação $X$, interagindo com um objeto, a radiação a ser detectada por um espectrômetro, passa a ser composta pelo feixe primário, atenuado pelo material adicionado, e uma fração de radiação espalhada. A soma destas duas contribuições passa a compor o feixe resultante. Esta soma do feixe primário atenuado, com o feixe de radiação espalhada, é o que se mede em um detector real na condição de feixe largo. O modelo proposto neste trabalho visa simular o espectro de um tubo de raios $X$, em situação de feixe largo, ou seja, igual, ou o mais fidedigno possível, ao que se medem em condições reais.

\subsection{Desenvolvimento matemático}

Primeiramente, se definiu como seria a geometria adotada para a barreira atenuadora/espalhadora. A adoção desta geometria foi feita a partir de um compromisso entre a busca da maior simplicidade possível no desenvolvimento do algoritmo computacional, e também da necessidade de que fosse factível a realização de experimentos para validação do modelo. 
A influência dos fótons provenientes de interações Compton, que atingem o espectrômetro em um experimento de transmissão, foi incorporada ao Modelo de TBC Modificado. A geometria aproximada adotada está apresentada na Figura 8, em uma vista de duas dimensões da geometria.

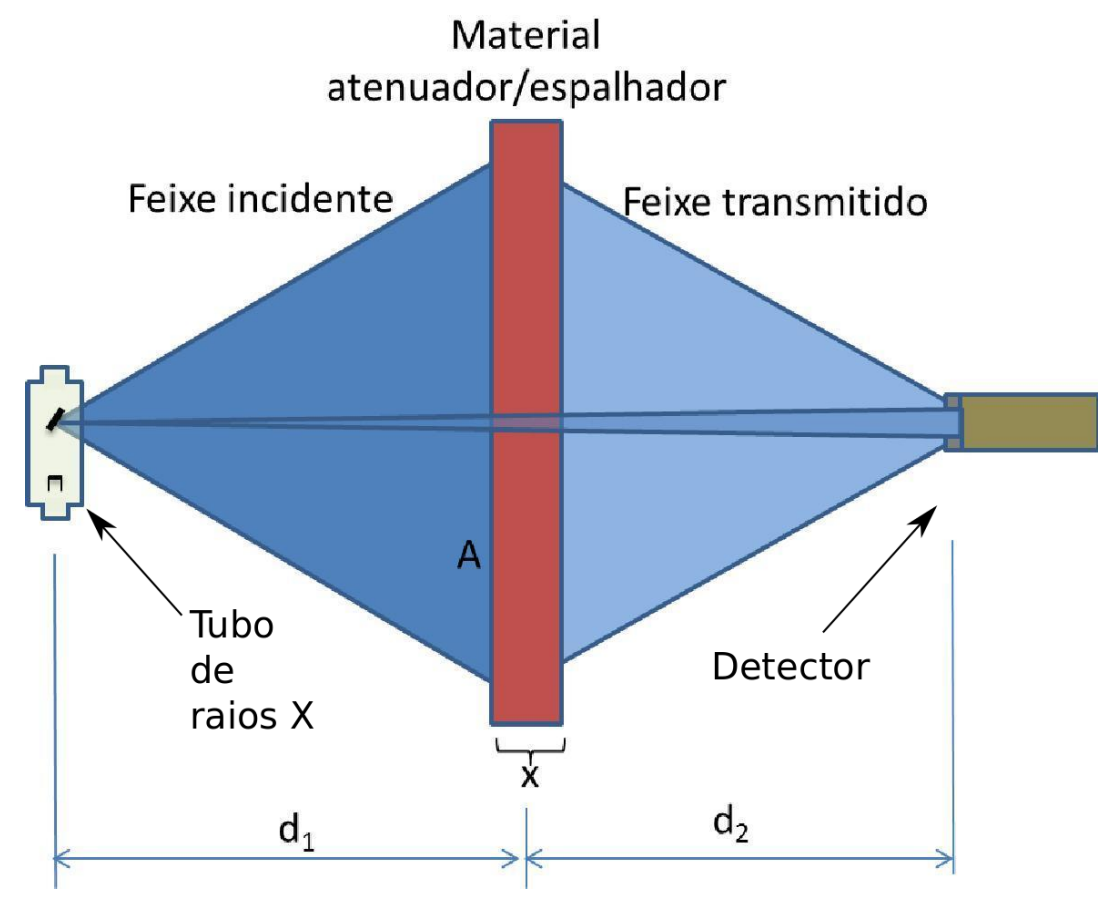

Figura 8 - Geometria de detecção utilizada nos experimentos para determinação dos espectros transmitidos por materiais utilizados, e adotada para incorporação da função de correção para o efeito Compton.

O espalhamento Compton devido à interação com a barreira tem como dependência os seguintes parâmetros:

- Espectro primário incidente no atenuador, que depende da tensão aplicada, corrente anódica, material do alvo, etc;

- Seção de choque diferencial de Klein-Nishina, $\left(\frac{d \sigma}{d \Omega}\right)_{K N}$;

- Propriedades físicas do material do qual é constituída a barreira (Coeficientes de atenuação, $\mu$, densidade, $\rho$, número atômico efetivo $Z_{e f}$ );

- Geometria do sistema (distâncias $d_{1}$ e $d_{2}$, área do feixe incidente $(A)$, ângulo sólido entre o detector e o espalhador, etc. como mostrados na Figura 8);

- Espessura da barreira, $x$. 
Para a obtenção de um modelo matemático que simule a interação Compton na presença de uma barreira espalhadora, em uma geometria de feixe largo, foi escolhida a estratégia de usar o espectro gerado pelo modelo de TBC Modificado e, a partir deste, calcular o espalhamento e a atenuação devido à barreira. Por fim somam-se ambos os espectros, o primário com sua devida atenuação, e o espalhado, que também sofre atenuação no seu caminho ao longo da barreira espalhadora, até que os fótons que constituem este espectro espalhado atinjam o plano do espectrômetro. Nesta modelagem, o espectrômetro é considerado um detector perfeito, ou seja, não são levados em consideração efeitos de modificação de sua eficiência de detecção com a energia dos fótons incidentes ${ }^{49}$, nem outros efeitos tipicamente encontrados em detectores reais ${ }^{50}$.

O espectro de energias dos fótons que atingem o espectrômetro é dado por.

$$
N_{T}(E)=N_{P}(E) e^{-\mu x}+N_{p}(E) \Phi(E)
$$

Onde:

- $N_{T}(E)$ representa o número total de fótons para cada energia do espectro, é o espectro total;

- $N_{P}(E)$ representa o espectro primário calculado utilizando o Modelo de TBC modificado.

- $e^{-\mu x}$ é o termo que representa a atenuação do feixe primário pelo material espalhador. Neste termo, $\mu$ é o coeficiente de atenuação do material da barreira, e $x$ é a espessura do material;

- $\Phi(E)$ é o termo a ser aplicado no espectro primário, que resulta dos eventos de espalhamento Compton que ocorrem no material.

\subsection{Escolha da geometria e das propriedades físicas da barreira espalhadora.}

O feixe de raios $X$ emitido pelo tubo de raios $X$ usado do Laboratório de Dosimetria das Radiações e Física Médica do Departamento de Física Nuclear do Instituto de Física da USP, que foi utilizado no procedimento de validação do modelo proposto, tem forma aproximadamente cônica ao sair do tubo. Por isto o feixe incidente foi modelado como uma região circular de interação com o material da barreira. Com base neste formato circular de interação, e considerando que as 
espessuras usuais da barreira são muito menores que a distância entre a fonte de raios $\mathrm{X}$ e a barreira, foi escolhida a geometria cilíndrica para cálculo do número de interações Compton no material. Nesta aproximação da região de interação por um cilindro considera-se o eixo do cilindro coincidente com o eixo do feixe. Na Figura 9 é mostrada a forma escolhida para a discretização do feixe de raios $X$ que atinge a barreira.

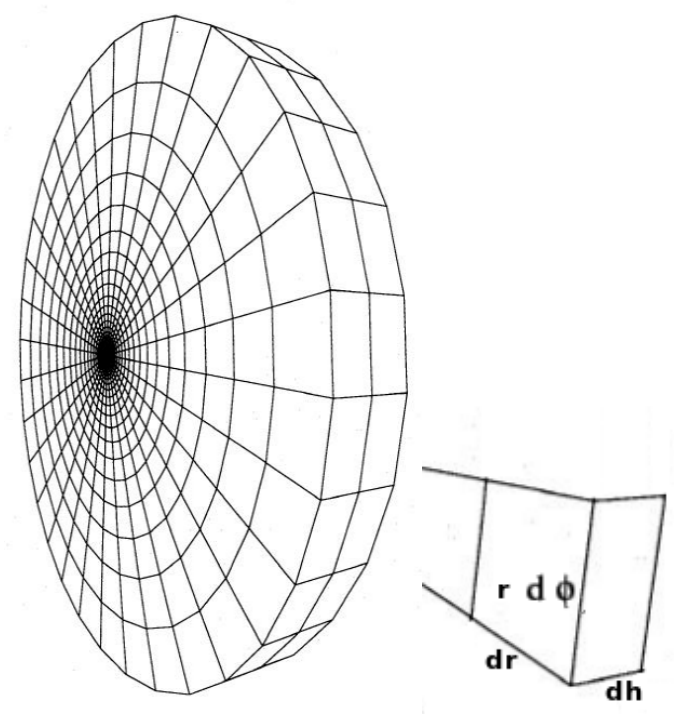

Figura 9 - Forma da barreira usada no modelo matemático para simulação de espalhamento Compton, com elemento de volume em detalhe. O cálculo do espalhamento Compton é feito para cada uma das células (voxels), o conjuntos de células forma a grade usada para discretização da barreira ( Adaptado de Pfenniger and Friedli ${ }^{51}$ )

No modelo matemático proposto foi considerado que os fótons que atingem o material realizam somente uma interação Compton no interior da barreira antes do fóton espalhado sair do material em direção ao detector. Ou seja, o modelo matemático proposto não contempla a possibilidade de múltiplos eventos Compton no material. Por esta razão o material utilizado nos cálculos e na validação do modelo foi o acrílico (polimetil-metacrilato, $\left.\left(\mathrm{C}_{5} \mathrm{O}_{2} \mathrm{H}_{8}\right)_{n}\right)$.

Para se chegar às características geométricas do material que comporia a barreira, foi necessário calcular o livre caminho médio dos fótons no interior da barreira. O livre caminho médio dos fótons espalhados pelo material, $M F P^{52}$, é definido como: 


$$
M F P \lesssim \frac{1}{\mu_{\text {inc }}}
$$

Onde $\mu_{i n c}$ é o coeficiente de atenuação linear para espalhamento Compton.

O livre caminho médio dos fótons pode ser entendido como a distância média que o fóton percorre no meio sem que ocorra uma nova interação Compton. Na Figura 10 observa-se que a escolha do acrílico como material da barreira garante que a probabilidade de ocorrência de múltiplos eventos Compton é bastante pequena considerando-se espessuras inferiores a $6 \mathrm{~cm}$. A parte inicial da curva é pouco relevante para o processo em estudo, uma vez que os feixes incidentes são filtrados por alumínio e, consequentemente, os espectros incidentes no material possuem poucos fótons com energias inferiores a $20 \mathrm{keV}$.

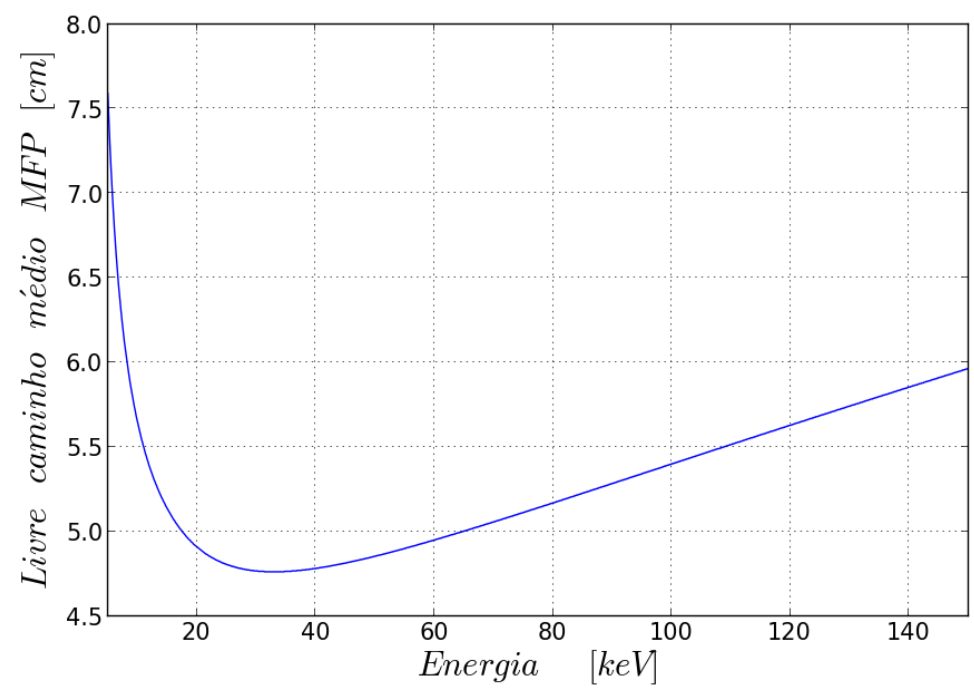

Figura 10 - Livre caminho médio do fóton no acrílico para ocorrência de interação Compton. Fótons com energias entre 20 e $150 \mathrm{keV}$ que percorrem distâncias menores que $6 \mathrm{~cm}$ no acrílico apresentam baixa probabilidade de realizarem espalhamento secundário.

Na Figura 11 pode-se ver uma comparação entre o coeficiente de atenuação total e o coeficiente de atenuação por interação Compton para o acrílico. Pode-se observar que as interações por espalhamento Compton se tornam mais importantes com o aumento na energia. 


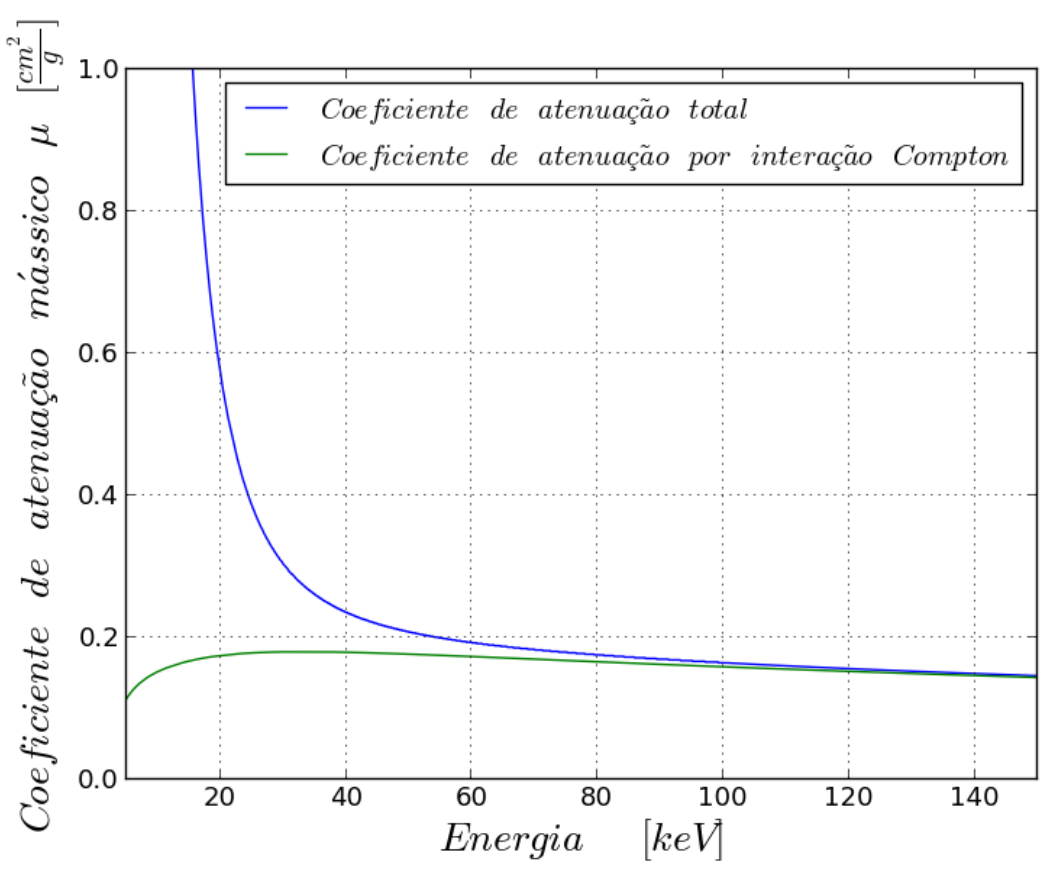

Figura 11 - Comparação entre o coeficiente de atenuação total e apenas por interação Compton para o acrílico na faixa de energias utilizada em radiologia diagnóstica.

\subsection{Cálculo do número de fótons espalhados.}

Para o cálculo do número de fótons espalhados no material absorvedor foi utilizada como estratégia de dividir (ou discretizar), matematicamente, a região de interação no material em pequenas células (voxels), com o intuito de, posteriormente, somar as contribuições dos fótons espalhados por cada voxel e que atingem o detector. $O$ número de fótons espalhados em cada célula varia de acordo com a posição geométrica desta célula na barreira, como será visto adiante. Estas células são elementos infinitesimais de volume para uma geometria cilíndrica. Podese ver a grade cilíndrica formada por este conjunto de voxels no modelamento matemático da barreira na Figura 9.

A quantidade de fótons espalhados devido a interações Compton foi calculada para cada um desses elementos fazendo-se uso do seu volume infinitesimal. Considerou-se que um elemento de volume era numericamente igual ao volume de uma célula (voxel). O volume da célula é um dos parâmetros de entrada no modelo. Para o cálculo do espalhamento Compton também é necessário saber a posição desta célula em relação ao espectrômetro e também à fonte de raios $X$. 
A Figura 12 traz as relações de dependência geométrica usadas no modelo. Com o uso da posição de cada célula (voxel), é calculado o número de fótons espalhados em cada uma destas células, e que emergem da interação em direção ao espectrômetro. No caminho feito dentro da barreira pelo feixe incidente até a célula, onde ocorre a interação, e depois, pelos fótons espalhados, até deixar a região da barreira, este feixe de fótons é atenuado pelo material que compõe a barreira.

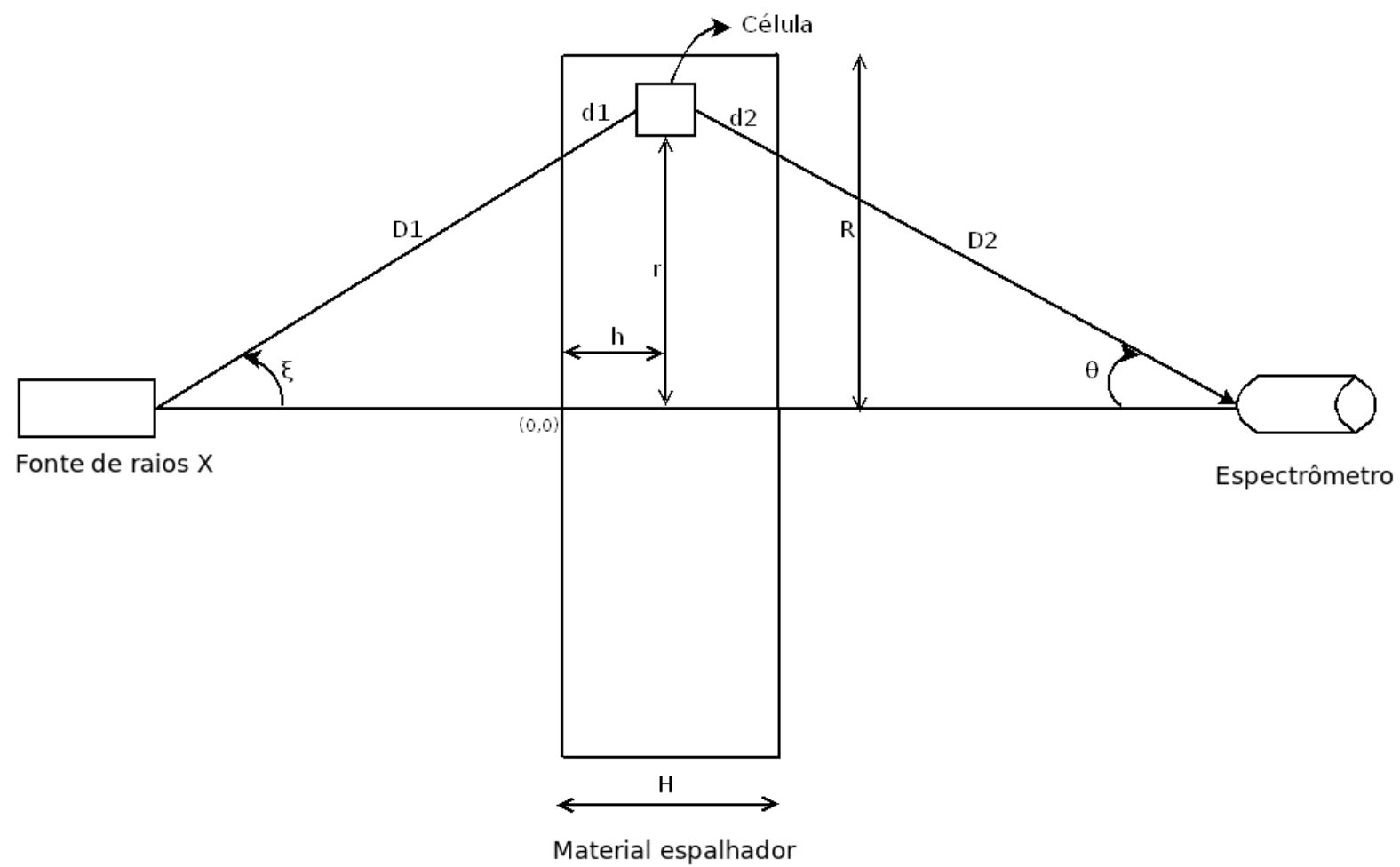

Figura 12 - Visão em duas dimensões da dependência em relação à geometria para o cálculo do espalhamento Compton em cada célula.

Na Figura 12 pode-se verificar as dependências espaciais para cada célula, ou voxel. Estas dependências são:

- Distância em relação ao eixo de simetria r.

- Ângulo azimutal $\phi$, que varia de 0 a $2 \pi$. Não pode ser visto na figura, pois esta figura mostra apenas uma vista em duas dimensões. 
- Distância entre o início do material espalhador e a célula, variando de 0 a $H$ no eixo de simetria.

O espalhamento total é dado pela integral de volume de todas as células, ou elementos de espalhamento.

$$
\text { Espalhamento total }=\Phi(E)=\int_{v} S(E) d V
$$

Onde $S(E)$ representa o espalhamento de uma única célula, e $\Phi(E)$ representa o somatório do espalhamento de cada célula, resultando no espalhamento de toda a barreira.

Os fótons que atingem a face de entrada do objeto espalhador e atravessam o material até a célula a ser considerada, bem como e os fótons que são espalhados no volume da célula e emergem em direção ao espectrômetro, sofrem atenuação pelo material. Como a atenuação é dependente da energia do fóton, os fótons que emergem após interação Compton em direção ao espectrômetro, sofrem atenuação diferente da dos fótons incidentes, pois os valores do coeficiente de atenuação são dependentes da energia do fóton. A energia dos fótons espalhados está representada na equação (8).

A atenuação dos fótons antes de atingirem a célula foi chamada de $A_{\text {inc }}$ (atenuação dos fótons incidentes) e a atenuação dos fótons depois da ocorrência do processo de espalhamento na célula foi chamada de $A_{\text {esp }}$ (atenuação dos fótons espalhados) . A função $\Phi(E)$ fica, então:

$$
\Phi(E)=\int A_{\text {inc }}(E) S(E) A_{\text {esp }}\left(E^{\prime}\right) d V
$$

Onde $\Phi(E)$ é uma função que deverá ser multiplicada pelo número de fótons que são gerados através do modelo de TBC modificado, para uma dada energia $E$, para se obter a fração de fótons espalhados que atingem o detector.

Pela geometria do problema tem-se:

$$
\begin{aligned}
& d 1=\frac{h}{\cos \xi} \\
& A_{\text {inc }}(E)=e^{-\frac{\mu(E) h}{\cos \xi}}
\end{aligned}
$$


De modo semelhante:

$$
\begin{gathered}
d 2=\frac{h}{\cos \theta} \\
A_{e s p}\left(E^{\prime}\right)=e^{\frac{-\mu\left(E^{\prime}\right)(H-h)}{\cos \theta}}
\end{gathered}
$$

Para cálculo de $\Phi(E)$ usa-se ${ }^{52}$ :

$$
\Phi(E)=6,02 \times 10^{23} \frac{\rho}{u} \int \frac{d \sigma(E, \eta)}{d \Omega} d \Omega r d r d \phi d h
$$

Onde $6,02 \times 10^{23} \frac{\rho}{u} r d r d \phi d h$ representa o número de elétrons de um volume infinitesimal do material espalhador, $\rho$ é a densidade neste volume infinitesimal, e $u$ é a massa molar do material. A equação de Klein-Nishina é representada por $\frac{d \sigma(E, \eta)}{d \Omega}$ e $d \Omega$ é o ângulo sólido formado entre o a célula espalhadora e o espectrômetro. $O$ termo $\eta$, ângulo de espalhamento, conforme a geometria mostrada na Figura 12 é dado por $\eta=\xi+\theta$. O significado geométrico dos ângulos $\xi$ e $\theta$, podem ser vistos na mesma figura.

O ângulo sólido formado pelo espectrômetro é calculado a partir de uma aproximação que considera sua área sensível igual à área de seu colimador, $\left(\pi R_{\text {espec }}^{2}\right)$, sendo $R$ o raio da abertura do colimador. Temos então como calcular o ângulo sólido que é dado por:

$$
\int d \Omega=\frac{\pi R_{e s p e c}^{2}}{(D 2)^{2}}
$$

A equação de Klein-Nishina ${ }^{15,52}$, definida na equação (10), pode então ser reescrita como:

$$
\frac{d \sigma(E, \eta)}{d \Omega}=\frac{r_{0}^{2}}{2}\left(1+\frac{\alpha(1-\cos \eta)^{2}}{\left(1+\cos ^{2} \eta\right)[1+\alpha(1-\cos \eta)]}\right) \frac{1+\cos ^{2} \eta}{[1+\alpha(1-\cos \eta)]}
$$

A equação (39) foi usada para calcular a secção de choque em cada célula. 
Por fim, a equação usada para a obtenção do espalhamento Compton é:

$$
\Phi(E)=6,02 \times 10^{23} \frac{\rho}{u} \pi R_{\text {espec }}^{2} \int_{0}^{R} \int_{0}^{2 \pi} \int_{0}^{H} e^{\frac{-\mu(E) h}{\cos \xi}} e^{\frac{-\mu\left(E^{\prime}\right)(H-h)}{\cos \theta}} \frac{d \sigma(E, \eta)}{d \Omega} \frac{1}{(D 2)^{2}} r d r d \phi d h \text { (40) }
$$

A equação (40) foi implementada computacionalmente em ambiente MATLAB $^{\circledR}$ (MathWorks inc, Natick, MA, USA). A Figura 13 apresenta o fluxograma do programa implementado. Este programa recebe como parâmetros de entrada para seu início, todas as variáveis necessárias para definição da geometria descrita neste desenvolvimento matemático, que são, a distância entre o tubo de raios $\mathrm{X}$ e a bareira espalhadora, altura e largura desta barreira, distância entre a barreira espalhadora e o espectrômetro, e finalmente a dimensão volumétrica das células, ou voxels. São também parâmetros de entrada as variáveis necessárias ao modelo de TBC Modificado, onde é calculado o espectro primário que é utilizado para o cálculo do espalhamento, este espectro primário é representado pelo termo $N_{p}(E)$ da equação (29), e tem como parâmetros de entrada a tensão de aceleração no tubo de raios $\mathrm{X}$, a corrente anódica aplicada no tubo, e a espessura do filtro de alumínio.

O tempo de execução do programa implementado é uma questão relevante, pois, a discretização da barreira espalhadora pelo modelo proposto implica em uma demanda de tempo computacional que pode ser incrementada ao ponto de ter seu uso pouco prático para validação por comparação com resultados experimentais. Nos experimentos realizados com células de dimensões do parâmetro $d r$ e $d h$ menores que $0,1 \mathrm{~mm}$, o tempo de execução era da ordem de algumas horas para o cálculo de um único espectro, utilizando um processador da marca Intel ${ }^{\circledR}$ modelo 13 com 8 GB de memória ram. A necessidade de validação deste modelo implicou na escolha de grades de discretização da barreira espalhadora que fossem viáveis em relação à demanda de tempo computacional, para a realização de cálculos de espectros em diferentes geometrias. Portanto foi fixada uma grade que permitisse que cada espectro fosse calculado em um tempo que variasse entre 5 e 15 minutos utilizando um computador com processador Intel ${ }^{\circledR}$ modelo 13 com 8 GB de memória 
ram. Este tempo de execução computacional é variável para uma mesma grade de discretização, devido aos outros parâmetros de entrada do modelo. A grade foi fixada, neste trabalho, com os parâmetros $d r=4 m m, d h=4 \mathrm{~mm}$, e $d \phi=1^{\circ}$.

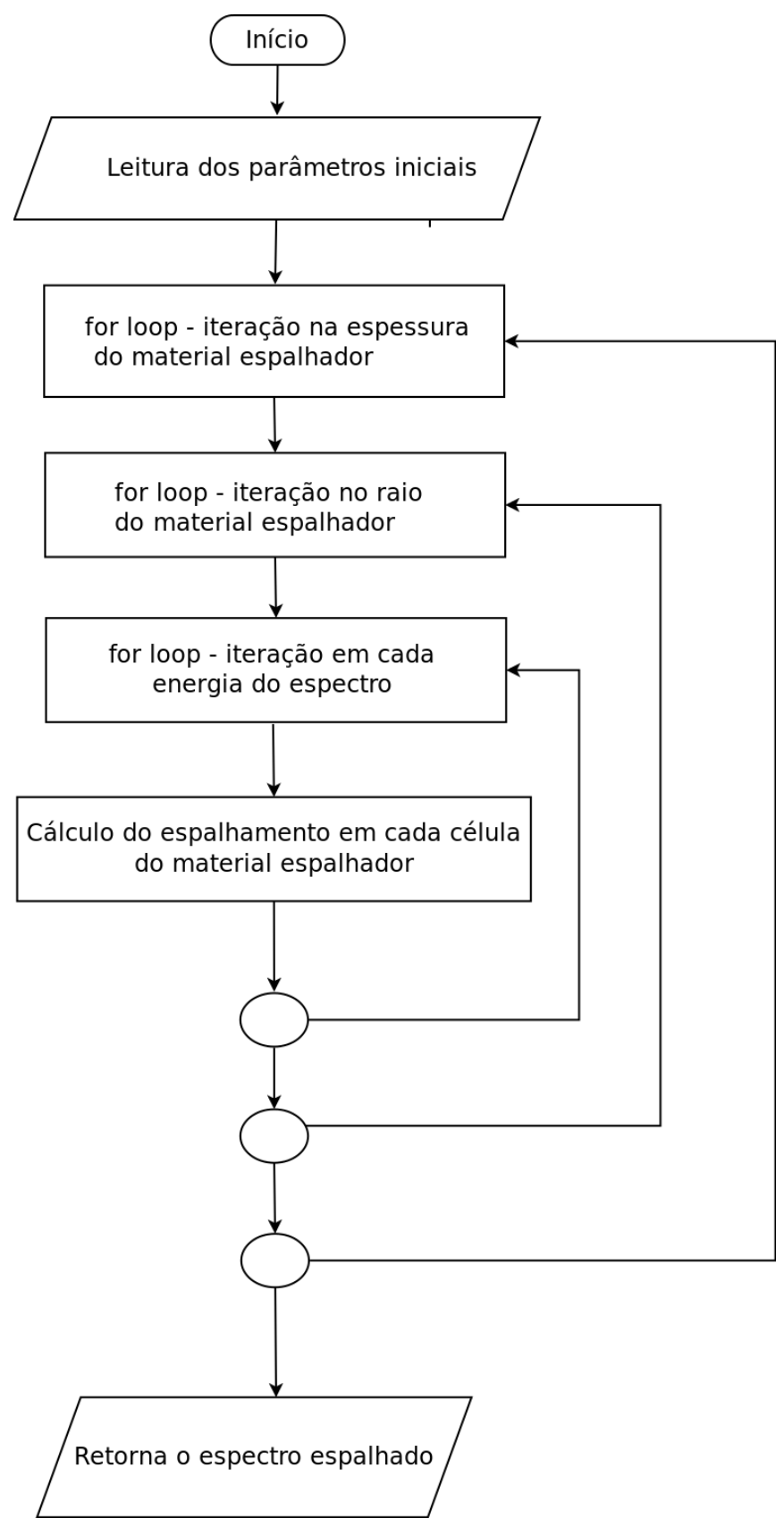

Figura 13 - Fluxograma do programa computacional que implementa o modelo matemático usado para o cálculo do espalhamento Compton.

A Figura 14 apresenta o pseudo-código do programa computacional tratado no fluxograma Figura 13 , e implementado em ambiente computacional MATLAB ${ }^{\circledR}$. 
- $\quad$ calcula_espalhamento_Compton(a, E_art, b, R_art, dim_cel, RE, dens, EspectroS,mi,E,B)

a - distancia entre a fonte e o material espalhador

E_art - espessura do material espalhador

b - distancia entre o espectrometro e o material espalhador

$\mathrm{R}$ art - raio do material espalhdor

dim_cel - dimensao em milimetros da celula (voxel)

$R E$ - raio da àrea frontal do elemento sensível do espectrometro

$\mathrm{aE}$ - distancia entre o inicio do material espalhador e a célula

Eb - distancia entre a célula e o fim do material espalhador

dens- densidade materialespalhador

EspectroS - espectro de Raios-X gerado pelo TBC

$\mathrm{mi}$ - coeficientes de atenuacao do material espalhador

B - coeficientes da função de espalhamento incoerente

- <pré-condição>: Espectro primário gerado pelo TBC, dimensões do material espalhador, características físicas deste material, posição e dimensão do espectrômetro.

- $\quad$ <pós-condição >: Espectro de fótons espalhados.

- Início:

○ Espectro_primário $\leftarrow$ normalização pela área frontal do espectrômetro.

- <loop>: Soma o número de fótons espalhados em cada célula(voxel) na

dimensão da espessura do material espalhador, já idealizado como um cilindro.

- <loop>: Soma fótons espalhados na dimansão do raio, do centro para a periferia do cilindro idealizado.

- <loop>: Calcula o epalhamento para cada energia do espectro.

- Espectro_atenuado $\leftarrow$ Espectro_primário * atenuação do espectro no caminho até a célula, onde ocorre a interação.

- Índice $\leftarrow$ Novo índice de energia para os fótons após a interação.

- $\mathrm{KN} \leftarrow$ Secção de choque de Klein-Nishina * função de espalhamento incoerente.

○ cts $\leftarrow$ número de elétrons na região de interação * $\mathrm{KN}$

○ $\quad$ espectrômetro $\leftarrow$ calcula o ângulo sólido em relação ao espectrômetro

○ fótons_espalhados $\leftarrow$ cts * espectrômetro.

○ fótons_espalhados $\leftarrow$ fótons_espalhados * atenuação no caminho da região de iteração até a saída do material espalhador.

$0<$ fim do loop>

o <fim do loop>

0 <fim do loop>

- $\quad$ retorna espectro de fótons espalhados

- $\quad$ Fim do algorítmo

Figura 14 - Pseudo-código do programa computacional que implementa o modelo matemático proposto neste trabalho. 


\subsection{Aparato experimental utilizado nas medições para validação do modelo proposto.}

A validação experimental do modelo proposto foi feita a partir da comparação com medições realizadas nas dependências do Laboratório de Dosimetria das Radiações e Física Médica do IFUSP. Para isto, foram medidos espectros transmitidos por barreiras de acrílico de diferentes espessuras, em condições de feixe largo. Foram avaliados espectros compostos de fótons primários transmitidos pelas barreiras adicionados a fótons espalhados pelo material da barreira e espectros de fótons somente espalhados pela barreira, eliminando-se os fótons relativos ao feixe primário utilizando-se uma barreira de chumbo interceptando o feixe primário. Como será explicado em detalhes na secção 3.6.

A fim de se obterem espectros de energia necessários para validação, foi montado um aparato experimental que permite representar a geometria apresentada esquematicamente na Figura 12. Pode-se ver nas Figuras 15 e 16 imagens do aparato experimental montado.

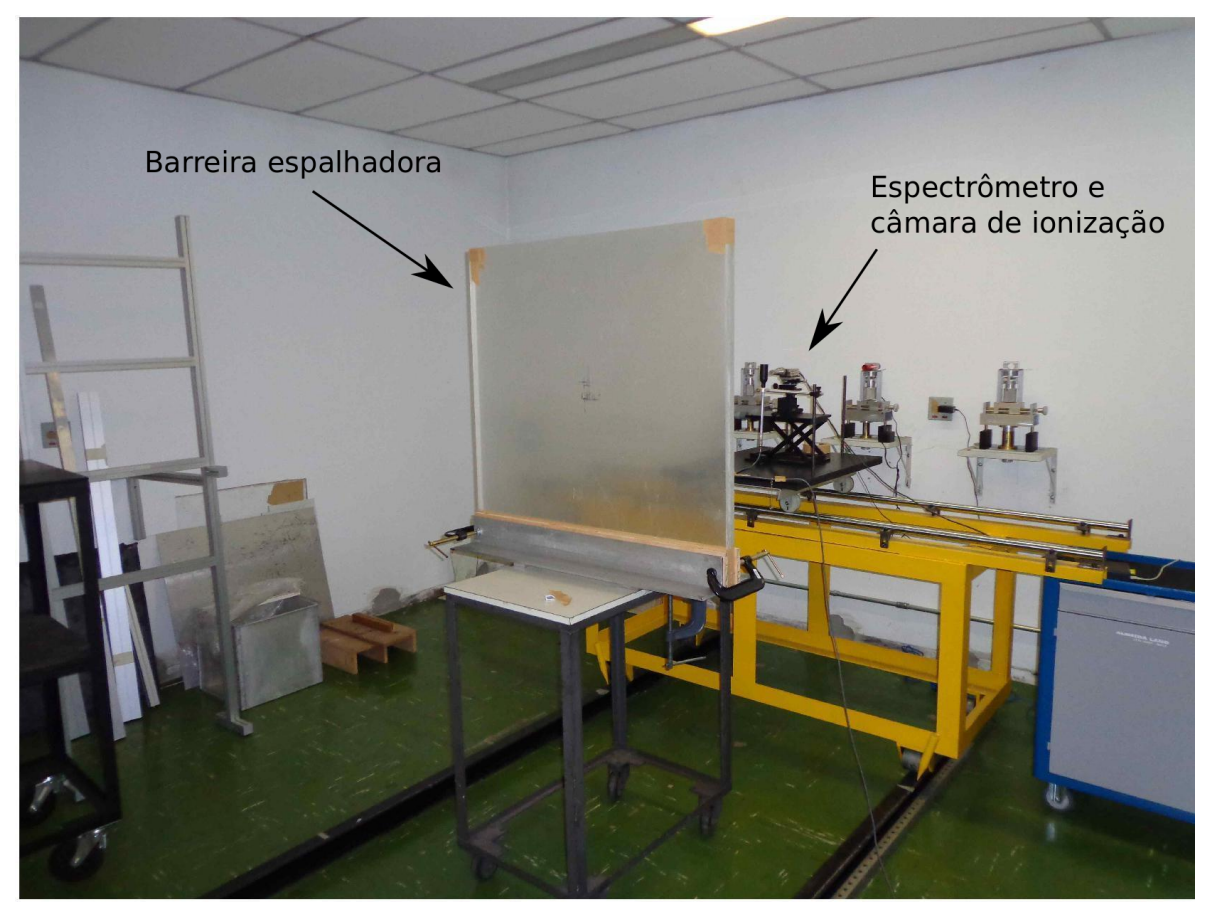

Figura 15 - Aparato experimental que permite representar a geometria apresentada esquematicamente na Figura 12: Barreira de acrílico em primeiro plano, espectrômetro e câmara de ionização ao fundo. 


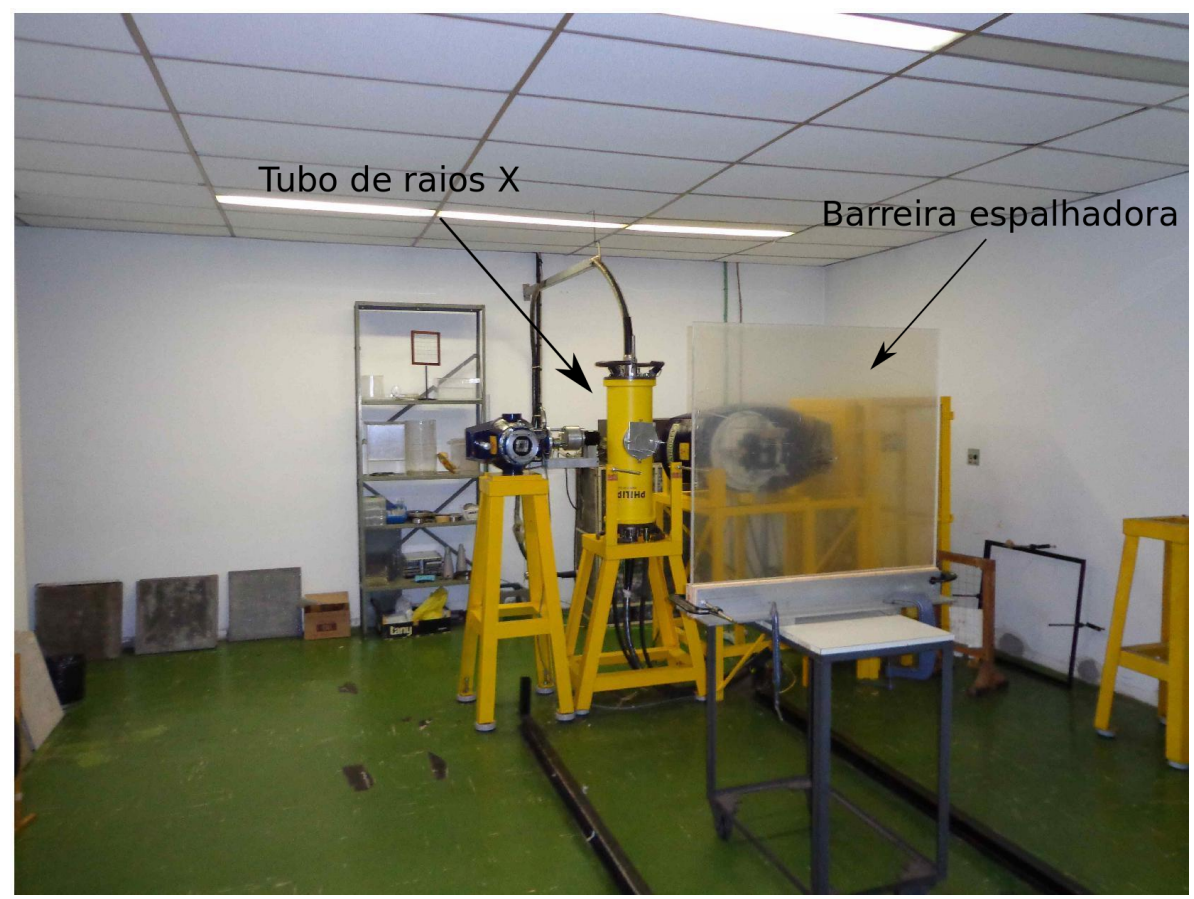

Figura 16 - Aparato experimental que permite representar a geometria apresentada esquematicamente na Figura 12: Tubo de raios $X$ ao fundo, e a barreira de acrílico.

O aparato experimental foi constituído, basicamente, do equipamento emissor de raios $X$, espectrômetro, câmara de ionização e barreira espalhadora. $O$ equipamento de raios $X$ utilizado é um modelo de uso industrial marca Philips (Hamburg, Germany), modelo MG 450. O tubo de raios $X$ acoplado a este equipamento é também fabricado pela Philips modelo MCN 421, com anodo de tungstênio com ângulo de 22 graus. A Tabela 1 mostra as características do equipamento emissor de raios $X$ usado nas medições.

Tabela 1 - Características do tubo de raios X usado nas medições (adaptado de Gonzales ${ }^{53}$ )

\begin{tabular}{cc}
\hline Modelo & Philips MCN 421 \\
$\mathrm{N}^{\circ}$ de Série & 942117257032 \\
Alvo (fixo) & Tungstênio \\
Inclinação do alvo & $22^{0}$ \\
Ângulo de saída do feixe & $30^{\circ}$ \\
Janela de saída & $2,2 \mathrm{~mm}$ de Berílio \\
\hline
\end{tabular}

O espectrômetro usado nas medições foi da marca Amptek, Inc. (Bedford, MA, USA) modelo XR-100T, com elemento sensível de telureto de cádmio ( $\mathrm{CdTe}$ ), com $9 \mathrm{~mm}^{2}$ ( $3 \mathrm{~mm} \times 3 \mathrm{~mm}$ ) de área nominal e $1 \mathrm{~mm}$ de espessura. $O$ elemento sensível está protegido por uma janela de berílio de $100 \mu \mathrm{m}$ de espessura. $\mathrm{O}$ 
espectrômetro usado possui um conjunto de colimadores de tungstênio, todos com $2 \mathrm{~mm}$ de espessura e diferentes diâmetros de abertura. Neste trabalho apenas o colimador com abertura de $2 \mathrm{~mm}$ de diâmetro foi usado.

A barreira espalhadora foi posicionada no eixo central do feixe de raios $X$. Foram utilizadas, para realização do experimento, duas placas compostas por acrílico (PMMA) ambas com $(1 \mathrm{~m} \times 1 \mathrm{~m})$ de lado, uma com $20 \mathrm{~mm}$ e a outra com $24 \mathrm{~mm}$ de espessura. As placas de acrílico foram usadas como barreira espalhadora, individualmente, e sobrepostas, o que permitiu a realização de medições com espessuras de barreira espalhadora de 20 mm, 24 mm e 44 mm.

A câmara de ionização utilizada é da marca PTW, modelo TW 23361 com volume de $30 \mathrm{~cm}^{3}$. Este instrumento foi usado em conjunto com um eletrômetro UNIDOS E (T10009) do mesmo fabricante. A câmara de ionização juntamente com o eletrômetro foi calibrada por um laboratório nacional acreditado de padrão secundário.

A câmara de ionização foi utilizada para medir o kerma no ar devido ao feixe primário e também aos fótons espalhados pela barreira de acrílico. Este detector foi posicionado à uma distância de $15 \mathrm{~cm}$ à frente do elemento sensível do espectrômetro. E foi utilizada em todas as medições, como se vê na Figura 17.

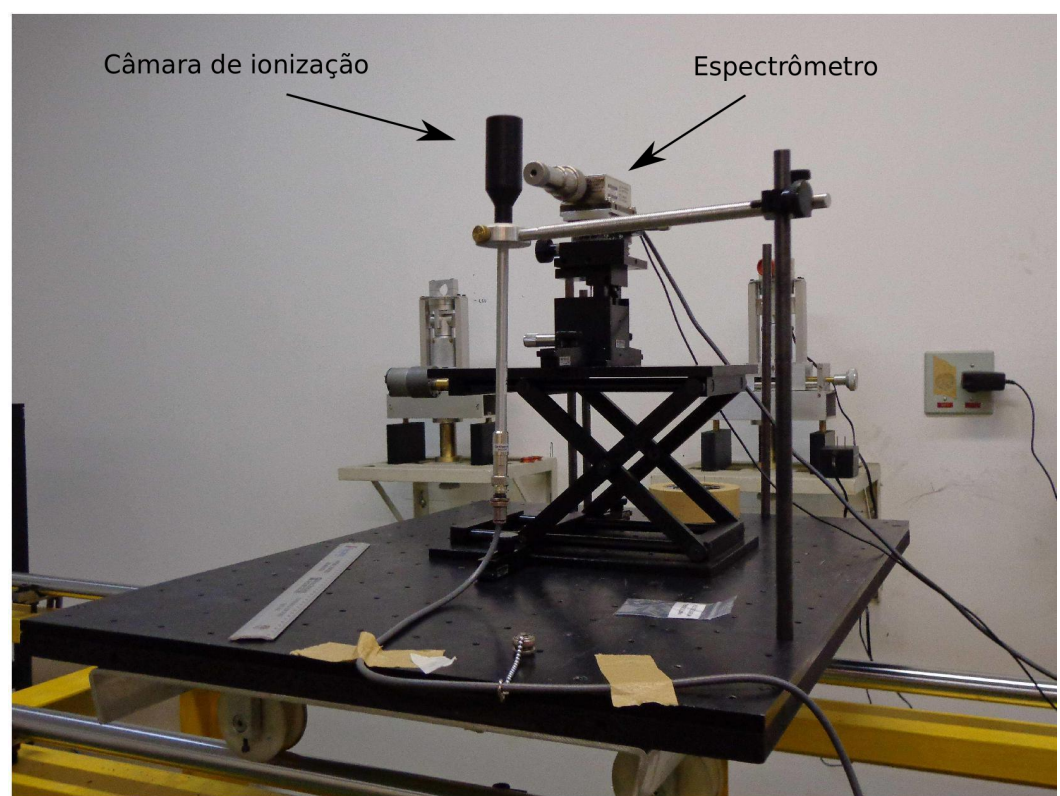

Figura 17 - Na mesma imagem estão a câmara de ionização e o espectrômetro, já montados e alinhados para as medições.

Imagens radiográficas foram utilizadas para fazer alinhamento entre o espectrômetro e câmara de ionização no centro do feixe de raios $X$ e para 
determinar o tamanho de campo nas distâncias em que foram posicionadas as barreiras. Para isto foi utilizado um equipamento de radiografias computadorizado, da marca AGFA (Greenville, SC, USA), modelo CR-30X. Este equipamento possui uma placa sensível à radiação nas energias tipicamente usadas em radiologia diagnóstica, designado por image plate (IP). A Figura 18 apresenta uma imagem do equipamento citado.

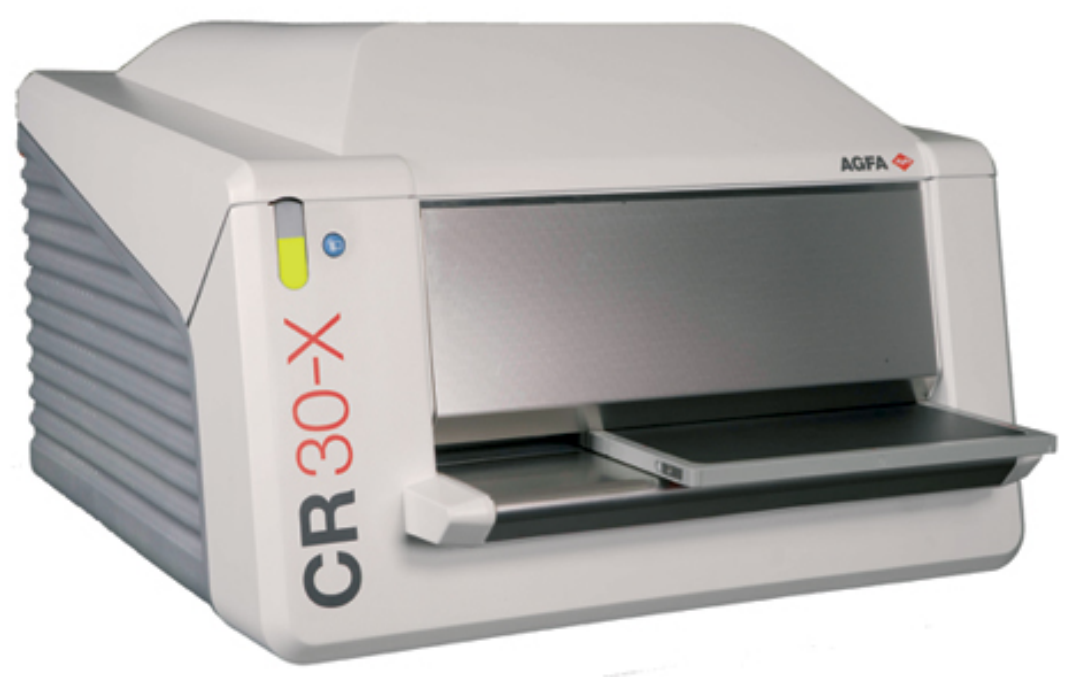

Figura 18 - Imagem do digitalizador computadorizado de radiografias, com seu respectivo image plate posicionado para leitura. (Adaptado de Mariano ${ }^{54}$ )

\subsection{Procedimento de alinhamento.}

Para fazer o alinhamento entre o espectrômetro e os demais componentes do aparato experimental foram utilizadas imagens radiográficas digitais do feixe de raios $X$. Nestas imagens pôde localizar o centro da barreira, marcado com um pequeno cilindro de chumbo, o elemento sensível do espectrômetro, e ainda a câmara de ionização. Estas imagens radiográficas foram produzidas fazendo-se uso do leitor de radiografias digitais (CR) descrito no item anterior. A Figura 19 mostra o (IP) posicionado atrás do espectrômetro, em relação ao feixe de raios $X$ incidente, em situação real de utilização. A Figura mostra, também, o posicionamento do espectrômetro e da câmara de ionização. 


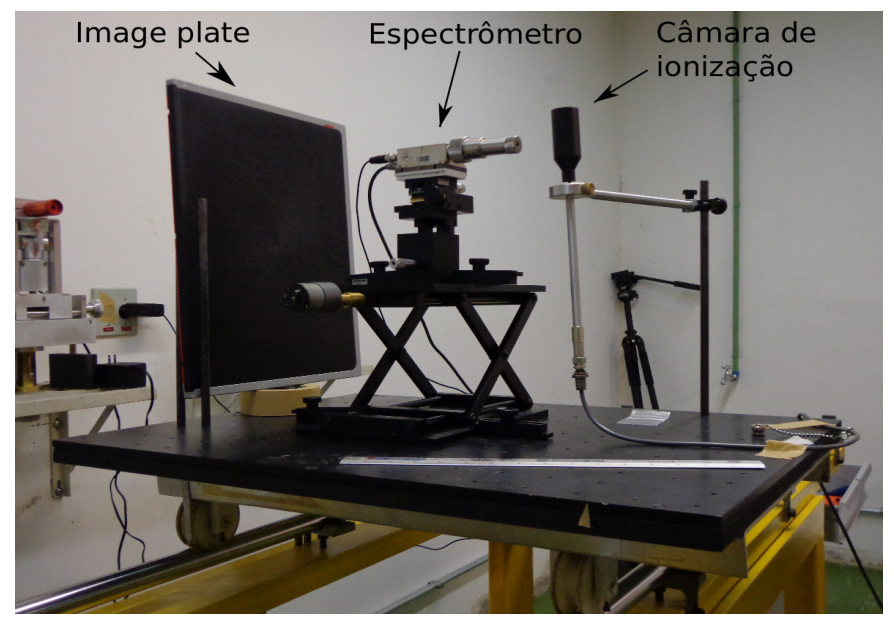

Figura 19: Equipamento de imageamento digital (IP) posicionado atrás do espectrômetro e da câmara de ionização para a aquisição de imagens, estas imagens foram usadas para centralização destes equipamentos em relação ao feixe de raios $X$.

A Figura 20 mostra um exemplo das imagens de radiografia digital usadas para alinhamento do espectrômetro no centro do feixe de raios $X$.

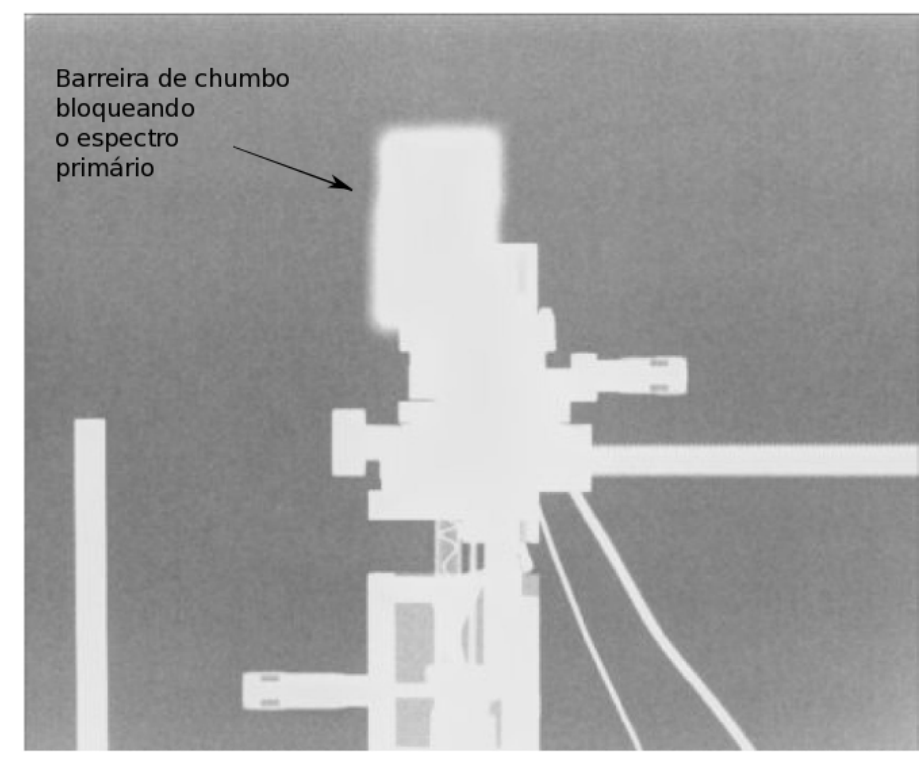

Figura 20 - Exemplo de uma das imagens radiográficas utilizadas para alinhamento do arranjo experimental. Pode-se observar a parte traseira do espectrômetro e a barreira para espectros primários.

\subsection{Medição dos Espectros}

O objetivo do experimento foi obter espectros experimentais para a validação do modelo proposto conforme apresentado na secção 3.1 que prevê a incorporação de fótons provenientes de interações Compton com um objeto espalhador no modelo 
de TBC modificado. As variáveis passíveis de seleção nos experimentos realizados foram:

- Tensão de aceleração aplicada ao tubo de raios $\mathrm{X}$.

- $\quad$ Corrente anódica aplicada no tubo.

- $\quad$ Espessura do filtro de alumínio.

- Distância entre o tubo e a barreira espalhadora.

- $\quad$ Distância entre o a barreira espalhadora e o espectrômetro.

- $\quad$ Altura e largura da barreira.

- Tamanho do feixe de radiação ao atingir a barreira.

- Espessura da barreira de acrílico.

As medições foram divididas em três séries. Variação no tamanho do campo, na espessura da barreira, e na distância entre a barreira espalhadora e a fonte de raios X. Em cada uma das séries foram mantidos constantes todos os parâmetros, a menos um deles, que foi o usado para testar os limites de validade do modelo. Além dessas variáveis, os espectros foram medidos em diferentes valores de tensão aplicada ao tubo de raios X, entre 50 e 150 kV. A filtração de alumínio usada na saída do tubo de raios $X$ foi de $15 \mathrm{~mm}$ para todas as medições. Esta filtração foi necessária devido ao compromisso entre efetuar as medições de espectros primários transmitidos e espalhados aplicando as mesmas técnicas, tensão, tempo e corrente ao tubo de raios $\mathrm{X}$, e evitar a saturação do espectrômetro, que ocasiona o problema de aumento no seu tempo morto.

O espectro detectado no espectrômetro é a soma das contribuições dos fótons do feixe primário que são atenuados pela barreira e dos fótons que são espalhados por esta barreira. Foi definido o espectro primário atenuado pela barreira representado por $\mathrm{P}$ e o espectro de fótons espalhados representado por $\mathrm{S}$.

Neste trabalho, foram realizadas medições de espectros compostos pelas contribuições dos fótons do espectro primário atenuados e espalhados, P+S, Figura 21 , e de espectros provenientes apenas por espalhamento pela barreira, S, Figura 22. 
Na Figura 21, é possível observar a representação do aparato experimenal usado para as medições de espectros primários transmitidos, mais o espalhamento pela barreira $\mathrm{P}+\mathrm{S}$.

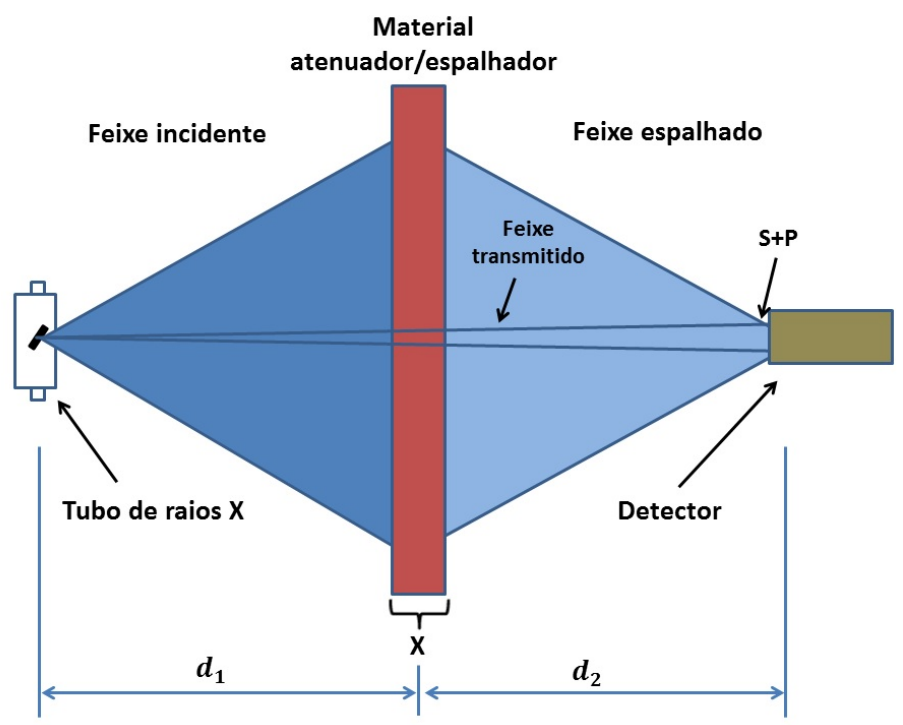

Figura 21 - Representação esquemática do aparato experimental usado nas medições de espectros transmitidos mais espalhados pela barreira, $\mathrm{P}+\mathrm{S}$.

Para as medições do espectros $S$, foi usado um aparato de chumbo em forma de cubo com lados de $1 \mathrm{~cm}$. Este objeto foi posicionado no centro do feixe de raios $X$ de modo a atenuar o espectro primário. Como o objeto é de alta densidade e número atômico, funcionou como um bloqueador do feixe primário. Como pode-se ver na Figura 22.

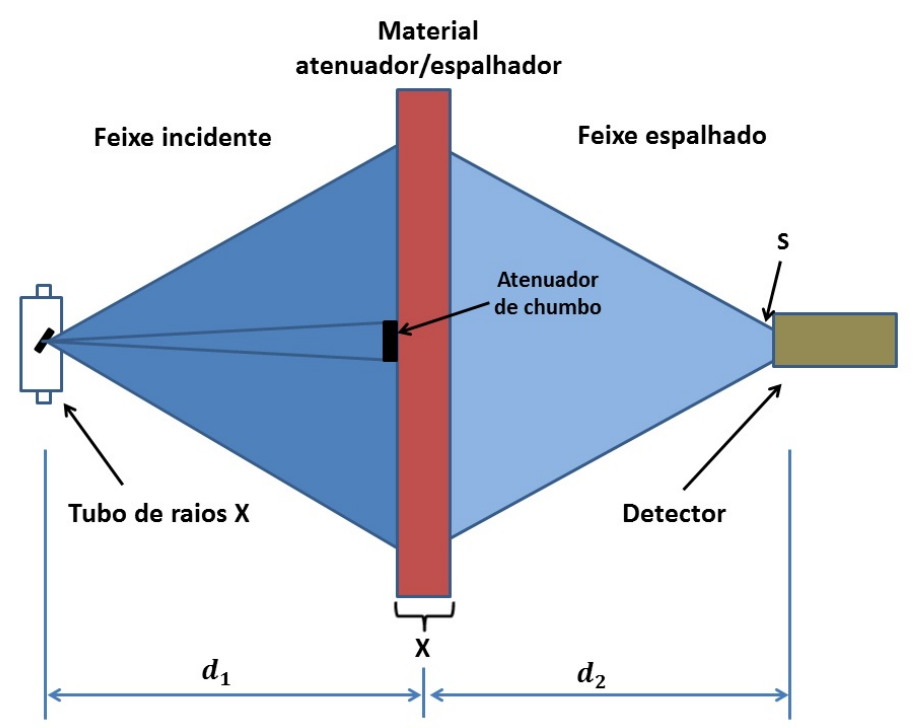

Figura 22 - Representação esquemática do aparato experimental usado nas medições de espectros espalhados pela barreira, $\mathrm{S}$ 
O espectrômetro foi posicionado na maior distância possível do tubo de raios $X$, ou seja, a 5,59 metros deste, para que o fluxo de fótons no detector não fosse alto demais e acarretasse um tempo morto muito alto no espectrômetro. As medições foram realizadas com a placa espalhadora em três posições distintas: 2 metros, 2,87 metros e 4,34 metros de distância do ponto focal do tubo de raios X. Estas distâncias foram escolhidas de modo a manter os outros parâmetros constantes. As distâncias entre a barreira e o ponto focal do tudo de raios $X$, bem como entre esta e o espectrômetro, foram medidas com uso de uma trena.

Foram utilizadas duas barreiras de acrílico, com mesma área de secção transversal e espessuras diferentes, adquiridas do mesmo fabricante e com as mesmas características construtivas. Com estas duas barreiras disponíveis, uma de $20 \mathrm{~mm}$ e a outra de $24 \mathrm{~mm}$ de espessura, pode-se variar a espessura total adotada nas medições em $20 \mathrm{~mm}, 24 \mathrm{~mm}$ e $44 \mathrm{~mm}$. As espessuras das duas barreiras de acrílico usadas no experimento foram medidas com uso de um paquímetro.

Por fim, para todos os espectros medidos, foram gerados espectros calculados computacionalmente com uso do programa já implementado, utilizando os mesmos parâmetros adotados nos experimentos. Pôde-se fazer comparações qualitativas e quantitativas entre os espectros medidos e calculados. A geração de uma simulação para cada um dos 154 espectros medidos demandou o desenvolvimento de uma rotina, também implementada em MATLAB ${ }^{\circledR}$, para automatização do processo.

Os espectros de raios $X$ medidos foram corrigidos utilizando um programa, também escrito em MATLAB, previamente desenvolvido para esta finalidade ${ }^{49,55}$. $O$ programa corrige os espectros medidos pela função resposta do detector de CdTe para energias na faixa do radiodiagnóstico. As correções são feitas por meio do processo de stripping ${ }^{40,56}$ e consideram função de escape, espalhamento Compton e eficiência do detector. Além disso o algoritmo implementado normaliza a área do espectro corrigido pelo valor de kerma no ar medido por câmaras de ionização nas mesmas configurações de medições dos espectros. Desse modo, os espectros corrigidos são apresentados em unidades de kerma no ar normalizado (mGy/mAs.keV) à $1 \mathrm{~m}$ de distância em função da energia (keV). 


\subsection{Métricas usadas para comparações entre espectros medidos e cálculados.}

Foram usadas duas métricas, ou figuras de mérito, para comparação entre espectros obtidos nas medições e espectros calculados com uso do modelo proposto neste trabalho. A primeira é um índice comparativo entres espectros que os compara quanto à sua forma. Esta figura de mérito representa a diferença quadrática média normalizada entre as amplitudes destes espectros, definida na Equação (41)

$$
\delta_{\text {nor }}^{2}=\frac{1}{N} \sum_{i=E_{1}}^{E_{N}} \frac{\left(N\left(E_{i}\right)-M\left(E_{i}\right)\right)^{2}}{M A X\left(N\left(E_{i}\right)-M\left(E_{i}\right)\right)^{2}}
$$

Onde, $N\left(E_{i}\right)$ é o valor do espectro calculado na energia $E_{i}$, e $M\left(E_{i}\right)$ é o valor do espectro medido na mesma energia. $\operatorname{MAX}\left(N\left(E_{i}\right)-M\left(E_{i}\right)\right)^{2}$ é o maior valor do qudrado entre $N\left(E_{i}\right)$ e $M\left(E_{i}\right)$.

A grandeza $\delta_{\text {nor }}^{2}$ varia no intervalo de 0 a 1 devido à normalização. Por fim, para melhor clareza, foi invertida a escala, equação (42).

$$
\delta^{2}=1-\delta_{\text {nor }}^{2}
$$

No caso de dois espectros iguais serem comparados pela figura de mérito $\delta^{2}$, teremos.

$$
\left(N\left(E_{i}\right)-M\left(E_{i}\right)\right)^{2}=0 \text { então } \delta^{2}=1
$$

A segunda figura de mérito usada foi a razão entre os valores de kerma no ar medido e kerma no ar calculado. Com uso desta figura de mérito é possível uma avaliação quantitativa da qualidade dos espectros pela comparação entre as áreas abaixo das curvas que representam estes espectros. Esta figura de mérito é uma relação indireta entre o número de fótons que existem nos espectros medido, e calculado. 


\subsection{Validação do modelo de TBC modificado para filtração adicional de $15 \mathrm{~mm}$ de Al}

Uma análise qualitativa preliminar foi realizada para verificar se o modelo de TBC modificado encontrava-se adequado às condições experimentais a serem adotadas para validação do modelo proposto no presente trabalho. Esta avaliação preliminar foi necessária, pois, para evitar a saturação do espectrômetro e, consequentemente, valores excessivamente altos do tempo morto do sistema de detecção, a fluência do feixe primário foi reduzida pela incorporação de um filtro adicional de $15 \mathrm{~mm}$ de alumínio. Contudo, o Modelo de TBC modificado havia sido validado somente para filtrações adicionais máximas de $5 \mathrm{~mm}$ de alumínio.

A Tabela 2 apresenta os parâmetros usados tanto nas medições dos espectros primários para esta avaliação preliminar, quanto na sua simulação computacional.

Tabela 2 - Parâmetros usados tanto nas medições de espectros P, quanto na sua simulação com uso do Modelo de TBC Modificado. Os valores de tensão, corrente e tempo foram aplicados no tubo de raios

\begin{tabular}{ccccccc}
\hline $\begin{array}{c}\text { Tensão } \\
{[\mathbf{k V}]}\end{array}$ & $\begin{array}{c}\text { Corrente } \\
{[\mathrm{mA}]}\end{array}$ & Tempo[s] & Filtro[mmAl] & $\begin{array}{c}\text { Distância } \\
{[\mathrm{m}]}\end{array}$ & $\begin{array}{c}\text { kerma } \\
\text { no ar } \\
{[\mu G y]} \\
\text { calculado }\end{array}$ & $\begin{array}{c}\text { kerma } \\
\text { no ar } \\
{[\mu G y]} \\
\text { medido }\end{array}$ \\
\hline 50 & 1,6 & 60 & 15 & 5,61 & 2,98 & 3,85 \\
80 & 0,7 & 60 & 15 & 5,61 & 11,79 & 12,98 \\
110 & 0,6 & 60 & 15 & 5,61 & 29,08 & 30,9 \\
150 & 0,4 & 60 & 15 & 5,61 & 43,74 & 44,72 \\
\hline
\end{tabular}

A Figura 23 apresenta uma avaliação comparativa entre espectros medidos e calculados com tensões de 50, 80, 110 e $150 \mathrm{kV}$, adotando-se filtração adicional de $15 \mathrm{~mm}$ de Al. 

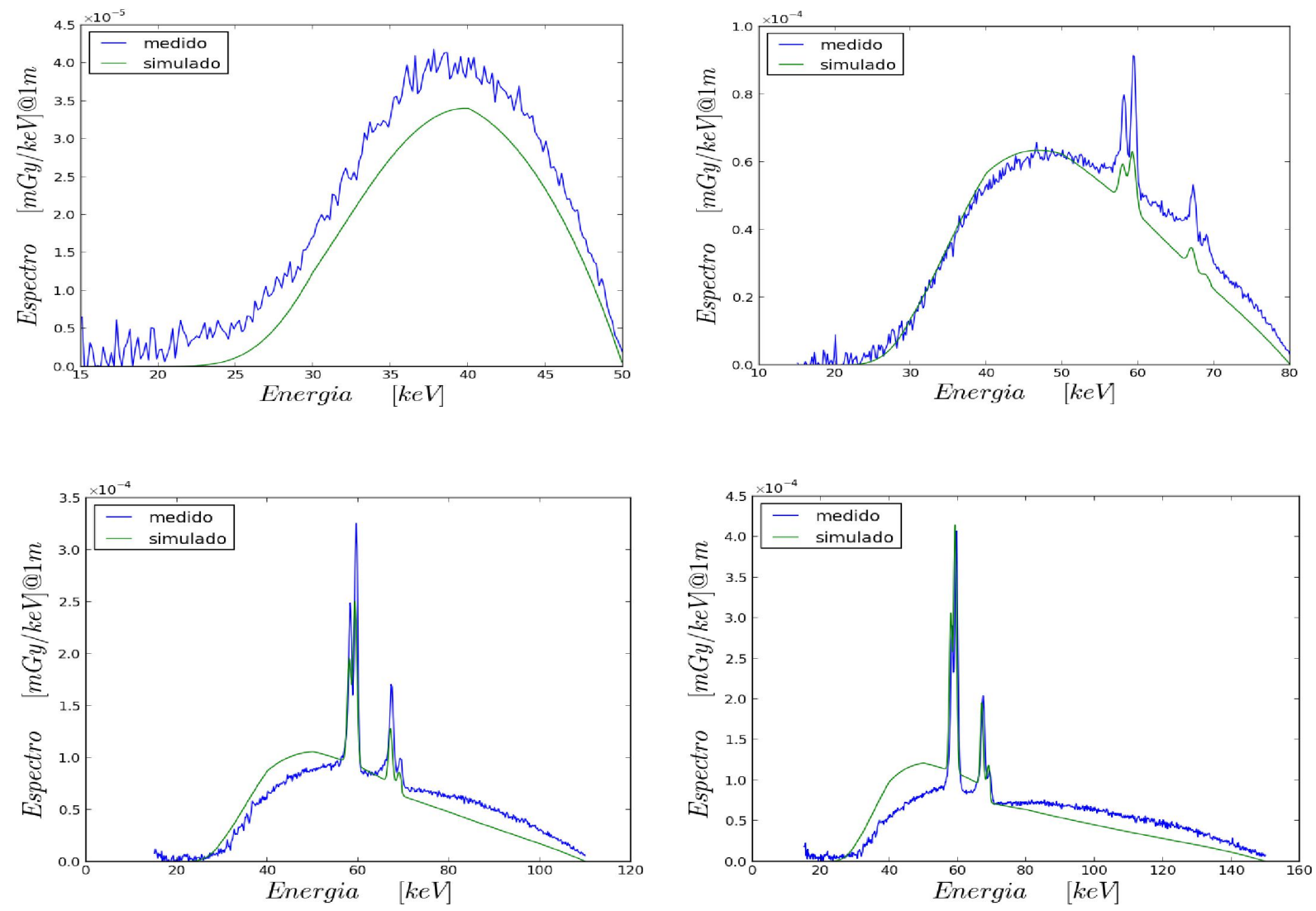

Figura 23 - Espectros medidos (linhas azuis) e calculados (linhas verdes) referentes às tensões de 50, 80, 110 e 150 kV aplicadas ao tubo de raios X. A filtração adicional considerada na simulação e adotada no procedimento experimental foi de $15 \mathrm{~mm}$ de $\mathrm{Al}$.

Pode-se verificar, na Figura 23, que a forma dos espectros calculados não corresponde, adequadamente, à forma dos espectros medidos. Identificou-se que estas diferenças na forma dos espectros ocorria devido à limitação do modelo de TBC modificado em termos da filtração adicional do tubo, cujo valor máximo deveria ser $5 \mathrm{~mm}$ de Al. Desta forma, foi necessário aplicar uma correção matemática aos espectros calculados através do modelo de TBC modificado. Esta correção deveria levar em consideração tanto a modificação na forma do espectro devido ao aumento da filtração adicional, que reduz mais os fótons de baixa energia que os de energia mais alta, quanto sua amplitude. A equação (43) mostra o ajuste que foi aplicado a cada espectro calculado através do modelo de TBC modificado.

$$
N(E, A, B)=A N_{0}(E) e^{-\mu(E) B}
$$

Onde $N(E)$ representa o número de fótons do espectro corrigido, $N_{0}(E)$ é o espectro calculado pelo modelo de TBC modificado e os parâmetros $A$ e $B$ são 
obtidos através de uma rotina computacional que compara os espectros calculados e medidos. Estes parâmetros foram obtidos para a faixa de tensões aplicadas ao tubo de raios $\mathrm{X}$ entre 50 a $150 \mathrm{kV}$, com intervalos de $10 \mathrm{kV}$.

Como apresentado na equação (42), o indicador de forma, $\delta^{2}$, é tão melhor quanto seu valor é mais próximo de 1. Assim, foram ajustados os valores dos parâmetros $A$ e $B$ de forma que o valor de $\delta^{2}$ fosse máximo. Para esta maximização foi desenvolvido um algoritmo computacional no qual o valor de $\delta^{2}$ foi calculado para um conjunto de pares de valores $A$ e $B$ formando uma superfície. O algoritmo localiza, então, o valor máximo desta superfície e o par de parâmetros $A$ e $B$ que deu origem a este valor máximo.

O indicador de forma foi, então, calculado para uma grade de valores de $A$ e $B$ aplicados aos espectros calculados. Para a constante multiplicativa $A$, escolheu-se um intervalo de 0 a 2. A constante que aparece no termo exponencial da equação (43) pode ser interpretada como uma correção para a filtração adicional a ser adotada para correção da forma do espectro. Para este valor foi adotado um intervalo entre 0 e $11 \mathrm{~mm} \mathrm{Al}$.

A Figura 24 mostra o diagrama de fluxo do programa criado para calcular o valor dos parâmetros do $\delta^{2}$. Esse procedimento foi repetido para os valores de tensão de aceleração aplicada no tubo de raios $X$ iguais aos utilizados no procedimento de medição dos espectros.

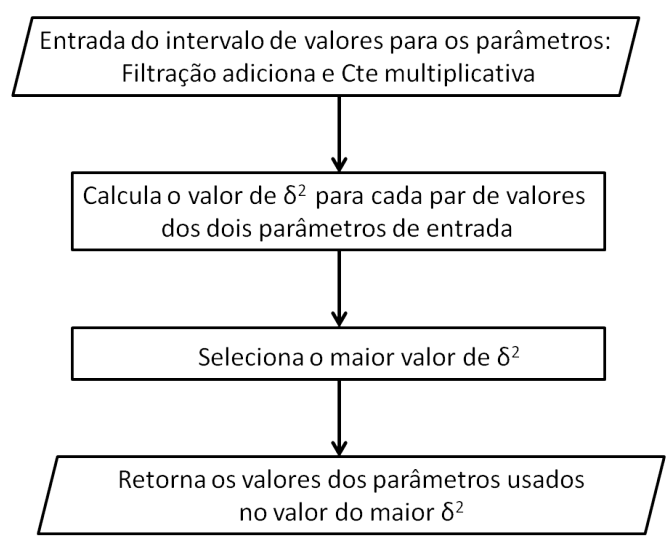

Figura 24 - Diagrama de fluxo mostrando o funcionamento do programa que calcula os parâmetros para ajuste dos espectros 
A Figura 25 mostra o exemplo de uma superfície formada pelo cálculo de $\delta^{2}$ em cada um dos pontos formados pelos valores de filtração adicional e constante multiplicativa.

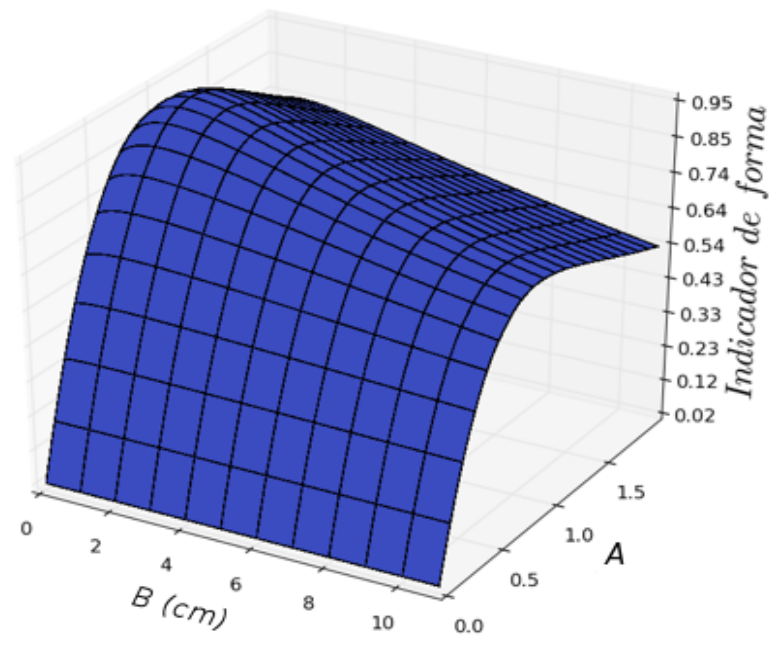

Figura 25 - Superfície formada pelo cálculo do indicador de forma $\delta^{2}$ aplicado aos diversos valores do fator exponencial $B(\mathrm{~cm})$, e da constante multiplicativa $A$ (adimensional), para espectro primário com tensão de 150 kV.

A Figura 26 mostra o resultado da aplicação do procedimento de correção aos espectros calculados com uso dos parâmetros obtidos pela localização do ponto de máximo do índice de forma $\delta^{2}$. Nesta figura é apresentado um espectro calculado sem barreira já ajustado de acordo com os parâmetros obtidos por maximização.
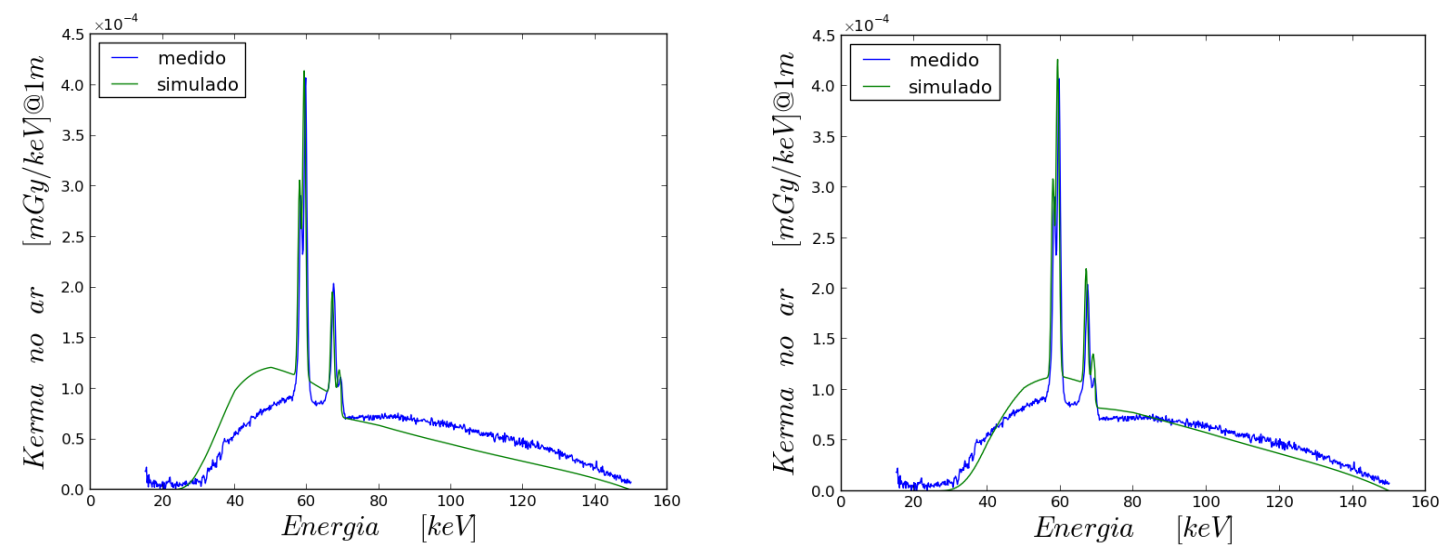

Figura 26 - Na figura da esquerda está um dos espectros primários apresentados na Figura 23 à direita, ajuste feito neste espectro primário, usando $B=1,06$ e $A=1$. 
A Tabela 3 apresenta os valores dos parâmetros $A$ e $B$ para as várias tensões aplicadas no tubo de raios $X$ nas medições de dados para validação. As incertezas nos parâmetros foram calculadas usando o maior valor da grade usada para maximização dos parâmetros, isto foi possível porque a superfície se mostrou suave nas redondezas do ponto de máximo.

Tabela 3 - Parâmetros de correção encontrados por maximização. No parâmetro $A$ a maior incerteza é de $1 \%$ e para o parâmetro $B$ a maior incerteza é de $0,1 \%$.

\begin{tabular}{ccc}
\hline & \multicolumn{2}{c}{ Parâmetros } \\
\hline Tensão $(\mathrm{kV})$ & $A$ & $B(\mathrm{~cm})$ \\
\hline 50 & 1,27 & 0 \\
60 & 1,23 & 0 \\
70 & 1,14 & 0,04 \\
80 & 1,08 & 0,14 \\
90 & 1,07 & 0,27 \\
100 & 1,04 & 0,38 \\
110 & 1,04 & 0,52 \\
120 & 1,06 & 0,69 \\
130 & 1,05 & 0,82 \\
140 & 1,97 & 0,85 \\
150 & 1,00 & 1,06 \\
\hline
\end{tabular}

Por fim a correção para filtração adicional de $15 \mathrm{mmAl}$ foi implementada no modelo, para cada valor de tensão, e seus respectivos parâmetros $A$ e $B$, fazendo uso da equação (44).

$$
\text { espectro corrigido }(k V)=\text { espectro primario }(k V) \times A(k V) e^{-\mu(E) B(k V)}
$$

Onde o espectro primário(kV) é gerado pelo modelo de TBC Modificado, $A(\mathrm{kV})$ e $B(\mathrm{kV})$, são os parâmetros de correção mostrados na Tabela 3, e $e^{-\mu(E) B(k V)}$ é o termo que aplica uma atenuação de forma a corrigir a forma do espectro. 


\subsection{Calibração da amplitude dos espectros calculados}

Na Figura 27 estão os valores médios da razão de valores de kerma no ar medido e calculado para todos os espectros $P+S$ obtidos nas medições, em função da tensão aplicada no tubo. Pode-se observar nesta figura que a relação entre os valores desta razão e a tensão aplicada no tubo de raios $X$ é aproximadamente linear. Um ajuste linear foi então aplicado aos dados resultando em coeficientes angular e linear com valores respectivamente iguais a $0,01(1)$ e $0,18(8)$ e $R^{2}=0,92$.

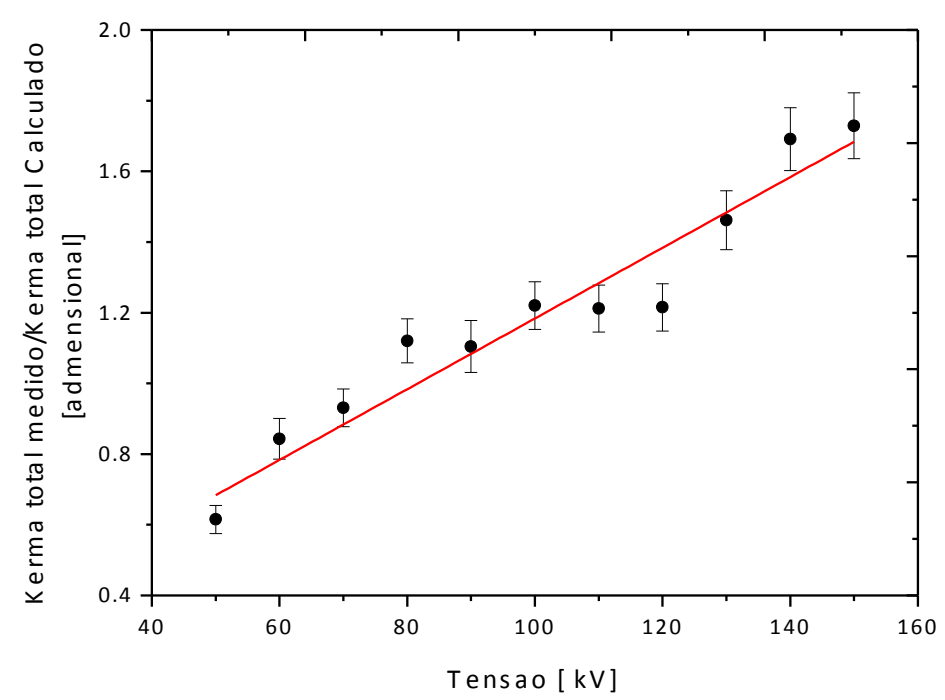

Figura 27 - Reta de calibração da amplitude dos espectros calculados, obtida por regressão linear a partir do conjunto de todos os valores de kerma no ar total medido/kerma no ar total calculado. Os dados considerados são os dos espectros de feixes atenuados pela barreira incluindo o espalhamento.

Os coeficientes da reta obtida por regressão linear apresentados na Figura 27 foram então incorporados ao modelo proposto como fatores de correção. Eles são aplicados aos dados no início do processo de simulação para que os resultados finais apresentem valores de kerma no ar resultantes correspondentes aos valores de kerma no ar dos espectros produzidos experimentalmente. A aplicação deste ajuste é dado na equação (45).

$$
\text { espectro calibrado }(k V)=\text { espectro corrigido }(k V) *(0,18+0,01 k V)
$$


Onde o espectro corrigido $(k V)$, é o espectro que já passou por uma correção conforme a metodologia apresentada na secção 3.8, $(0,18+0,01 \mathrm{kV})$ é a aplicação do ajuste linear, e finalmente o espectro calibrado $(k V)$ é espectro resultante desta calibração.

Na Tabela 4 estão os novos valores de razões entre Kerma no ar medido e calculado para espectros primários, que são espectros obtidos nas medições sem a presença da barreira espalhadora, e por isto, sem espalhamento.

Tabela 4 - Figura mérito dada por divisão entre os valores de kerma no ar medido e calculado, para os pares de espectros primários utilizados par a verificação do ajuste descrito na equação (45).

\begin{tabular}{cccccc}
\hline $\begin{array}{c}\text { Tensão } \\
{[\mathbf{k V}]}\end{array}$ & $\begin{array}{c}\text { Corrente } \\
{[\mathbf{m A}]}\end{array}$ & Tempo[s] & Filtro[mmAl] & $\begin{array}{c}\text { Distância } \\
{[\mathbf{m}]}\end{array}$ & $\begin{array}{c}\text { Kerma no ar medido } \\
\text { Kerma no ar calculado }\end{array}$ \\
\hline 50 & 0,6 & 60 & 15 & 5,61 & 1,363 \\
60 & 1,1 & 60 & 15 & 5,61 & 1,183 \\
70 & 0,9 & 60 & 15 & 5,61 & 1,197 \\
80 & 0,7 & 60 & 15 & 5,61 & 1,149 \\
90 & 0,7 & 60 & 15 & 5,61 & 1,134 \\
100 & 0,6 & 60 & 15 & 5,61 & 1,098 \\
110 & 0,6 & 60 & 15 & 5,61 & 1,103 \\
120 & 0,6 & 60 & 15 & 5,61 & 1,118 \\
130 & 0,5 & 60 & 15 & 5,61 & 1,116 \\
140 & 0,4 & 60 & 15 & 5,61 & 1,080 \\
150 & 0,4 & 60 & 15 & 5,61 & 1,097 \\
\hline
\end{tabular}

Na Figura 28 pode-se observar uma comparação entre espectro calculado e medido, onde a aplicação dos coeficientes do ajuste da reta, resultou em uma simulação de espectro com boa concordância qualitativa e quantitativa com o espectro experimental. 


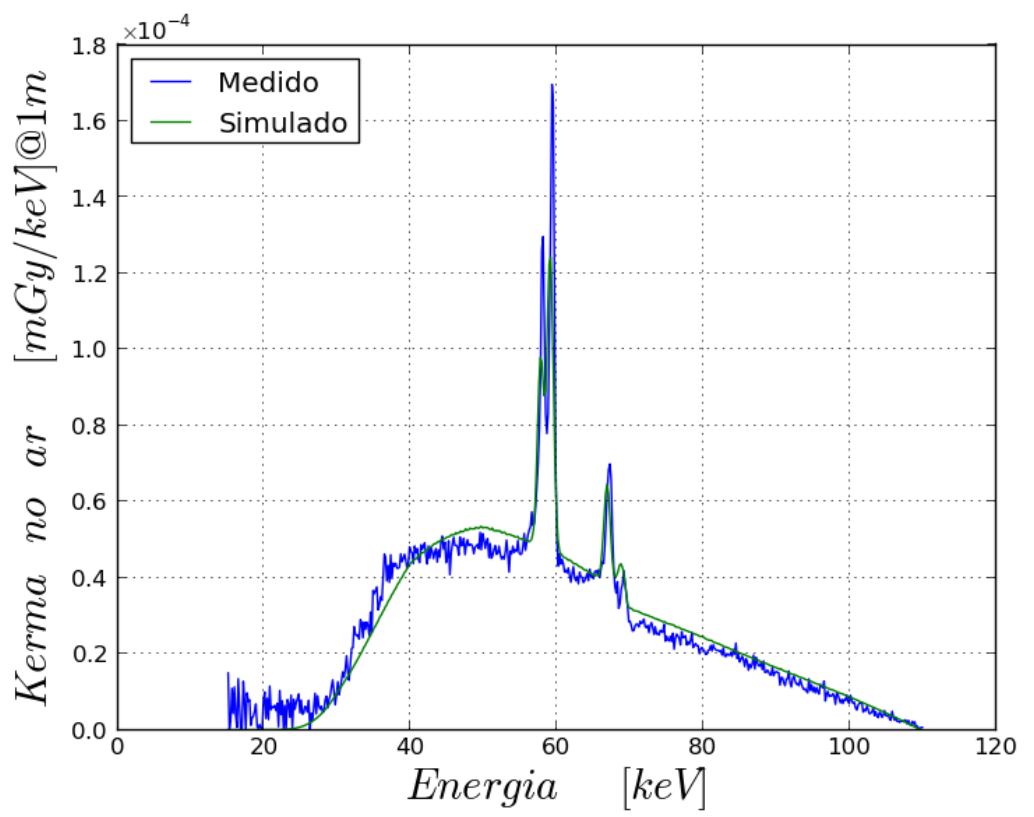

Figura 28 - Exemplo de comparação entre espectros de espalhamento medido e calculado. Os espectros representam o feixe espalhado pela barreira de acrílico de $20 \mathrm{~mm}$ à $2 \mathrm{~m}$ da fonte e para tamanho de campo de $39,5 \mathrm{~cm}$ de raio. 


\section{RESULTADOS}

Foram feitas medições, com objetivo de validar, por comparação, a inclusão de eventos Compton devido à interação de fótons de raios $\mathrm{X}$ com uma barreira de acrílico no modelo de TBC modificado. Para cada espectro experimental obtido, foi calculado um espectro simulado pelo modelo proposto neste trabalho, utilizando os mesmos parâmetros de entrada utilizados para gerar os espectros experimentais.

Na seção dos Materiais e Métodos, foi explicada a separação das etapas de medição em diferentes grupos, com o objetivo de analisar a resposta do modelo à variação de cada um de seus parâmetros de entrada quando os demais parâmetros eram mantidos fixos.

Os parâmetros escolhidos para avaliação da resposta do modelo foram:

- Tamanho do campo.

- $\quad$ Espessura da barreira de acrílico.

- Distância entre a barreira espalhadora e o tubo de raios X.

O tamanho do campo é uma medida da área que o feixe de raios $\mathrm{X}$ atinge na barreira. Definiu-se por registrar o tamanho do campo como o raio da circunferência delimitada pelo feixe de raios $X$ ao atingir o objeto espalhador. Foram feitas medições para tamanhos de campo com raio de $39,5 \mathrm{~cm}, 27,5 \mathrm{~cm}$.e $18,2 \mathrm{~cm}$. Para a avaliação dos efeitos da variação da espessura da barreira nos espectros de raios $X$, foram usadas barreiras de acrílico de 20, e 24, e $44 \mathrm{~mm}$ de espessura. A distância entre a barreira e a fonte de raios $X$, foi limitada pelas dimensões da sala onde foi montado todo o aparato experimental. Desse modo, as medições foram feitas em apenas três diferentes distâncias: 2,0 m, 2,87 m e 4,34 m.

A análise dos resultados foi dividida para os espectros $P+S$ ( feixe primário atenuado pela barreira mais feixe espalhado pela barreira) e para os $S$ ( feixe espalhado pela barreira ), isto porque para os espectros $S$, a análise quantitativa não foi possível devido à baixa contagem de fótons no espectrômetro, neste caso, os espectros $S$ tratados foram normalizados pelo seu kerma no ar total. Nos casos dos 
espectros $\mathrm{P}+\mathrm{S}$, foi feita análise quantitativa e qualitativa. A análise qualitativa foi feita usando o índice de forma $\delta^{2}$, e para a análise quantitativa foi usado o valor da razão entre kerma no ar medido e kerma no ar calculado.

Por fim, os dados das figuras usadas nas análises estão nas tabelas apresentadas no anexo I.

Para os dois tipos de espectros medidos, $\mathrm{P}+\mathrm{S}$ e $\mathrm{S}$, foram utilizadas, sempre que possível, as mesmas técnicas de irradiação, tensão (kV) e carga (mAs), e configurações que incluem três diferentes tamanhos de campo, espessuras da barreira e distâncias da barreira. As Tabelas 5, 6 e 7 apresentam todas as técnicas de irradiação e configurações de medições de espectros utilizadas.

As incertezas experimentais associadas às medições de kerma no ar são, no pior, caso de 10,3\%. Para a derivação deste valor de incerteza nas medições foi utilizada a metodologia descrita no trabalho de Gonzales $^{53}$, e foi a considerada em todas as medições de espectros feitas no presente trabalho. 
Tabela 5 - Dados obtidos nas medições para a variação com o tamanho do campo. São apresentados os valores de kerma no ar e as respectivas técnicas radiográficas utilizadas em cada conjunto de medições $\mathrm{S}$ e $\mathrm{P}+\mathrm{S}$. As incertezas associadas aos valores de kerma no ar foram estimadas em no máximo $10,3 \%{ }^{53}$. Espessura da barreira de $20 \mathrm{~mm}$ e distância da barreira de $2 \mathrm{~m}$.

\begin{tabular}{|c|c|c|c|c|c|c|c|}
\hline & & \multicolumn{3}{|c|}{$\mathrm{P}+\mathrm{S}$} & \multicolumn{3}{|c|}{$\mathbf{S}$} \\
\hline $\begin{array}{c}\text { Tensão } \\
(\mathrm{kV})\end{array}$ & $\begin{array}{c}\text { Raio do } \\
\text { Campo } \\
(\mathrm{cm})\end{array}$ & $\begin{array}{c}\text { Corrente } \\
(\mathrm{mA})\end{array}$ & $\begin{array}{c}\text { Tempo } \\
\text { (s) }\end{array}$ & $\begin{array}{c}\text { Kerma } \\
\text { no ar } \\
\text { medido } \\
(\mathrm{mGy})\end{array}$ & $\begin{array}{l}\text { Corrente } \\
(\mathrm{mA})\end{array}$ & $\begin{array}{c}\text { Tempo } \\
\text { (s) }\end{array}$ & $\begin{array}{c}\text { Kerma } \\
\text { no ar } \\
\text { medido } \\
\text { (mGy) }\end{array}$ \\
\hline \multirow{3}{*}{50} & 18,20 & 1,6 & 240 & 7,97 & 1,6 & 240 & 0,59 \\
\hline & 27,50 & 1,6 & 240 & 8,69 & 1,6 & 240 & 0,84 \\
\hline & 39,50 & 1,6 & 240 & 9,22 & 1,6 & 240 & 1,27 \\
\hline \multirow{3}{*}{60} & 18,20 & 1,1 & 240 & 14,63 & 1,1 & 240 & 1,22 \\
\hline & 27,50 & 1,1 & 240 & 14,64 & 1,1 & 240 & 1,6 \\
\hline & 39,50 & 1,1 & 240 & 16,73 & 1,1 & 240 & 2,38 \\
\hline \multirow{3}{*}{70} & 18,20 & 0,9 & 240 & 22,95 & 0,9 & 240 & 2,01 \\
\hline & 27,50 & 0,9 & 240 & 24,82 & 0,9 & 240 & 2,68 \\
\hline & 39,50 & 0,9 & 240 & 26,11 & 0,9 & 240 & 3,77 \\
\hline \multirow{3}{*}{80} & 18,20 & 0,7 & 240 & 29,78 & 0,7 & 240 & 1,54 \\
\hline & 27,50 & 0,7 & 240 & 32,04 & 0,7 & 240 & 3,52 \\
\hline & 39,50 & 0,7 & 240 & 33,64 & 0,7 & 240 & 4,89 \\
\hline \multirow{3}{*}{90} & 18,20 & 0,7 & 240 & 45,97 & 0,7 & 240 & 2,55 \\
\hline & 27,50 & 0,7 & 240 & 50,18 & 0,7 & 240 & 5,48 \\
\hline & 39,50 & 0,7 & 240 & 51,76 & 0,7 & 240 & 7,68 \\
\hline \multirow{3}{*}{100} & 18,20 & 0,6 & 240 & 54,42 & 0,6 & 240 & 3,03 \\
\hline & 27,50 & 0,6 & 240 & 58,49 & 0,6 & 240 & 6,47 \\
\hline & 39,50 & 0,6 & 240 & 61,09 & 0,6 & 240 & 8,95 \\
\hline \multirow{3}{*}{110} & 18,20 & 0,6 & 240 & 73,56 & 0,6 & 240 & 4,39 \\
\hline & 27,50 & 0,6 & 240 & 79,04 & 0,6 & 240 & 8,83 \\
\hline & 39,50 & 0,6 & 240 & 82,48 & 0,6 & 240 & 12,03 \\
\hline \multirow{3}{*}{120} & 18,20 & 0,6 & 240 & 96,07 & 0,6 & 240 & 5,66 \\
\hline & 27,50 & 0,6 & 240 & 102,6 & 0,6 & 240 & 11,51 \\
\hline & 39,50 & 0,6 & 240 & 107,4 & 0,6 & 240 & 15,71 \\
\hline \multirow{3}{*}{130} & 18,20 & 0,5 & 240 & 99,25 & 0,5 & 240 & 6,11 \\
\hline & 27,50 & 0,5 & 240 & 109,6 & 0,5 & 240 & 11,98 \\
\hline & 39,50 & 0,5 & 240 & 111,4 & 0,5 & 240 & 16,19 \\
\hline \multirow{3}{*}{140} & 18,20 & 0,4 & 240 & 89,32 & 0,4 & 240 & 5,55 \\
\hline & 27,50 & 0,4 & 240 & 96,57 & 0,4 & 240 & 11,17 \\
\hline & 39,50 & 0,4 & 240 & 100 & 0,4 & 240 & 14,54 \\
\hline \multirow{3}{*}{150} & 18,20 & 0,4 & 240 & 108,6 & 0,4 & 240 & 6,75 \\
\hline & 27,50 & 0,4 & 240 & 116,8 & 0,4 & 240 & 13,7 \\
\hline & 39,50 & 0,4 & 240 & 122 & 0,4 & 240 & 17,64 \\
\hline
\end{tabular}


Tabela 6 - Dados obtidos nas medições, para a variação com a espessura da barreira. São apresentados os valores de kerma no ar e as respectivas técnicas radiográficas utilizadas em cada conjunto de medições S e P+S. Com tamanho de campo de $39,5 \mathrm{~cm}$ e distância da barreira de $2 \mathrm{~m}$. As incertezas associadas aos valores de kerma no ar foram estimadas em $10,3 \%{ }^{53}$

\begin{tabular}{|c|c|c|c|c|c|c|c|}
\hline \multirow[b]{2}{*}{$\begin{array}{l}\text { Tensã } \\
\text { o (kV) }\end{array}$} & \multirow[b]{2}{*}{$\begin{array}{c}\text { Espessura } \\
\text { da barreira } \\
(\mathrm{mm})\end{array}$} & \multicolumn{3}{|c|}{$\mathrm{P}+\mathrm{S}$} & \multicolumn{3}{|c|}{$S$} \\
\hline & & $\begin{array}{c}\text { Corrente } \\
(\mathrm{mA})\end{array}$ & $\begin{array}{c}\text { Tempo } \\
\text { (s) }\end{array}$ & $\begin{array}{c}\text { Kerma } \\
\text { no ar } \\
\text { medido } \\
\text { (mGy) }\end{array}$ & $\begin{array}{c}\text { Corrente } \\
(\mathrm{mA})\end{array}$ & $\begin{array}{c}\text { Tempo } \\
\text { (s) }\end{array}$ & $\begin{array}{c}\text { Kerma } \\
\text { no ar } \\
\text { medido } \\
\text { (mGy) }\end{array}$ \\
\hline \multirow{3}{*}{50} & 20 & 1,6 & 240 & 9,22 & 1,6 & 240 & 1,27 \\
\hline & 24 & 1,6 & 240 & 8,56 & 1,6 & 240 & 1,41 \\
\hline & 44 & 1,6 & 240 & 5,07 & 1,6 & 240 & 1,22 \\
\hline \multirow{3}{*}{60} & 20 & 1,1 & 240 & 16,73 & 1,1 & 240 & 2,38 \\
\hline & 24 & 1,1 & 240 & 15,71 & 1,1 & 240 & 2,69 \\
\hline & 44 & 1,1 & 240 & 9,65 & 1,1 & 240 & 2,24 \\
\hline \multirow{3}{*}{70} & 20 & $\overline{0,9}$ & 240 & 26,11 & 0,9 & 240 & 3,77 \\
\hline & 24 & 0,9 & 240 & 24,59 & 0,9 & 240 & 4,24 \\
\hline & 44 & 0,9 & 240 & 15,63 & 0,9 & 240 & 3,59 \\
\hline \multirow{3}{*}{80} & 20 & 0,7 & 240 & 33,64 & 0,7 & 240 & 4,89 \\
\hline & 24 & 0,7 & 240 & 31,83 & 0,7 & 240 & 5,5 \\
\hline & 44 & 0,7 & 240 & 20,57 & 0,7 & 240 & 4,64 \\
\hline \multirow{3}{*}{90} & 20 & 0,7 & 240 & 51,76 & 0,7 & 240 & 7,68 \\
\hline & 24 & 0,7 & 240 & 48,89 & 0,7 & 240 & 8,47 \\
\hline & 44 & 0,7 & 240 & 33,21 & 0,7 & 240 & 7,26 \\
\hline \multirow{3}{*}{100} & 20 & 0,6 & 240 & 61,09 & 0,6 & 240 & 8,95 \\
\hline & 24 & 0,6 & 240 & 57,91 & 0,6 & 240 & 9,96 \\
\hline & 44 & 0,6 & 240 & 38,36 & 0,6 & 240 & 8,48 \\
\hline \multirow{3}{*}{110} & 20 & 0,6 & 240 & 82,48 & 0,6 & 240 & 12,03 \\
\hline & 24 & 0,6 & 240 & 78,28 & 0,6 & 240 & 13,52 \\
\hline & 44 & 0,6 & 240 & 52,32 & 0,6 & 240 & 11,53 \\
\hline \multirow{3}{*}{120} & 20 & 0,6 & 240 & 107,4 & 0,6 & 240 & 15,71 \\
\hline & 24 & 0,6 & 240 & 101,7 & 0,6 & 240 & 17,6 \\
\hline & 44 & 0,6 & 240 & 68,77 & 0,6 & 240 & 15,16 \\
\hline \multirow{3}{*}{130} & 20 & 0,5 & 240 & 111,4 & 0,5 & 240 & 16,19 \\
\hline & 24 & 0,5 & 240 & 105,6 & 0,5 & 240 & 18,2 \\
\hline & 44 & 0,5 & 240 & 72,23 & 0,5 & 240 & 15,66 \\
\hline \multirow{3}{*}{140} & 20 & 0,4 & 240 & 100 & 0,4 & 240 & 14,54 \\
\hline & 24 & 0,4 & 240 & 94,96 & 0,4 & 240 & 16,29 \\
\hline & 44 & 0,4 & 240 & 64,53 & 0,4 & 240 & 14,08 \\
\hline \multirow{3}{*}{150} & 20 & 0,4 & 240 & 122 & 0,4 & 240 & 17,64 \\
\hline & 24 & 0,4 & 240 & 115,6 & 0,4 & 240 & 19,8 \\
\hline & 44 & 0,4 & 240 & 79,21 & 0,4 & 240 & 17,26 \\
\hline
\end{tabular}


Tabela 7 - Dados obtidos nas medições para a variação com a distância da barreira. São apresentados os valores de kerma no ar e as respectivas técnicas radiográficas utilizadas em cada conjunto de medições $\mathrm{S}$ e P+S. Com tamanho de campo de $39,5 \mathrm{~cm}$ e espessura da barreira de $20 \mathrm{~mm}$. As incertezas associadas aos valores de kerma no ar foram estimadas em $10,3 \%{ }^{53}$

\begin{tabular}{|c|c|c|c|c|c|c|c|}
\hline \multirow[b]{2}{*}{$\begin{array}{c}\text { Tensão } \\
\text { (kV) }\end{array}$} & \multirow[b]{2}{*}{$\begin{array}{l}\text { Distância } \\
\text { (m) }\end{array}$} & \multicolumn{3}{|c|}{$\mathrm{P}+\mathrm{S}$} & \multicolumn{3}{|c|}{$S$} \\
\hline & & $\begin{array}{c}\text { Corrente } \\
(\mathrm{mA})\end{array}$ & $\begin{array}{c}\text { Tempo } \\
\text { (s) }\end{array}$ & $\begin{array}{c}\text { Kerma } \\
\text { no ar } \\
\text { medido } \\
\text { (mGy) }\end{array}$ & $\begin{array}{c}\text { Corrente } \\
(\mathrm{mA})\end{array}$ & $\begin{array}{c}\text { Tempo } \\
\text { (s) }\end{array}$ & $\begin{array}{c}\text { Kerma } \\
\text { no ar } \\
\text { medido } \\
\text { (mGy) }\end{array}$ \\
\hline \multirow{3}{*}{50} & 2 & 1,6 & 240 & 5,07 & 1,6 & 240 & 1,22 \\
\hline & 2,87 & 1,6 & 240 & 5,15 & 1,6 & 240 & 3,75 \\
\hline & 4,34 & 1,6 & 240 & 5,05 & 1,6 & 960 & 7,07 \\
\hline \multirow{3}{*}{60} & 2 & 1,1 & 240 & 9,65 & 1,1 & 240 & 2,24 \\
\hline & 2,87 & 1,1 & 240 & 9,66 & 1,1 & 240 & 7,1 \\
\hline & 4,34 & 1,1 & 240 & 9,84 & 1,1 & 480 & 10,78 \\
\hline \multirow{3}{*}{70} & 2 & 0,9 & 240 & 15,63 & 0,9 & 240 & 3,59 \\
\hline & 2,87 & 0,9 & 240 & 15,42 & 0,9 & 240 & 11,9 \\
\hline & 4,34 & 0,9 & 240 & 15,16 & 0,9 & 480 & 17,33 \\
\hline \multirow{3}{*}{80} & 2 & 0,7 & 240 & 20,57 & 0,7 & 240 & 4,64 \\
\hline & 2,87 & 0,7 & 240 & 20,22 & 0,7 & 240 & 14,74 \\
\hline & 4,34 & 0,7 & 240 & 19,96 & 0,7 & 480 & 23,2 \\
\hline \multirow{3}{*}{90} & 2 & 0,7 & 240 & 33,21 & 0,7 & 240 & 7,26 \\
\hline & 2,87 & 0,7 & 240 & 31,63 & 0,7 & 240 & 12,06 \\
\hline & 4,34 & 0,7 & 240 & 31,12 & 0,7 & 480 & 37,49 \\
\hline \multirow{3}{*}{100} & 2 & 0,6 & 240 & 38,36 & 0,6 & 240 & 8,48 \\
\hline & 2,87 & 0,6 & 240 & 37,65 & 0,6 & 240 & 15,31 \\
\hline & 4,34 & 0,6 & 240 & 37,16 & 0,6 & 240 & 22,57 \\
\hline \multirow{3}{*}{110} & 2 & 0,6 & 240 & 52,32 & 0,6 & 240 & 11,53 \\
\hline & 2,87 & 0,6 & 240 & 51,24 & 0,6 & 240 & 20,74 \\
\hline & 4,34 & 0,6 & 240 & 50,65 & 0,6 & 240 & 31,11 \\
\hline \multirow{3}{*}{120} & 2 & 0,6 & 240 & 68,77 & 0,6 & 240 & 15,16 \\
\hline & 2,87 & 0,6 & 240 & 67,41 & 0,6 & 240 & 27,5 \\
\hline & 4,34 & 0,6 & 240 & 66,43 & 0,6 & 240 & 40,93 \\
\hline \multirow{3}{*}{130} & 2 & 0,5 & 240 & 72,23 & 0,5 & 240 & 15,66 \\
\hline & 2,87 & 0,5 & 240 & 70,19 & 0,5 & 240 & 28,9 \\
\hline & 4,34 & 0,5 & 240 & 69,14 & 0,5 & 240 & 42,86 \\
\hline \multirow{3}{*}{140} & 2 & 0,4 & 240 & 64,53 & 0,4 & 240 & 14,08 \\
\hline & 2,87 & 0,4 & 240 & 63,29 & 0,4 & 240 & 26,11 \\
\hline & 4,34 & 0,4 & 240 & 62,5 & 0,4 & 240 & 38,97 \\
\hline \multirow{3}{*}{150} & 2 & 0,4 & 240 & 79,21 & 0,4 & 240 & 17,26 \\
\hline & 2,87 & 0,4 & 240 & 77,76 & 0,4 & 240 & 32,09 \\
\hline & 4,34 & 0,4 & 240 & 76,24 & 0,4 & 240 & 47,64 \\
\hline
\end{tabular}




\subsection{Análise quantitativa e qualitativa dos espectros $\mathrm{P}+\mathrm{S}$}

\section{Variação com o tamanho do campo.}

Foram feitas medições com 3 diferentes tamanhos de campo. Para cada um destes diferentes tamanhos de campo, mediu-se um conjunto de 11 espectros, aplicando-se tensões entre $50 \mathrm{kV}$ e $150 \mathrm{kV}$. Para cada espectro medido foi calculado um espectro com os mesmos parâmetros de entrada.

Na Figuras 29 a 31 são mostrados os espectros usados para análise de variação com o tamanho do campo.
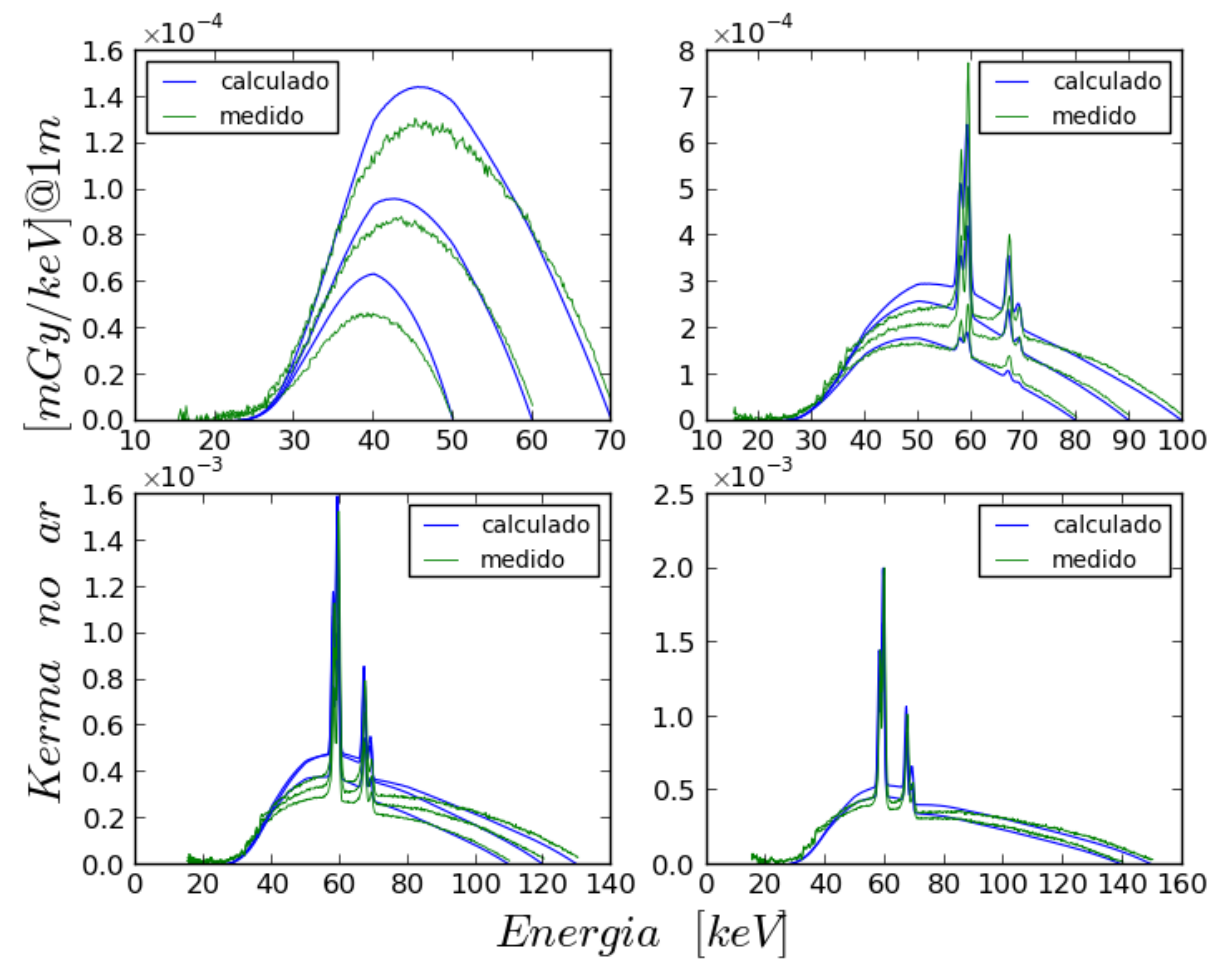

Figura 29 - Espectros P+S. Raio do campo $39,5 \mathrm{~cm}$, distância da barreira $2 \mathrm{~m}$, e espessura $20 \mathrm{~mm}$. 

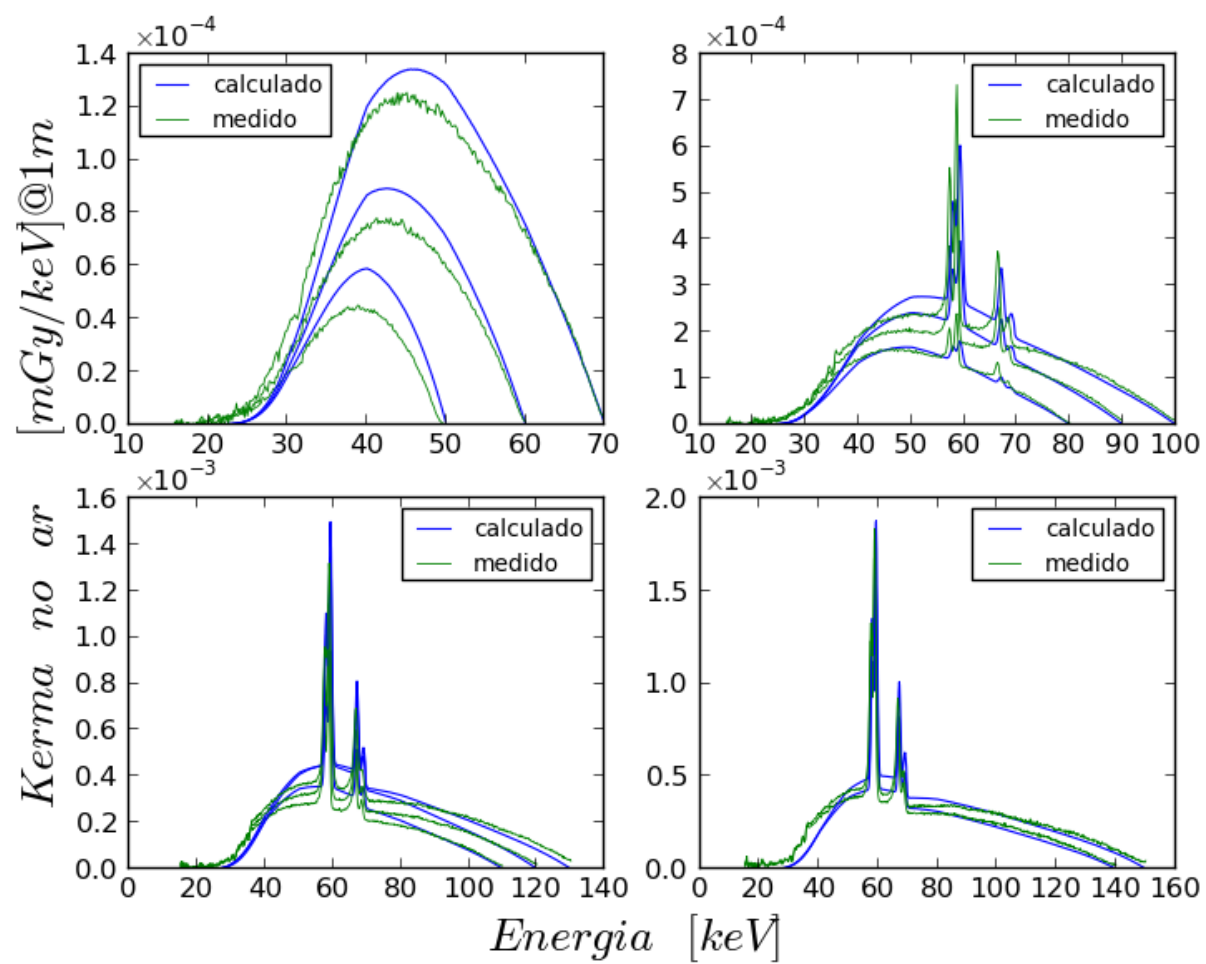

Figura 30 - Espectros P+S. Raio do campo $27,5 \mathrm{~cm}$, distância da barreira $2 \mathrm{~m}$, e espessura $20 \mathrm{~mm}$.
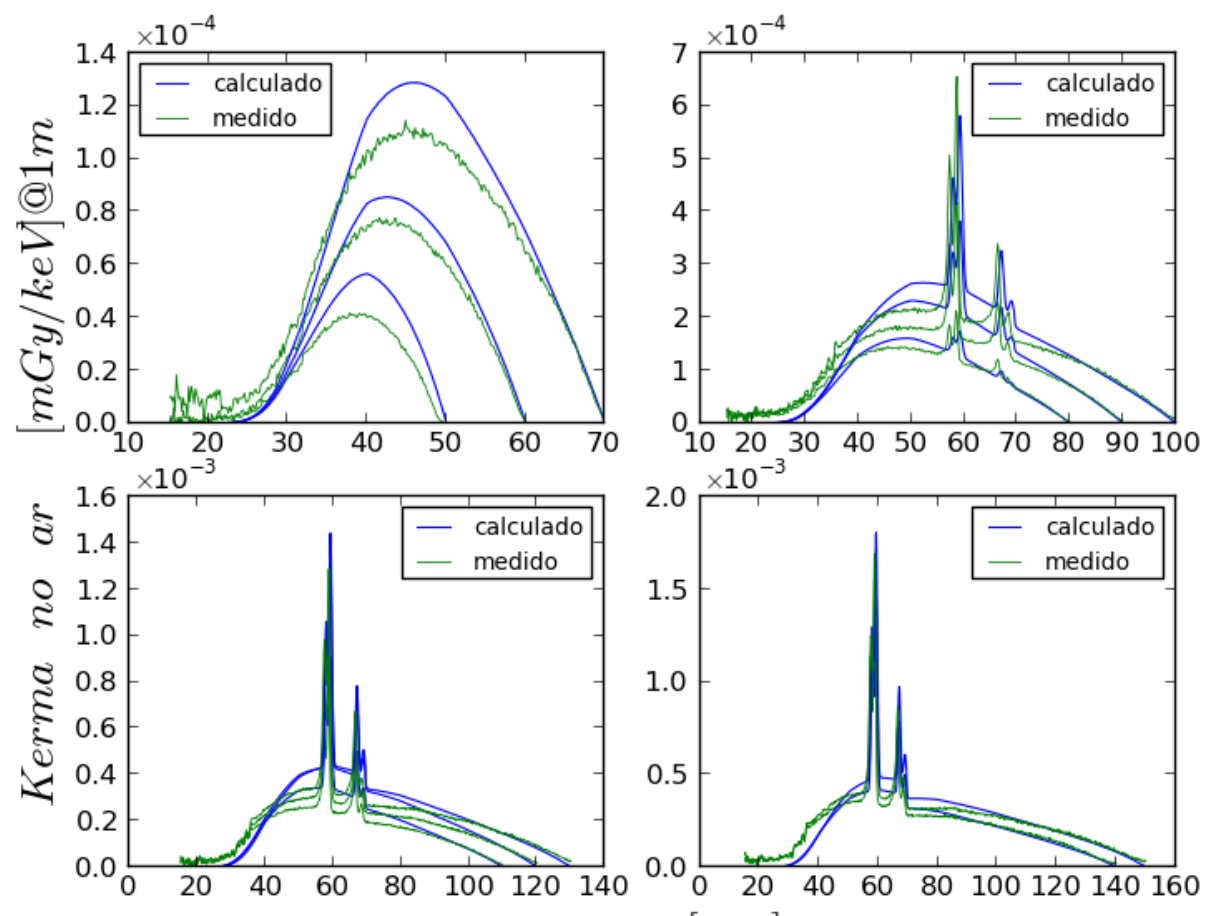

Energia $[\mathrm{keV}]$

Figura 31 - Espectros P+S. Raio do campo 18,2 cm, distância da barreira $2 \mathrm{~m}$, e espessura $20 \mathrm{~mm}$. 
Na Figura 32 é apresentada uma primeira comparação entre espectros medidos e simulados para a série de medições de variação no tamanho do campo. Esta primeira comparação é feita pela razão entre o kerma no ar total pelo kerma no ar calculado. Está se comparando, neste caso, a área abaixo da curva entre os espectros medido e calculado. Os resultados desta primeira comparação são feitos para cada par de espectros medido e calculado, ao longo dos três tamanhos de campos em que foram feitas medições. Neste caso, o valor 1 no eixo das ordenadas significa que o kerma no ar total calculado ficou exatamente igual ao medido. Este seria um resultado ideal nesta figura de mérito $\delta^{2}$.

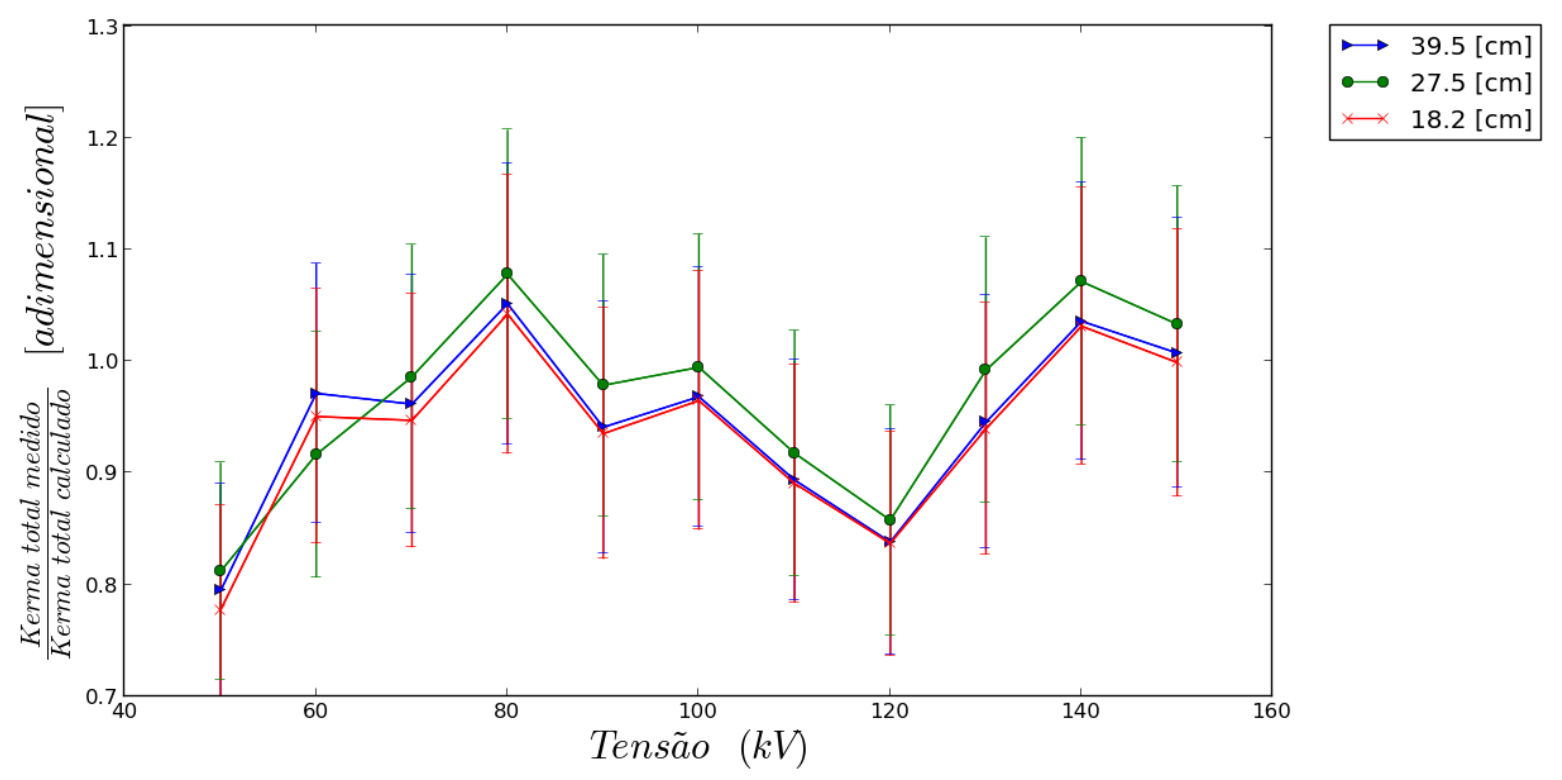

Figura 32 - Variação no tamanho de campo para espectros $\mathrm{P}+\mathrm{S}$, barreira de $20 \mathrm{~mm}$ de espessura à $2 \mathrm{~m}$ da fonte de raios $\mathrm{X}$.

Da Figura 32 pode-se concluir que o modelo de espalhamento Compton não apresenta uma diferença significativa para diferentes tamanhos de campo. A qualidade do modelo é muito semelhante para $18,2 \mathrm{~cm}$ e $39,5 \mathrm{~cm}$. O modelo apresentou resultados com até $20 \%$ de diferença do ideal que é 1 . Entretanto, a diferença na resposta quantitativa do modelo entre valores de uma mesma tensão é muito pequena, podendo-se afirmar que a sensibilidade do modelo à variação no 
tamanho de campo é menos significativa do que em relação à variação nos valores de tensão.

Na figura 33 pode-se analisar a qualidade da simulação com uso da figura de mérito $\delta^{2}$, para espectros $\mathrm{P}+\mathrm{S}$, com barreira de $20 \mathrm{~mm}$ de acrílico, à $2 \mathrm{~m}$ do tubo de raios $\mathrm{X}$, e para diferentes tamanho de campo.

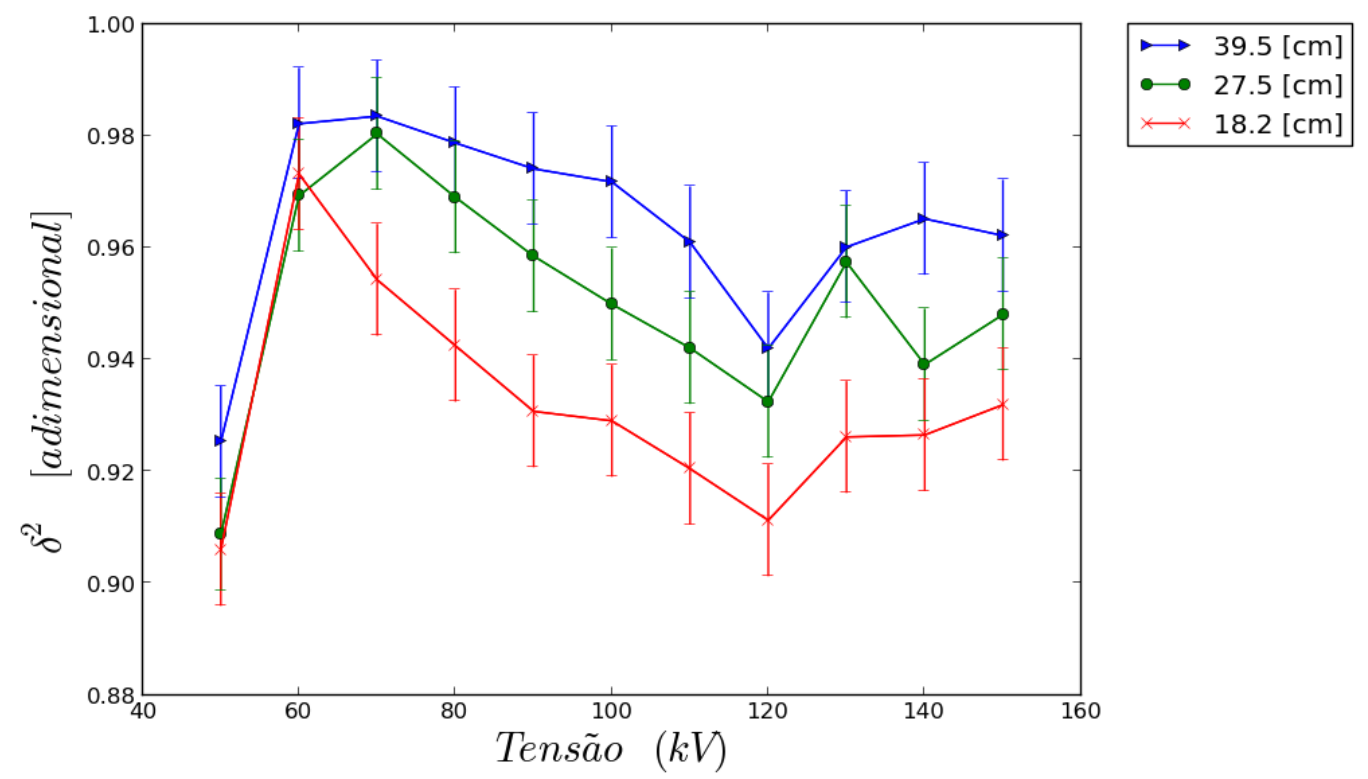

Figura 33 - Valores de figura de mérito $\delta^{2}$ para espectros medidos com diferentes tamanhos de campo. Feixes $\mathrm{P}+\mathrm{S}$. Barreira de acrílico de $20 \mathrm{~mm}$ espessura à $2 \mathrm{~m}$ da fonte.

Pela análise dos valores de $\delta^{2}$ apresentados na Figura 33, observa-se que o comportamento da distribuição muda em relação à razão entre os valores de kerma no ar. Neste caso, a forma do espectro calculado é mais próxima da forma do espectro medido, para tamanho de campo de $39,5 \mathrm{~cm}$. Pelos valores do indicador $\delta^{2}$, pode-se constatar que a forma dos espectros calculados é muito próxima dos medidos, ficando, em todos os casos acima de 0,90, e nos melhores casos acima de 0,98 . Observa uma tendência no comportamento do modelo, apresentando melhores resultados com aumento do tamanho de campo, para espectros acima de $60 \mathrm{kV}$. 


\section{Variação com a espessura da barreira.}

Na sequência da análise da resposta do modelo de espalhamento Compton, foram feitas comparações de espectros espalhados e transmitido para varias espessuras da barreira. Foram usadas as barreiras de acrílico com espessuras de 20 mm, 24 mm e $44 \mathrm{~mm}$. Nas Fuguras 34 a 36 são mostrados os espectros usados para análise da variação com a espessura da barreira.
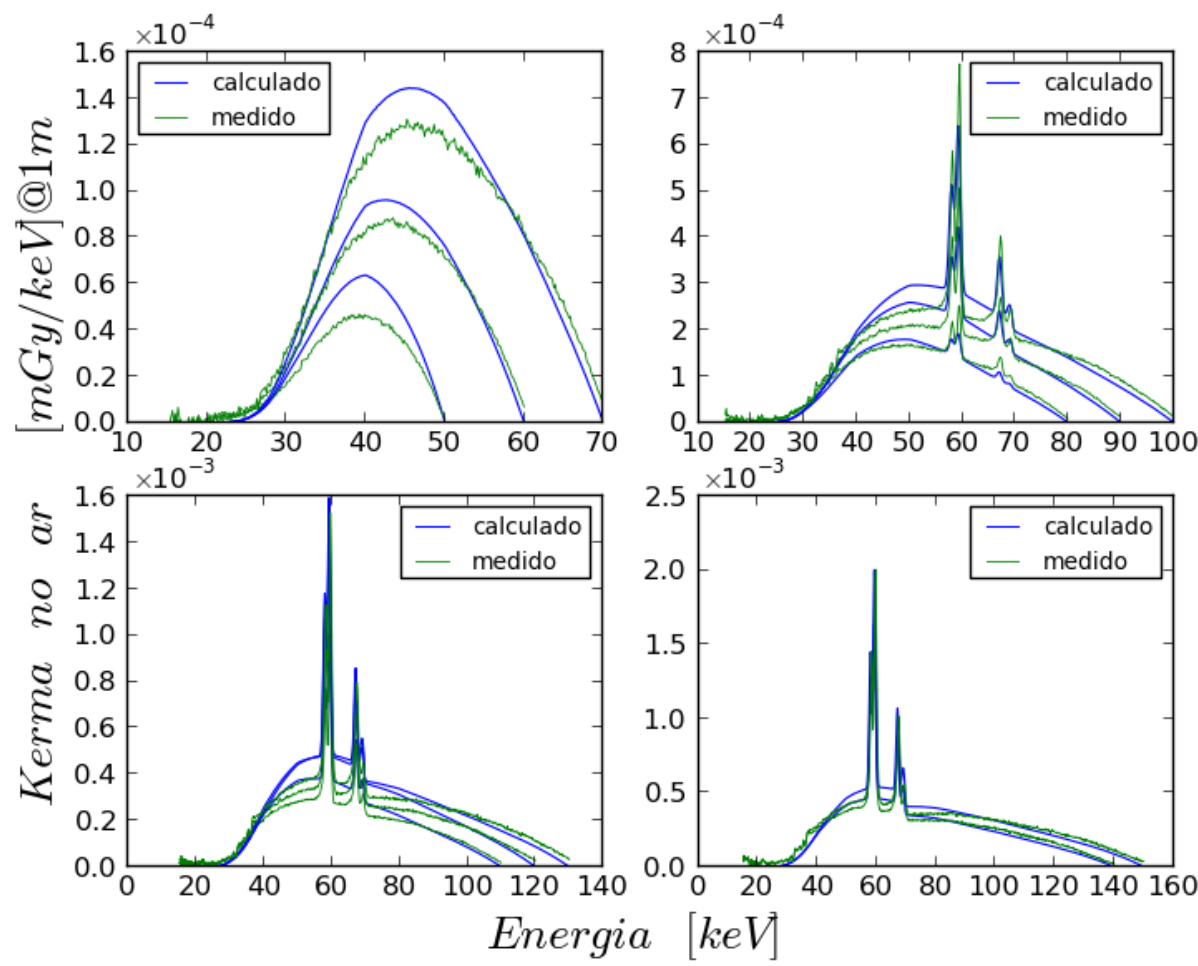

Figura 34 - Espectros P+S. Raio do campo $39,5 \mathrm{~cm}$, distância da barreira $2 \mathrm{~m}$,e espessura $20 \mathrm{~mm}$. 

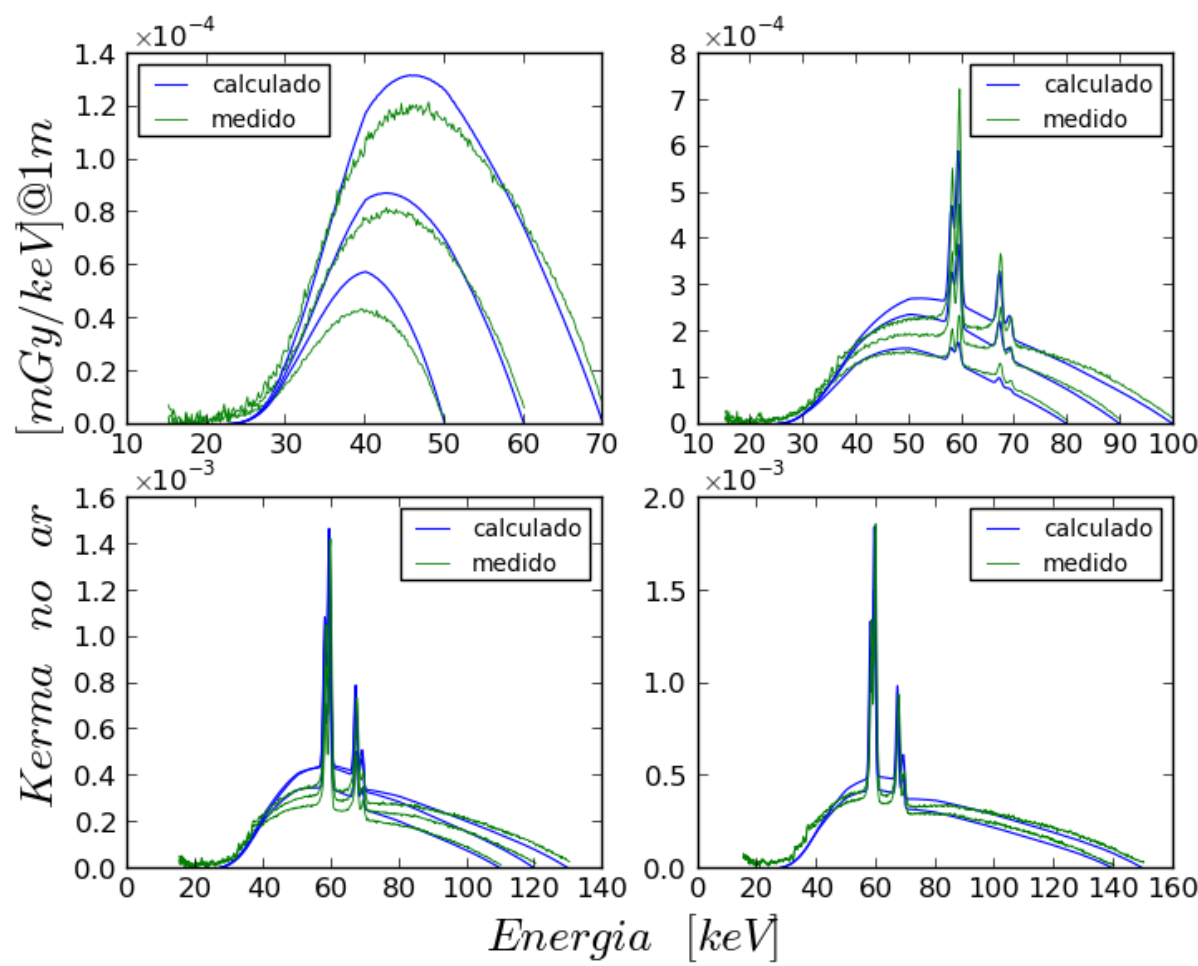

Figura 35 - Espectros P+S. Raio do campo $39,5 \mathrm{~cm}$, distância da barreira $2 \mathrm{~m}$, e espessura $24 \mathrm{~mm}$.
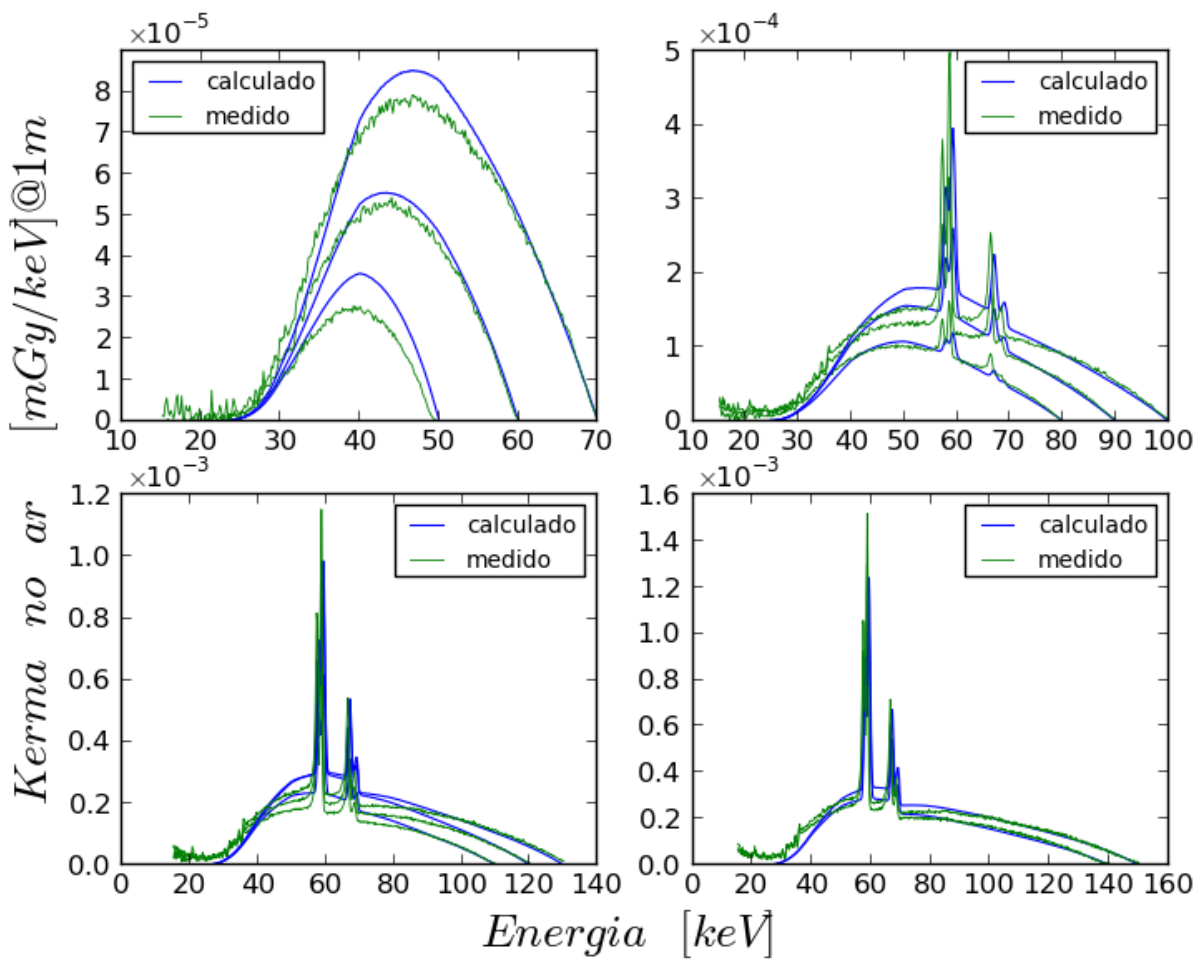

Figura 36 - Espectros P+S. Raio do campo $39,5 \mathrm{~cm}$, distância da barreira $2 \mathrm{~m}$,e espessura $44 \mathrm{~mm}$. 
As Figuras 37 e 38 mostram os resultados da análise para feixes $\mathrm{P}+\mathrm{S}$. As comparações foram feitas da mesma forma que na variação no tamanho do campo. A Figura 37 mostra valores das razões entre kerma no ar medido e calculado, para espectros $\mathrm{P}+\mathrm{S}$.

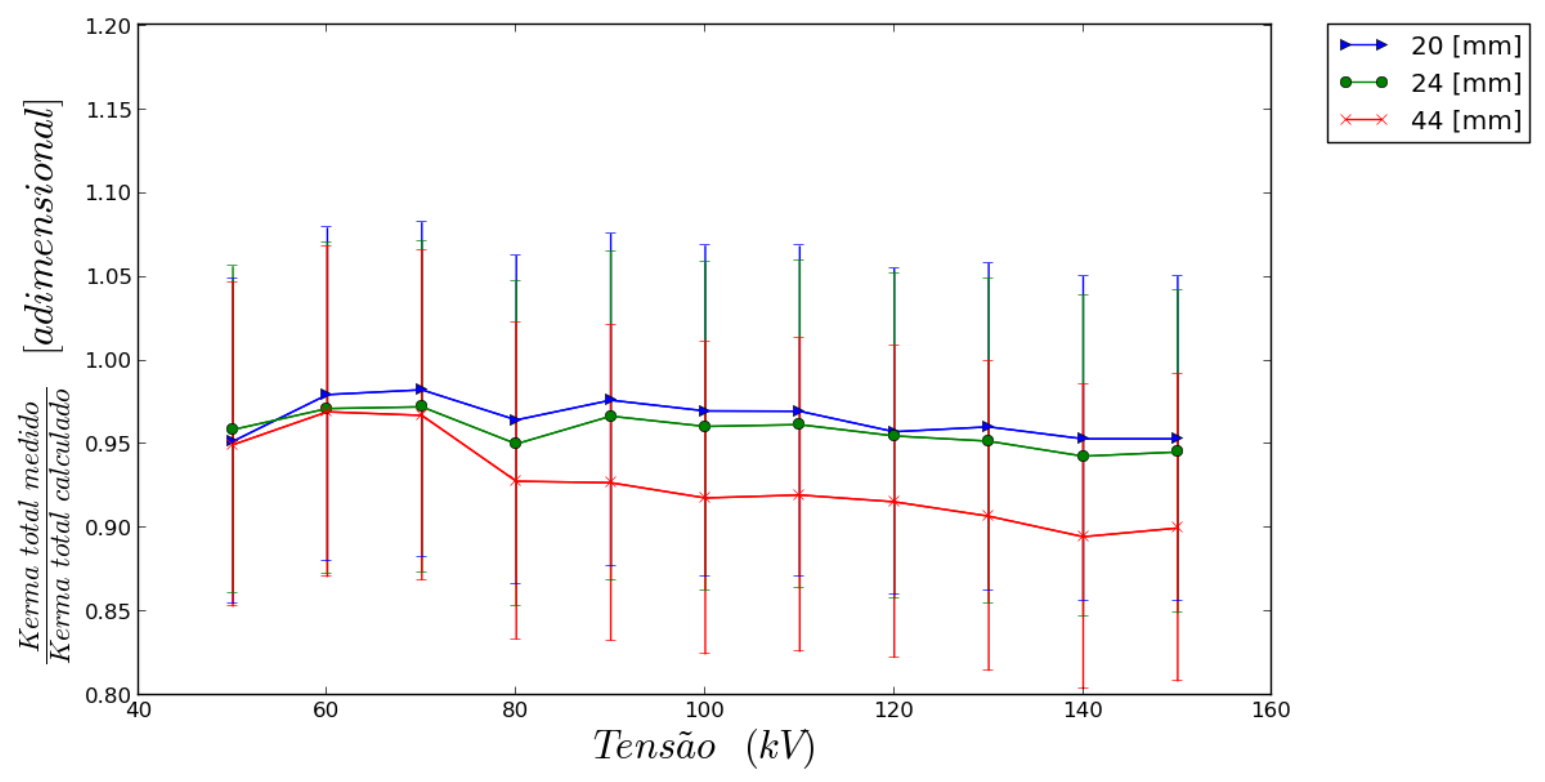

Figura 37 - Razão entre valores de kerma no ar medidos e calculados considerando diferentes espessuras da barreira. Foram utilizados espectros $P+S$, para tamanho de campo de $39,5 \mathrm{~cm}$ à uma distância de $2 \mathrm{~m}$.

Os dados apresentados na Figura 37 mostram uma tendência da qualidade do modelo diminuir com o aumento da espessura da barreira. Apesar, disso, os valores dessa razão para cada configuração de medição estão próximos, apresentando uma diferença menor que $10 \%$ para todos os pontos deste gráfico.

Na Figura 38 estão comparações, ainda na variação na espessura da barreira, pelo índice de mérito $\delta^{2}$ 


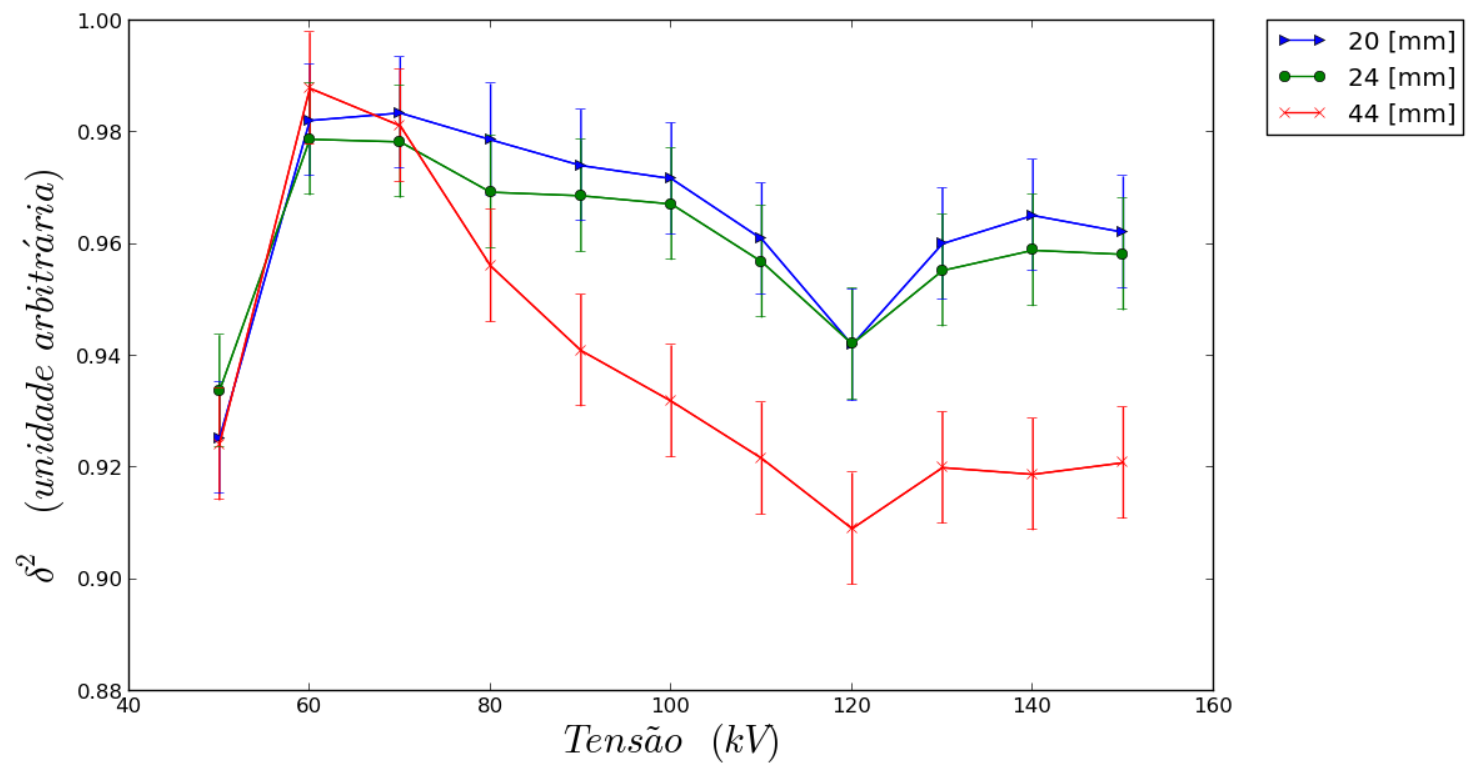

Figura 38 - Valores de $\boldsymbol{\delta}^{2}$, considerando diferentes espessuras da barreira. Foram utilizados espectros $\mathrm{P}+\mathrm{S}$. Tamanho do campo de $39,5 \mathrm{~cm}$ e uma distância de $2 \mathrm{~m}$.

Os dados apresentados na Figura 38 mostram uma tendência da qualidade do modelo diminuir com o aumento da espessura da barreira, tal como foi apresentado na Figura 37. Portanto, nesse caso, essa tendência aparece nas análises feitas com as duas figuras de mérito. Aqui vale a ressalva de que o modelo proposto comporta apenas interações Compton primárias, ou seja, apenas uma interação ao longo do caminho do fóton na barreira. Se esta barreira for de uma espessura que haja interações secundárias, ou seja, que o livre caminho médio do fóton seja menor que a espessura da barreira, os resultados seriam, provavelmente, piores.

\section{Variação com a distância da barreira.}

Assim como foi feito a variação com o tamanho de campo e com a espessura da barreira, também se variou o parâmetro distância da barreira. Como nas medições anteriores manteve-se os outros parâmetros de entrada do modelo constantes.

Nas Figuras 39 a 41 são mostrados os espectros usados para análise de variação com a espessura da barreira. 

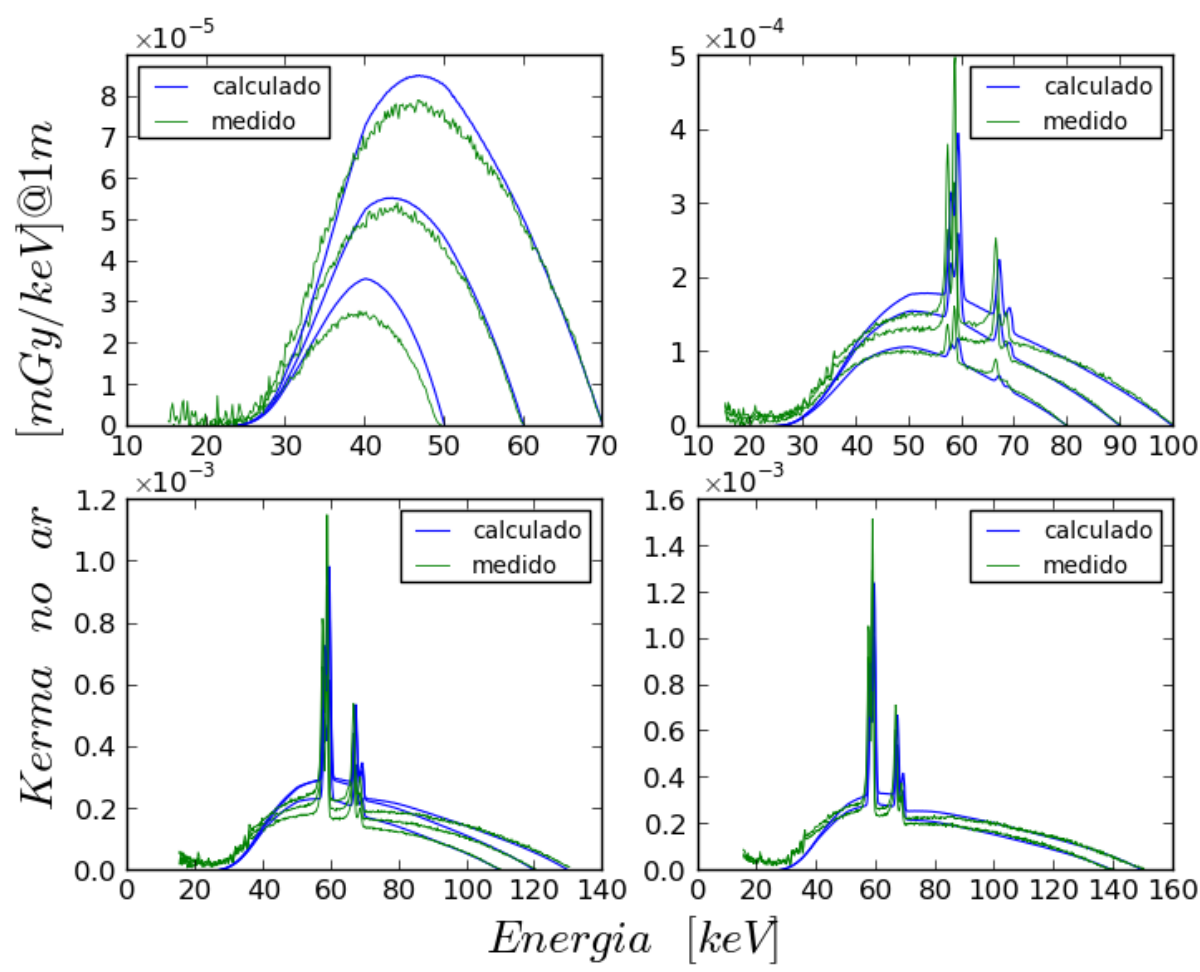

Figura 39 - Espectros P+S. Raio do campo $39,5 \mathrm{~cm}$, distância da barreira $2 \mathrm{~m}$,e espessura $44 \mathrm{~mm}$.
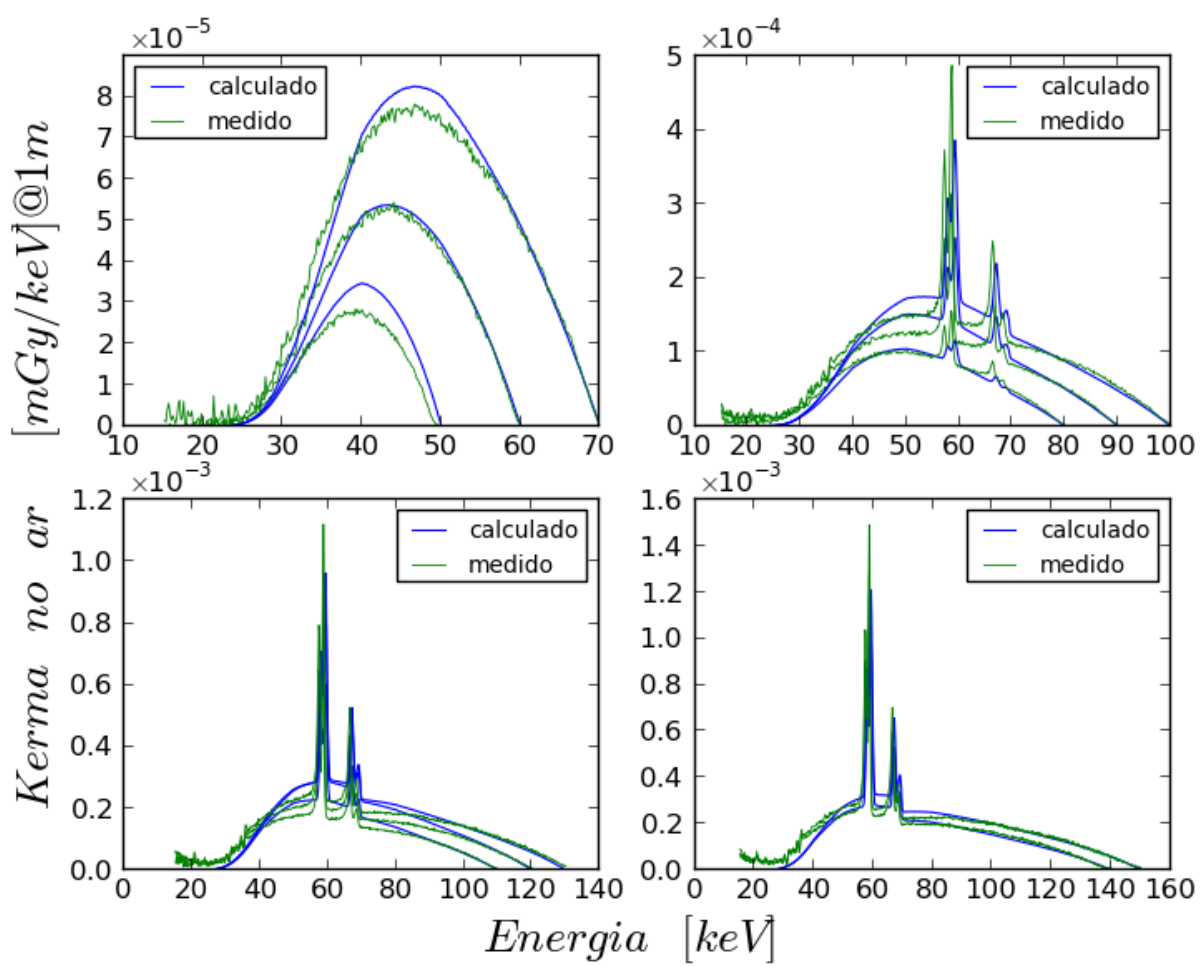

Figura 40 - Espectros P+S. Raio do campo $39,5 \mathrm{~cm}$, distância da barreira 2,87 m, espessura $44 \mathrm{~mm}$. 

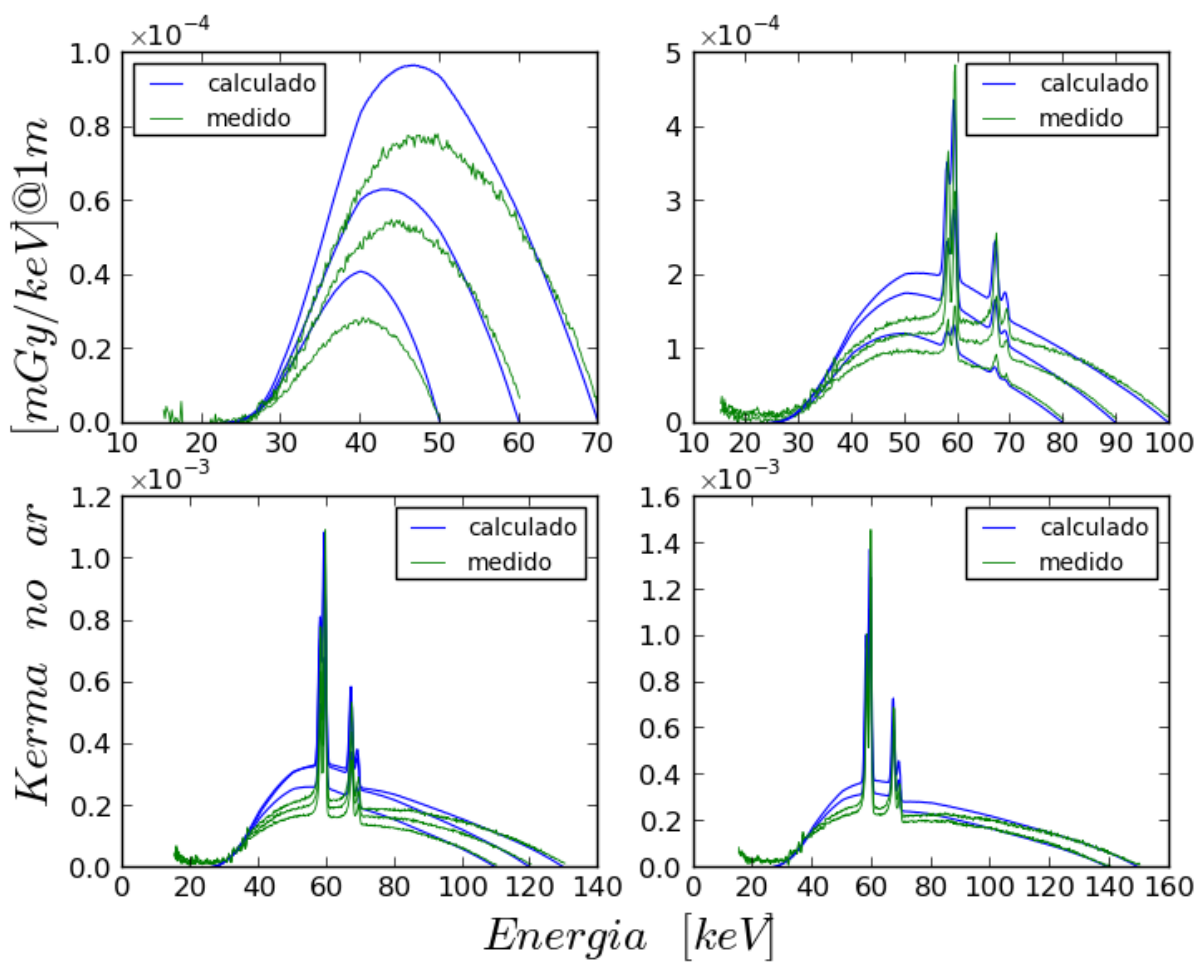

Figura 41 - Espectros P+S. Raio do campo 39,5 cm , distância da barreira 4,34 m, espessura 44mm.

As Figuras 42 e 43 trazem os resultados de comparações entre espectros medidos e calculados na mesma sequência das variações no tamanho do campo e espessura da barreira. 


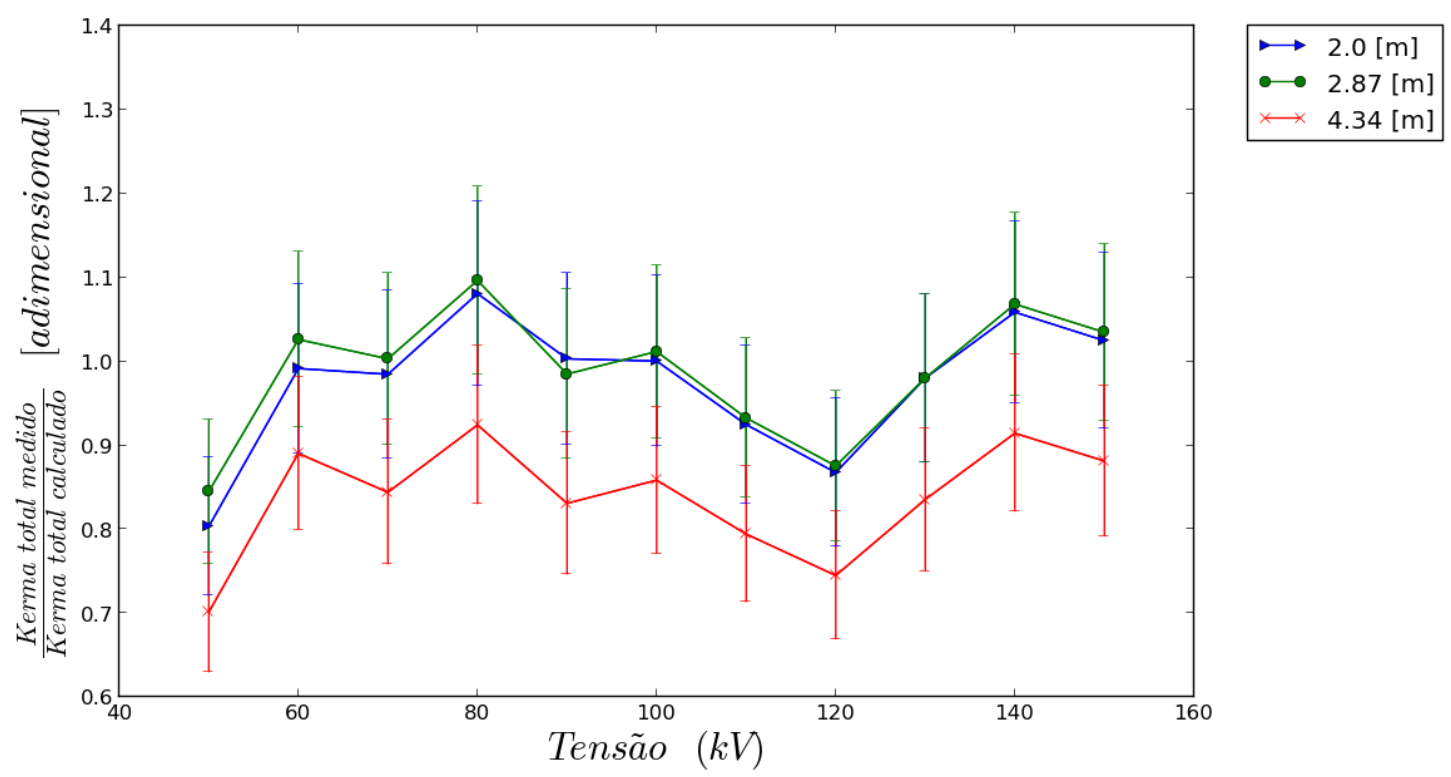

Figura 42 - Variação na distância da barreira, para espectros $\mathrm{P}+\mathrm{S}$. Tamanho de feixe de $39,5 \mathrm{~cm}$. Barreira com $44 \mathrm{~mm}$ de espessura.

Da Figura 42 pode-se observar uma possível tendência a partir dos dados de 4,34 metros de uma degradação do modelo pois, nesta situação, se encontram os piores resultados, porém, pela falta de mais medições em distâncias intermediárias, é dificil uma conclusão neste sentido.

Por fim, na Figura 43, são analisadas as formas dos espectros calculados pelo modelo, e analisados pelo índice de mérito $\delta^{2}$. 


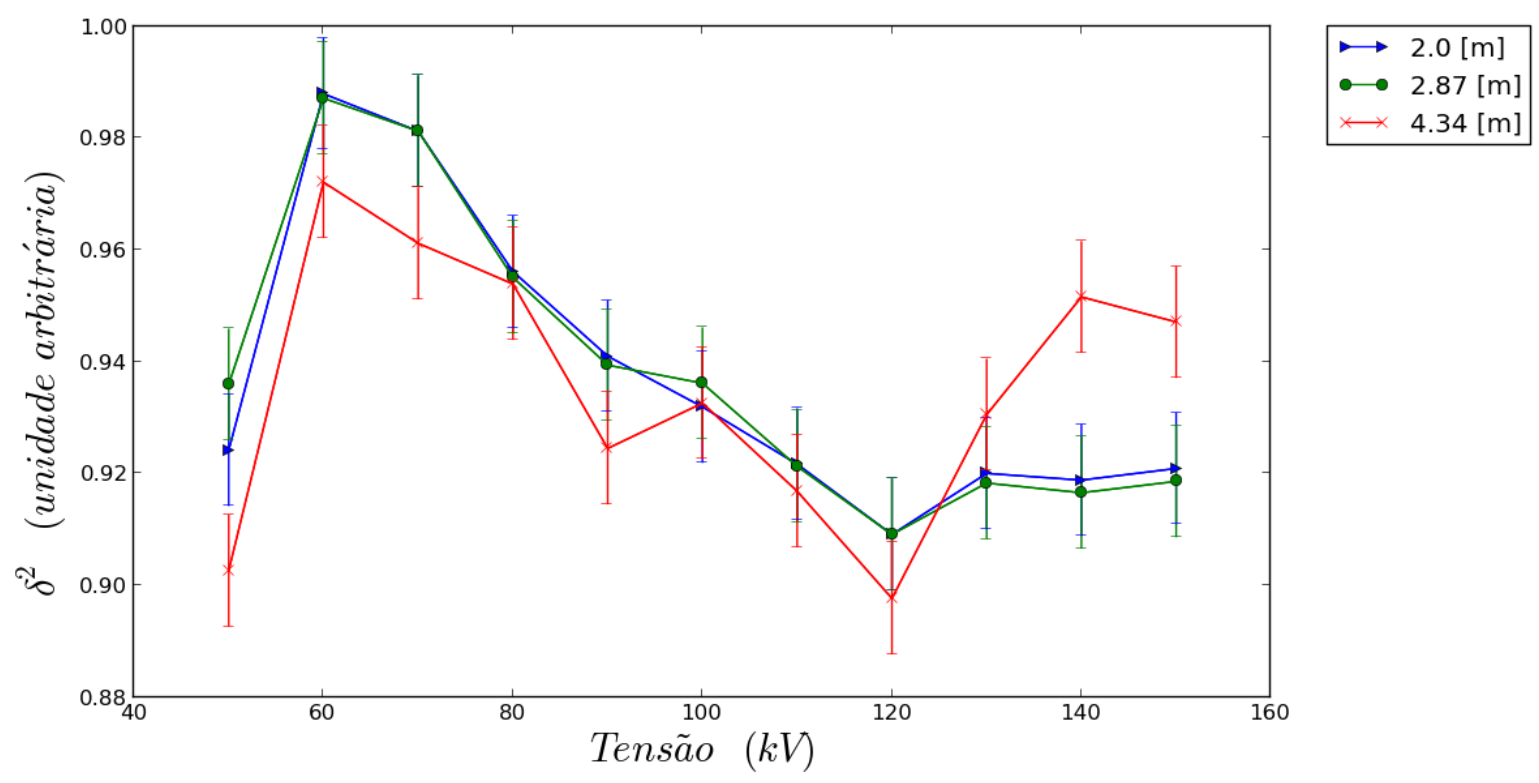

Figura 43 - Variação na distância da barreira pelo $\delta^{2}$, fótons de espectros P+S. Tamanho de feixe de $39,5 \mathrm{~cm}$. Barreira com $44 \mathrm{~mm}$ de espessura.

Diferentemente da razão entre os kerma no ar medido e simulado, onde havia uma degradação para espectros calculados com a barreira à $4,34 \mathrm{~m}$ de distância da fonte de raios $\mathrm{X}$, ao longo das diferentes distâncias o modelo se mostrou menos sensível quanto à morfologia dos espectros. Temos então, neste caso, espectros com a forma parecida, mas deslocados na amplitude em relação aos calculados.

$\mathrm{Na}$ maioria das comparações, os resultados de tamanho de campo de 39,5 $\mathrm{cm}$ e barreira a $2 \mathrm{~m}$ de distância da fonte de raios $\mathrm{X}$, foram muito melhores que os demais.

\subsection{Análise qualitativa dos espectros $\mathrm{S}$.}

\section{Variação com o tamanho do campo.}

Os dados dos espectros medidos e calculados são mostrados nas Figuras 44 a 46. 


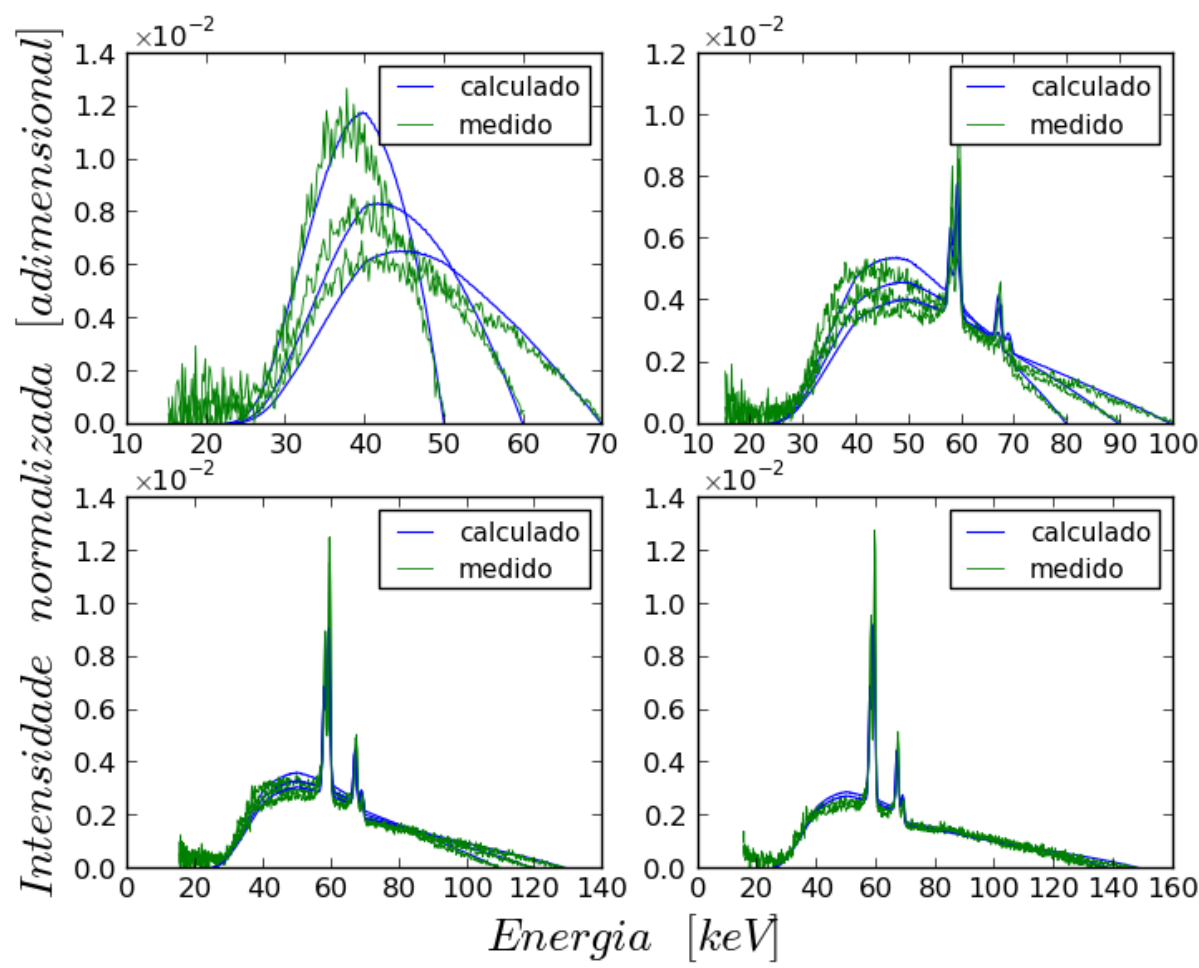

Figura 44 - Espectros S .Raio do campo $39,5 \mathrm{~cm}$, distância da barreira $2 \mathrm{~m}$, espessura $20 \mathrm{~mm}$.

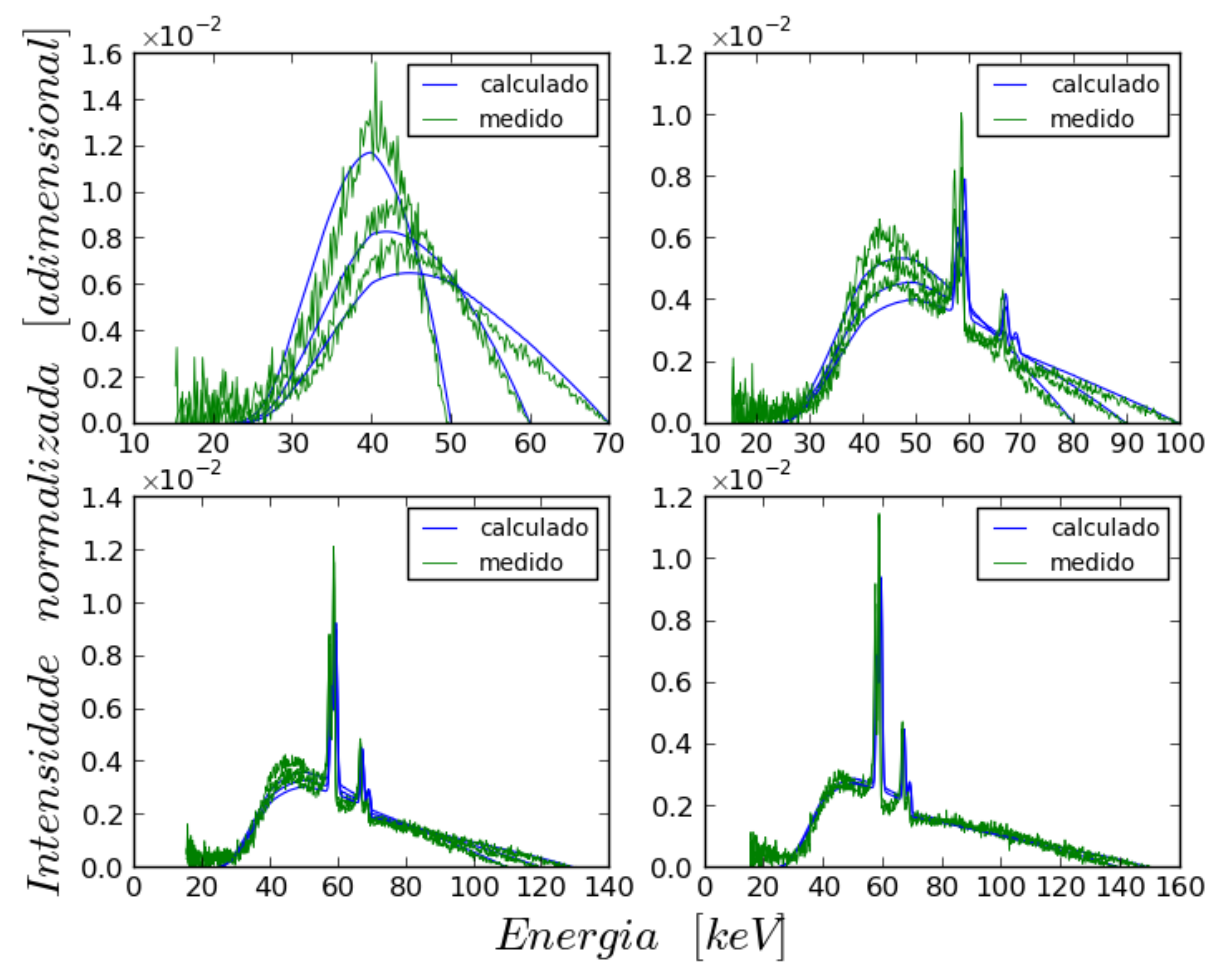

Figura 45 - Espectros S. Raio do campo $27,5 \mathrm{~cm}$, distância da barreira $2 \mathrm{~m}$, e espessura $20 \mathrm{~mm}$. 


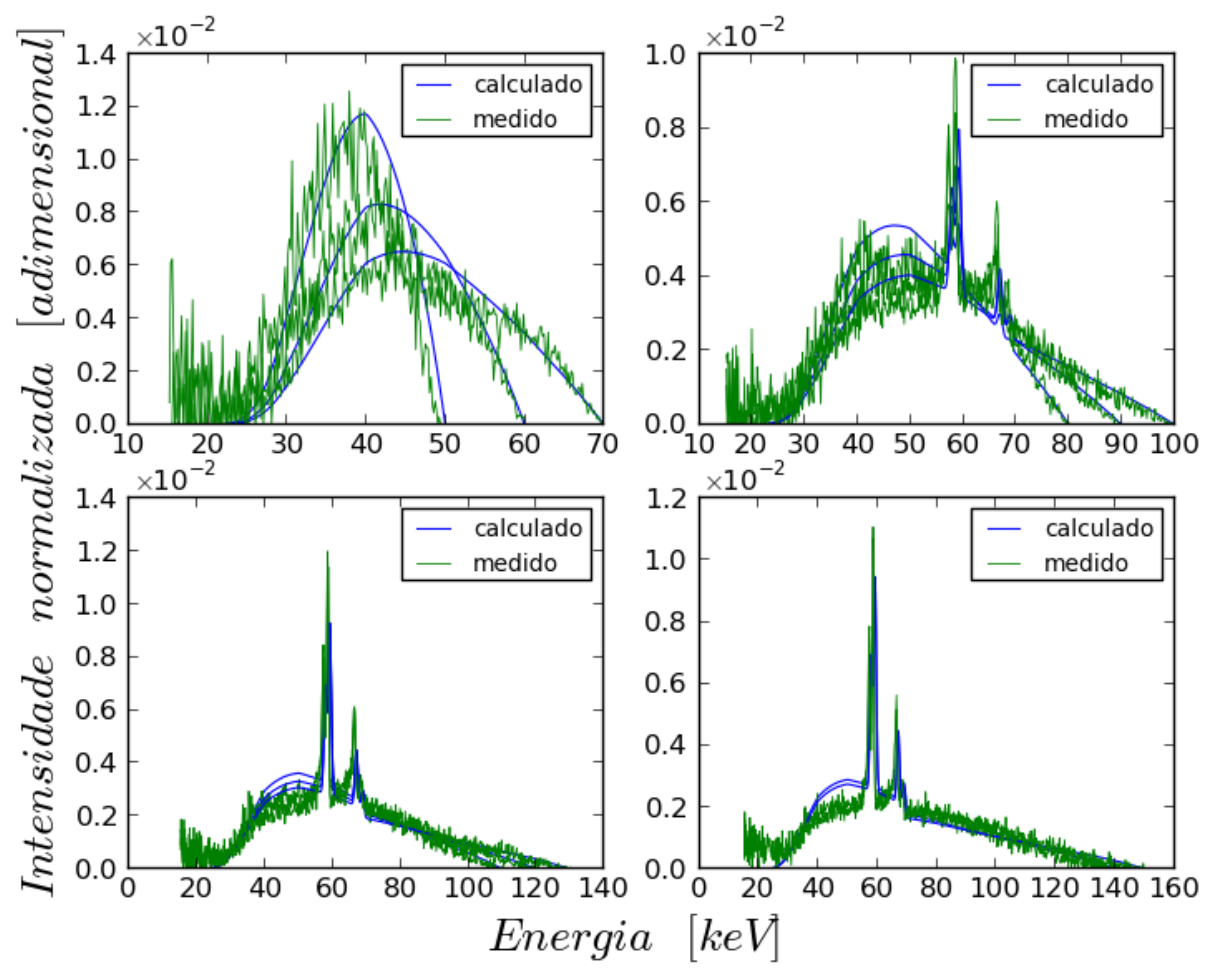

Figura 46 - Espectros S. Raio do campo 18,2 cm, distância da barreira 2 m,e espessura $20 \mathrm{~mm}$.

A Figura 47 apresenta as comparações na variação no tamanho de campo, apenas para os fótons espalhados pela barreira, pelo índice de forma $\boldsymbol{\delta}^{\mathbf{2}}$.

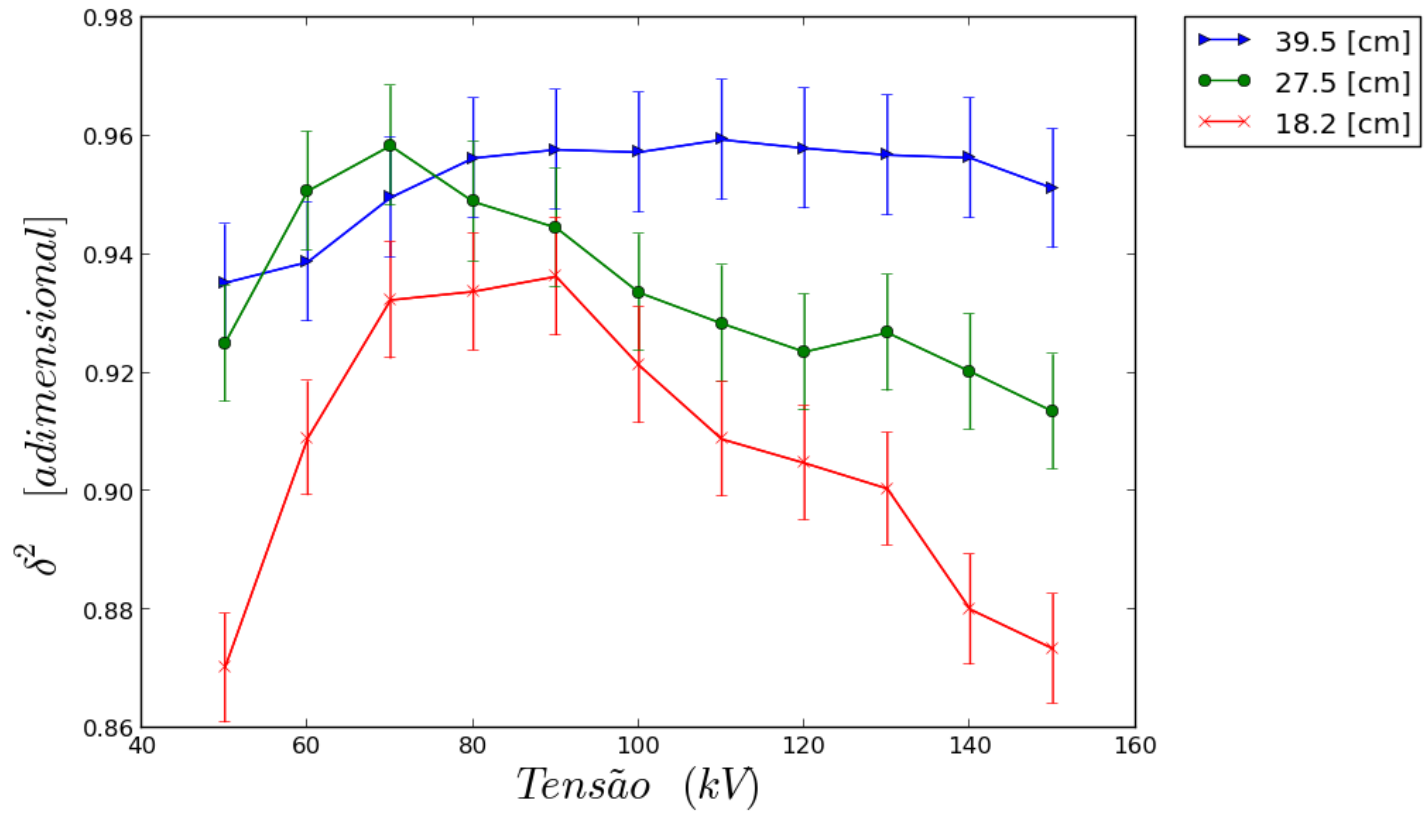

Figura 47 - Valores de figura de mérito $\delta^{2}$ para espectros medidos com diferentes tamanhos de campo. Feixes espalhados pela barreira de acrílico $20 \mathrm{~mm}$ de espessura à $2 \mathrm{~m}$ da fonte. 
Pode-se analisar da Figura 47, que os espectros calculados estão com uma qualidade na forma, dada por, $\delta^{2}$, adequada para tamanho de campo $39,5 \mathrm{~cm}$. Para os outros valores de tamanho de campo, ocorre uma diminuição na qualidade do modelo. Pode-se notar que os espectros que geraram estes baixos valores de $\delta^{2}$, apresentam maior divergência na forma. Os piores resultados podem ser observados na Figura 46 que apresenta os espectros para tamanho de campo de $18,2 \mathrm{~cm}$. Os espectros de menor $\mathrm{kV}$, nesta mesma figura apresentam um grande ruído experimental, relacionado com baixas contagens no espectrômetro, enquanto os espectros de maior $\mathrm{kV}$ apresentam uma diferença perceptível entre espectros medido e calculado na faixa de 40 a $60 \mathrm{kV}$. Este comportamento pode ser uma característica do modelo, pois tem tendência crescente com o aumento do kV. Para os casos de baixos $\mathrm{kV}$, a pequena contagem de fótons para os espectros abaixo de $60 \mathrm{kV}$, pode ser notada visualmente pelo ruído dos espectros apresentados.

\section{Variação com a espessura da barreira.}

Os espectros usados para análise do comportamento do modelo com a variação da espessura da barreira estão nas Figuras 48 a 50. 

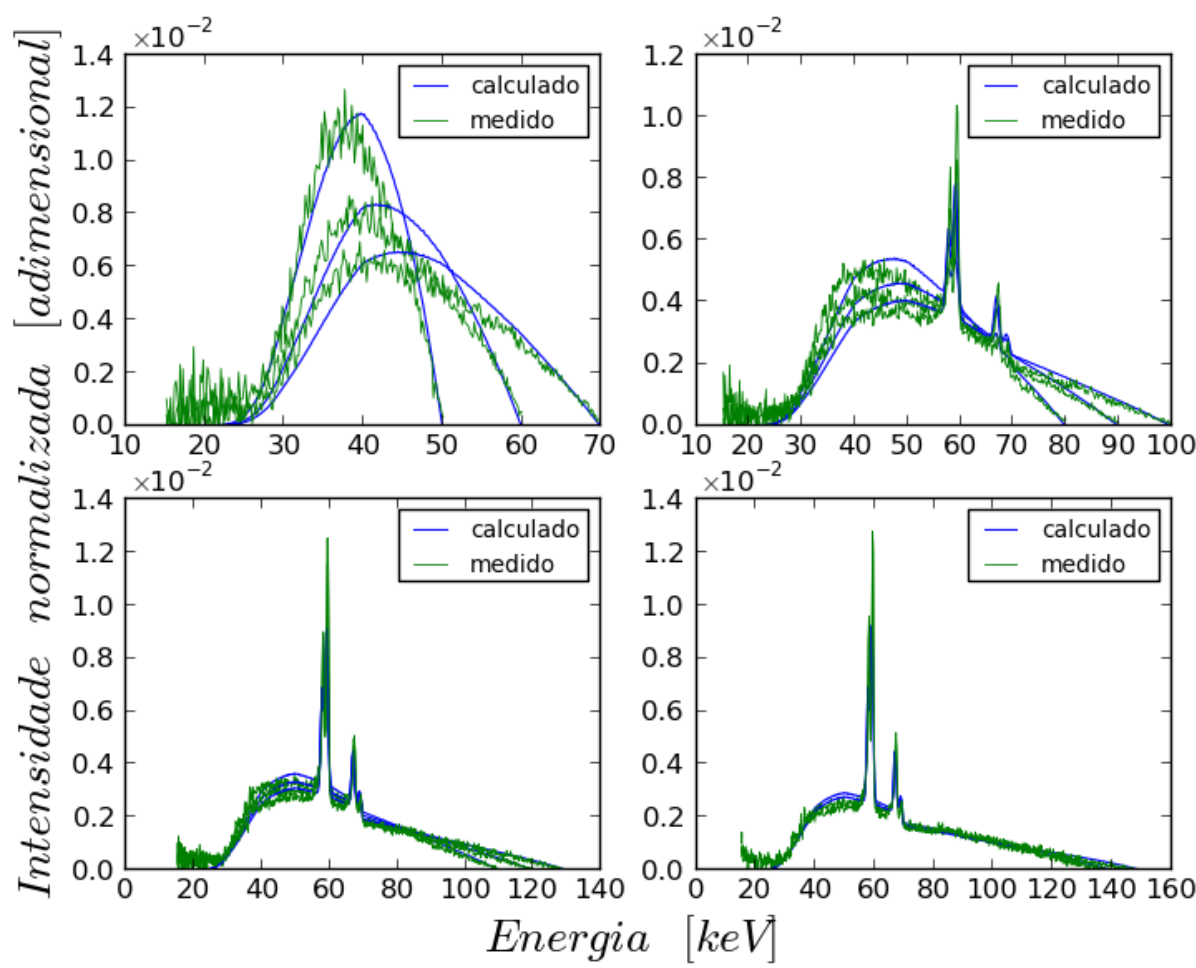

Figura 48 - Espectros S. Raio do campo $39,5 \mathrm{~cm}$, distância da barreira $2 \mathrm{~m}$, espessura $20 \mathrm{~mm}$.
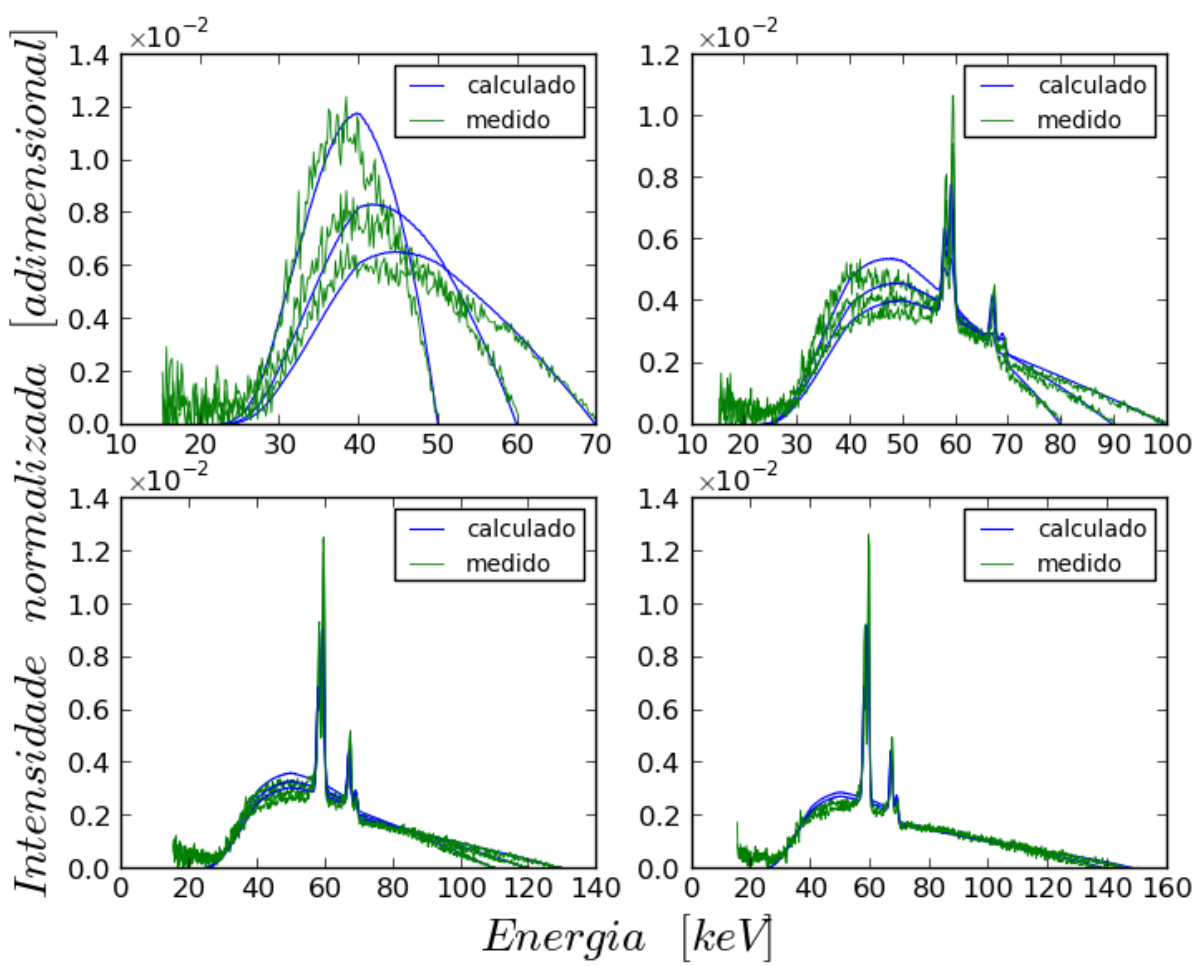

Figura 49 - Espectros S. Raio do campo $39,5 \mathrm{~cm}$, distância da barreira 2 m,e espessura 24 mm. 


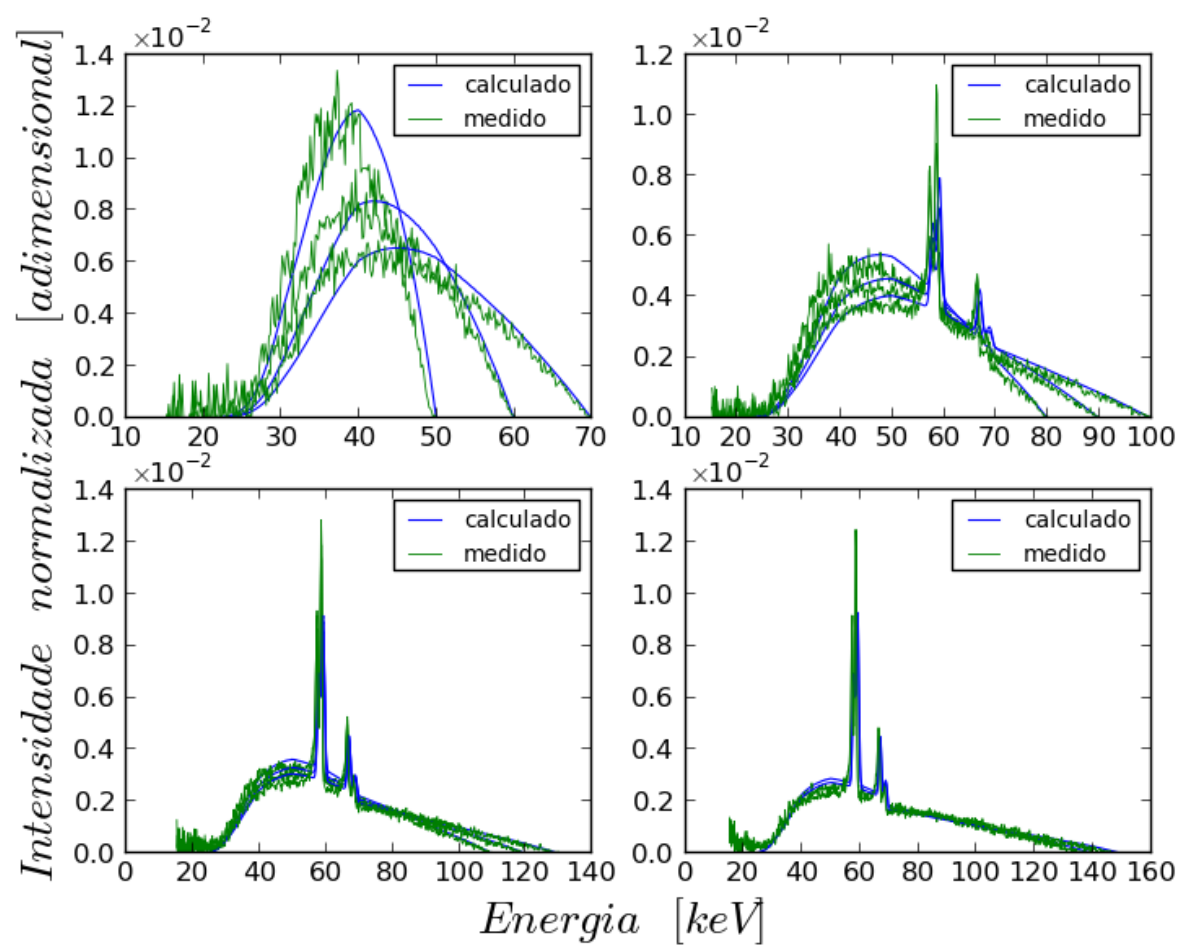

Figura 50 - Espectros S. Raio do campo $39,5 \mathrm{~cm}$, distância da barreira $2 \mathrm{~m}$, espessura $44 \mathrm{~mm}$.

$\mathrm{Na}$ Figura 51 são apresentados os resultados para espectros $\mathrm{S}$, para diferentes espessuras da barreira.

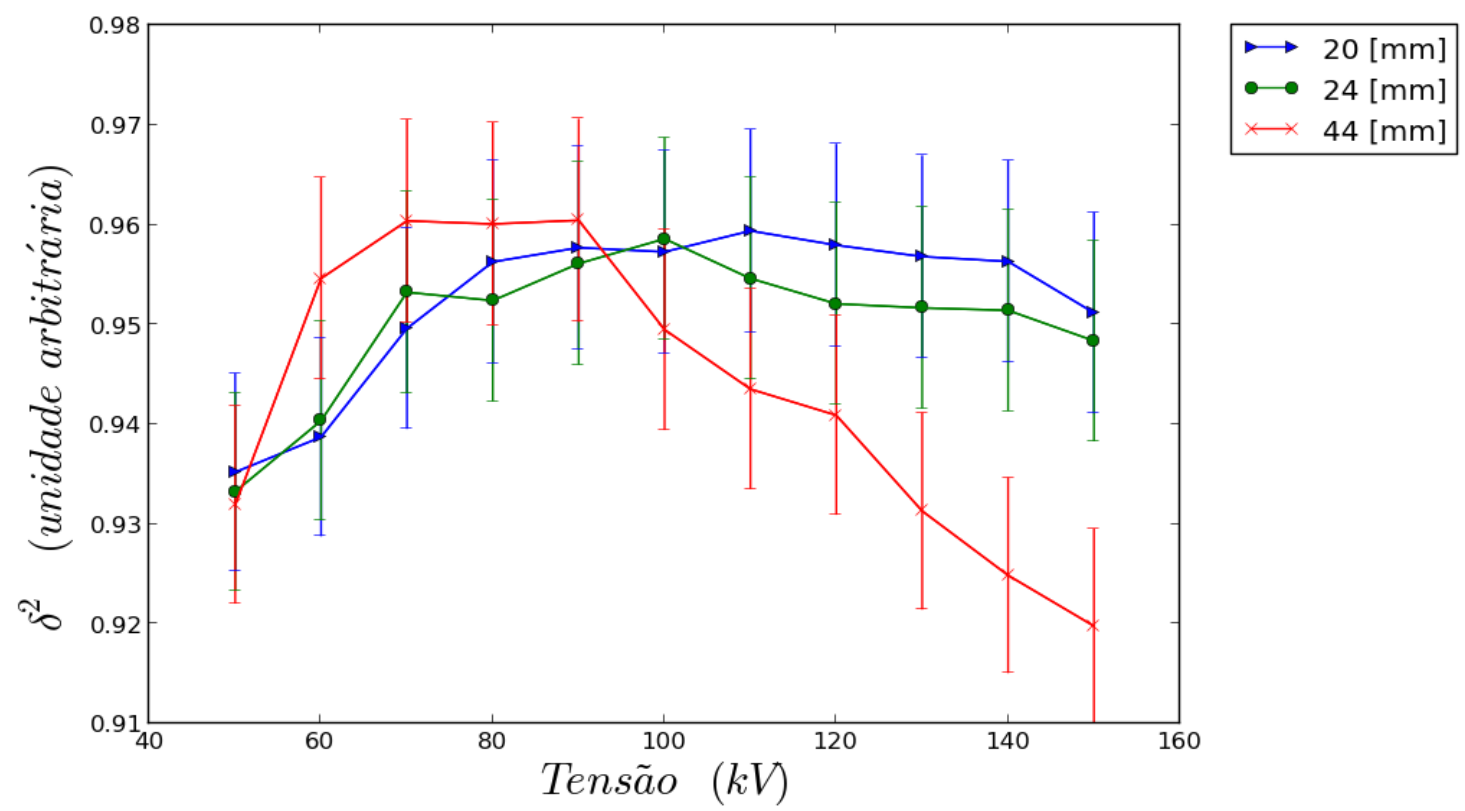

Figura 51 - Valores de $\delta^{2}$ considerando diferentes espessuras da barreira. Foram utilizados espectros S para tamanho de campo de $39,5 \mathrm{~cm}$ e uma distância de $2 \mathrm{~m}$ 
Para os valores obtidos em espectros espalhados, S. Observou-se que a variação na espessura da barreira não deixou clara nenhuma tendência bem definida no modelo para diferentes espessuras. Para a barreira de $44 \mathrm{~mm}$ houve um decréscimo na qualidade do modelo para espectros acima de $90 \mathrm{kV}$, no entanto mesmo nestes casos o modelo apresentou $\delta^{2}$ acima de 0.92 , o que representa um bom resultado, como pode ser observado pode ser observado na Figura 50.

\section{Variação com a distância da barreira.}

Para esta análise qualitativa da variação com a distância da barreira são mostrados os espectros nas Figuras 52 a 54 .

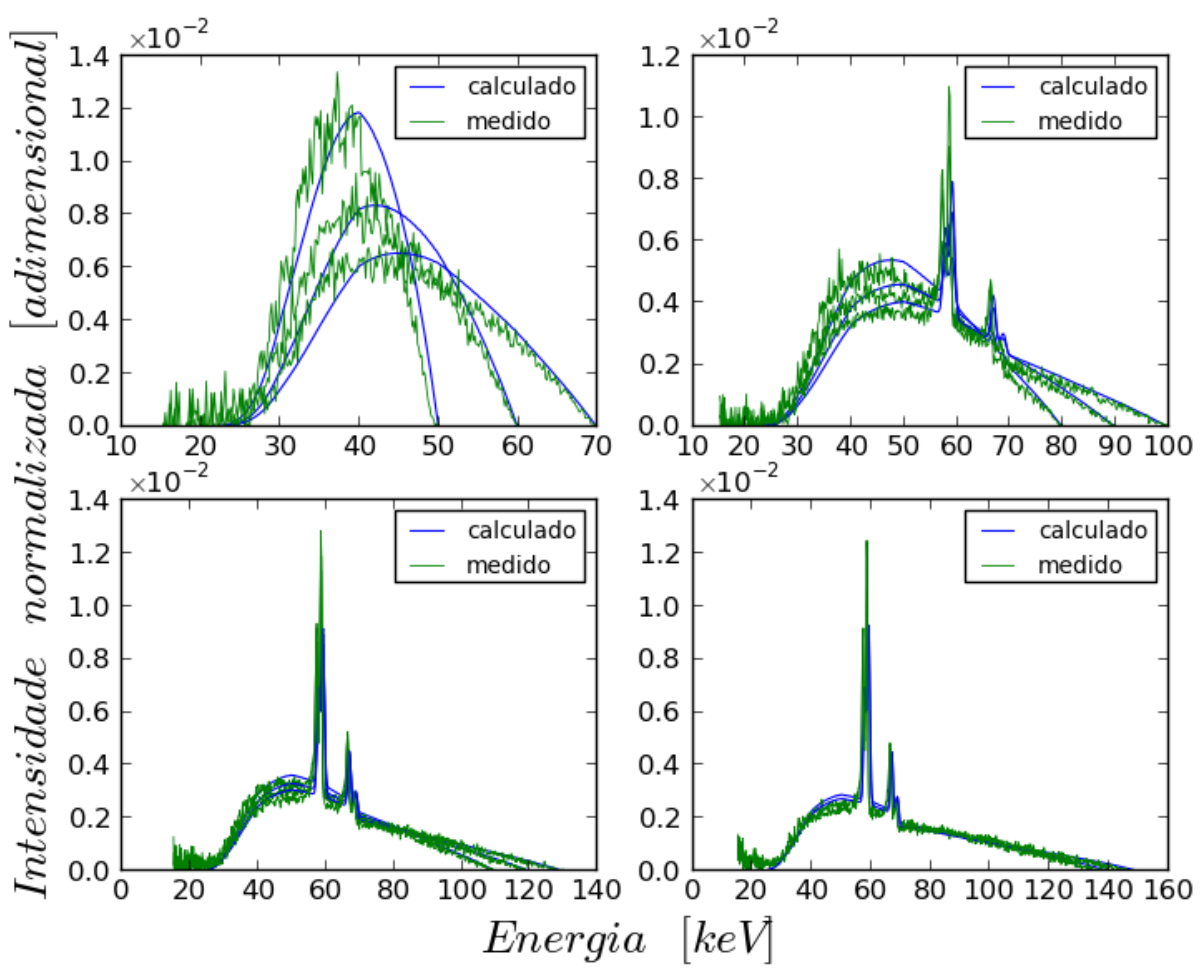

Figura 52 - Espectros S. Raio do campo $39,5 \mathrm{~cm}$, distância da barreira $2 \mathrm{~m}$,e espessura $44 \mathrm{~mm}$ 

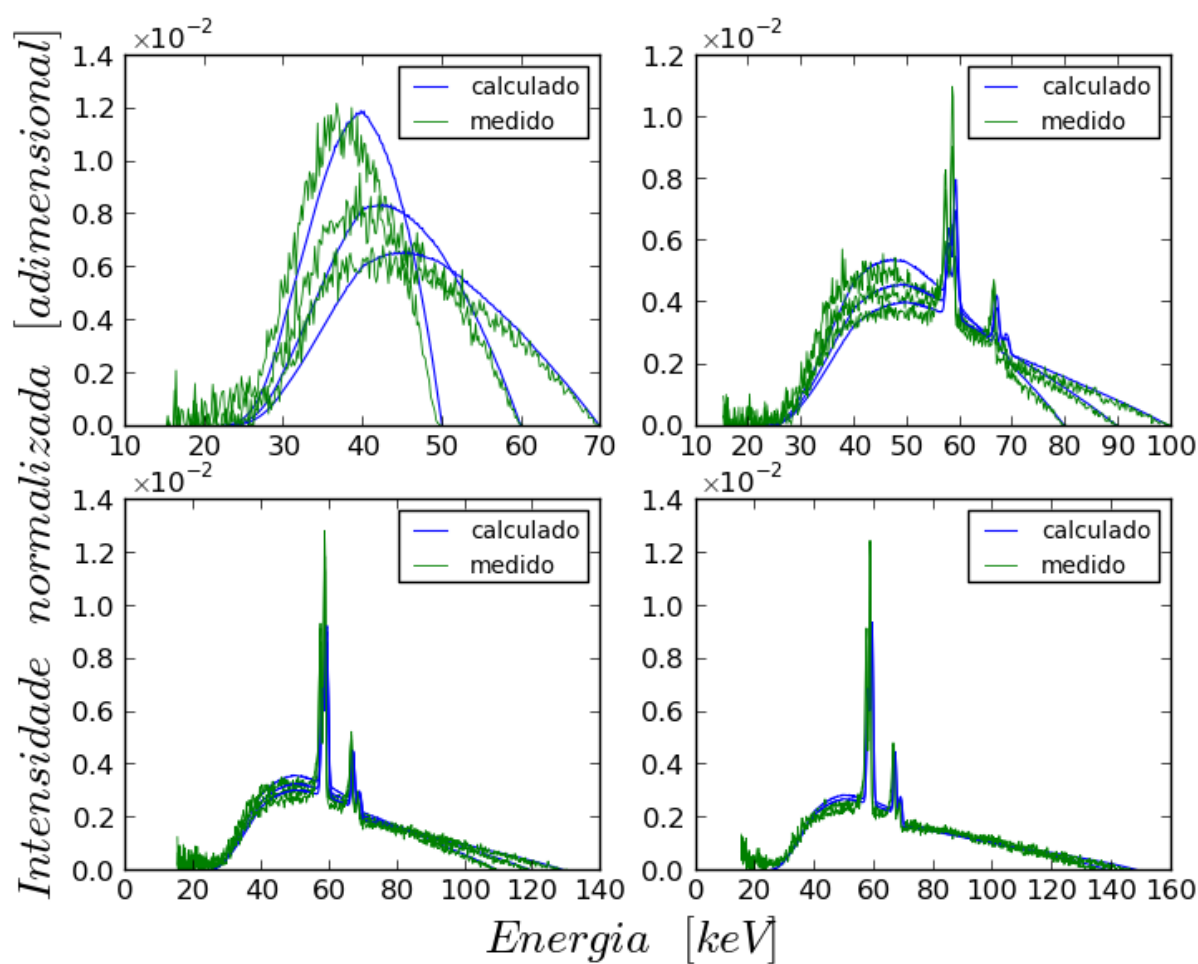

Figura 53 - Espectros S. Raio do campo 39,5 cm , distância da barreira 2,87 m,e espessura $44 \mathrm{~mm}$.
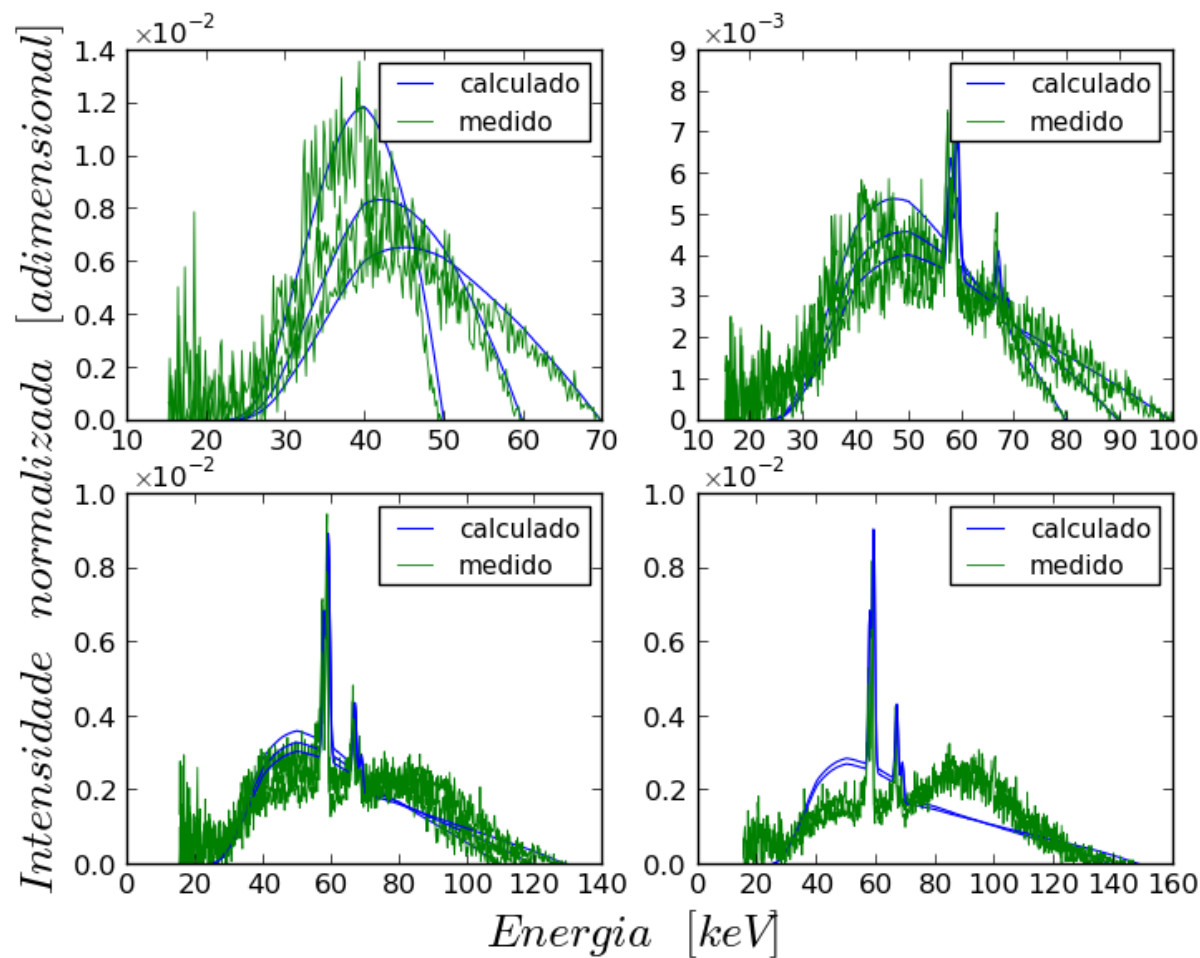

Figura 54 - Espectros S. Raio do campo $39,5 \mathrm{~cm}$, distância da barreira 4,34 m,e espessura $44 \mathrm{~mm}$. 
Na Figura 55 são analisadas as formas dos espectros S para variação na distância da barreira.

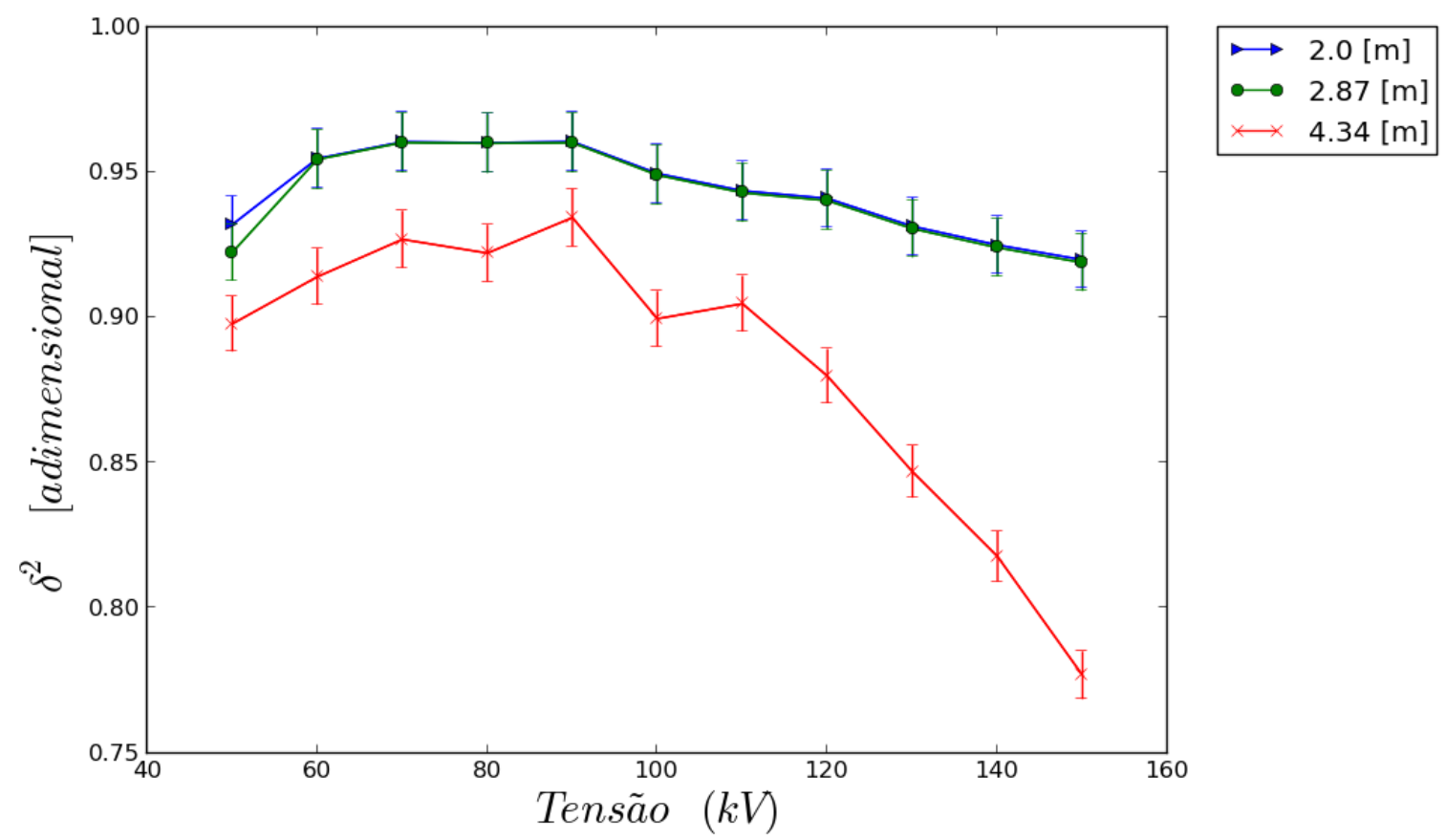

Figura 55 - Variação com a distância da barreira, espectros S, pela figura de mérito $\delta^{2}$. Tamanho de feixe de $39,5 \mathrm{~cm}$. Barreira com $44 \mathrm{~mm}$ de espessura.

Pode-se observar, a partir Figura 55 uma concordância muito grande entre os espectros medidos com a barreira posicionada à $2 \mathrm{~m}$ e à $2,87 \mathrm{~m}$ do tudo de raios $\mathrm{X}$, além disso em ambos os casos os valores de $\delta^{2}$ estão acima de 0,9 o que mostra uma boa qualidade do modelo, ainda que para energias baixas os valores de contagens seja baixo, e por isto o ruído no espectro alto.

Com a barreira à 4,34 metros, por outro lado, observa-se os piores valores de $\boldsymbol{\delta}^{2}$, encontrados em todos os espectros analisados. A provável causa dos resultados ruins está relacionado à uma baixa resposta, na qualidade do modelo quando em situação de um ângulo de espalhamento mais alto do que em todas as situações anterioes, este foi o caso de maior ângulo de espalhamento possível, pois foi usado um tamanho de campo de $39,5 \mathrm{~cm}$ de raio com uma barreira à apenas 0,74 metros do espectrômetro. 


\section{Análise geral do modelo}

A Figura 56 apresenta os resultados da analise comparativa dos valores de kerma no ar medido e calculado a partir do espectro simulado para os espectros $\mathrm{P}+\mathrm{S}$. Os resultados estão separados por tipo de parâmetros variados para a obtenção dos espectros.

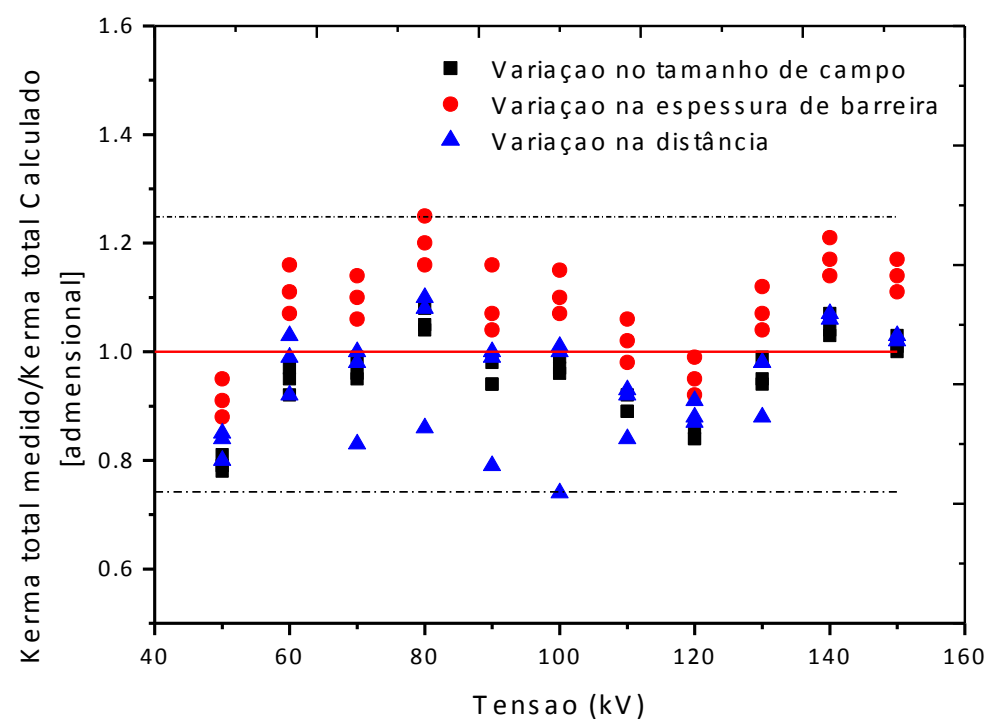

Figura 56: Razão dos valores de kerma no ar para os espectros $\mathrm{P}+\mathrm{S}$ para todas as configurações de medições. A linha vermelha indica o valor ideal da razão, 1. As linhas pontilhadas indicam os valores máximos e mínimos obtidos. As incertezas não foram incluídas na figura para maior clareza.

De acordo com a Figura 56, os valores máximos e mínimos da razão entre os valores de kerma no ar medido e calculado foram 1,25 e 0,75 . Isso indica que a máxima variação dessa grandeza entre os espectros medidos e simulados foi de $25 \%$. Para os casos de variações na espessura da barreira, os resultados mostram que para a maioria dos espectros o kerma total medido obtido foi maior que o kerma calculado. 


\section{CONCLUSÃO E PERSPECTIVAS}

O modelo proposto neste trabalho incorporou várias considerações e aproximações baseadas na geometria do problema, na teoria da física das radiações (como por exemplo na consideração de ocorrerem apenas espalhamentos primários) e ainda em ajustes feitos a partir de comparações com os espectros obtidos empiricamente.

Foram feitas medições para validação do modelo proposto, separando os espectros medidos em espectros que incluem os fótons primários e espalhados, $\mathrm{P}+\mathrm{S}$, e espectros compostos apenas pelos fótons espalhados, $\mathrm{S}$. Análises foram feitas a partir de comparações entre espectros de raios $X$ obtidos nas medições $e$ calculados com uso do modelo proposto neste trabalho.

A figura de mérito $\delta^{2}$ foi usada para a comparação entre cada par composto pelo espectro medido e seu respectivo espectro calculado. Esta função foi definida na secção 3.3 do capítulo de Materiais e Métodos, e representa a diferença na forma do espectro calculado quando comparado a um empírico obtido sob as mesmas condições. Foi, também, utilizada a razão entre os kermas no ar experimentais e calculados para a avaliação quantitativa da fidelidade do cálculo dos espectros pelo modelo proposto em relação aos obtidos experimentalmente.

A análise dos resultados foi dividida entre análise quantitativa e qualitativa para os espectros $\mathrm{P}+\mathrm{S}$, onde se usou a razão kerma no ar medido e kerma no ar calculado para a análise quantitativa, e o índice $\delta^{2}$ para análise qualitativa. Para os espectros $S$ foi feita apenas a análise qualitativa.

Foram obtidos valores da razão entre os valores de kerma no ar medido e calculado entre 0,75 e 1,25 para os espectros $P+S$, o que mostrou um bom resultado quantitativo da qualidade do modelo. $\mathrm{Na}$ análise qualitativa dos espectros $\mathrm{P}+\mathrm{S}$, observou-se uma boa concordância na forma dos espectros calculados, nas três configurações experimentais usadas, variação no tamanho do campo, espessura da barreira, e distância da barreira. Em apenas uma posição da barreira o índice de forma $\delta^{2}$, ficou menor do que 0,9 .

Nas análises comparativas dos espectros $S$ realizadas para diferentes tamanhos de campo, a qualidade se mostrou semelhante, com fator de mérito $\delta^{2}$ 
entre 0,87 e 0,96 para raios do feixe de 18,2 cm e 39,5 cm. No entanto nota-se que há uma diferença mais acentuada para o tamanho de campo de $27,5 \mathrm{~cm}$, onde o indicador $\delta^{2}$ variou entre 0,91 e 0,96 . Desse modo, não se pode concluir uma tendência de comportamento com o aumento, ou diminuição no tamanho do campo. Para diferentes espessuras da barreira, a qualidade se mostrou semelhante nas três espessuras utilizadas, o indicador $\delta^{2}$ variou entre 0,92 e 0,96, e não se pode concluir alguma tendência. Finalmente, para a distância da barreira, pode-se concluir uma grande semelhança entre os resultados de $2 \mathrm{~m}$ e 2,87 m, ambos com boa qualidade dos espectros medidos, dada por $\delta^{2}$ variando entre 0,92 e 0,96. Para os dados de 4,34 m, houve uma piora na qualidade do modelo, apresentando menor valor de $\delta^{2}$, 0,78 , este foi o menor índice obtido todas as comparações de espectros S.

As considerações e ajustes adotados permitiu a construção de um modelo para cálculos de espectros de feixe largo em boa conformidade com dados experimentais na maior parte das geometrias usadas para sua validação. Em alguns casos, como nos de tamanho do feixe de $27,5 \mathrm{~cm}$ e $39,5 \mathrm{~cm}$ na barreira, e com esta barreira à 2 metros do tubo de raios $X$, a conformidade entre espectros medidos $\mathrm{e}$ calculados foi melhor que $90 \%$ nas duas figuras de mérito usadas para comparação.

Apesar disso, pode-se reconhecer algumas limitações do modelo que estão associadas a propriedades físicas existentes no experimento e que não foram adotadas na modelagem proposta. Entre elas, destaca-se a não consideração do efeito anódico ${ }^{15,16}$, que resulta na produção de feixes largos não uniformes. Esta não-uniformidade se estende tanto à forma quanto à intensidade dos espectros, em função de sua posição do feixe na direção paralela ao eixo anodo-catodo. A não inclusão do efeito anódico no modelo proposto pode ser uma das causas das discrepâncias encontradas com a aplicação das figuras de mérito, em especial em geometrias de feixes mais largos e com o espectrômetro próximo ao material espalhador.

Outra possível fonte de discrepâncias entre o feixe medido e o calculado pode ter origem na ligeira diferença de fluência de fótons medidos pela câmara de ionização e pelo espectrômetro. Para a aplicação da metodologia para correção da amplitude do espectro em unidades de kerma foi necessária a instalação da câmara de ionização interpondo o feixe de raios $X$ e o espectrômetro. Porém a própria 
câmara de ionização acarreta uma pequena atenuação do feixe de raios $X$, reduzindo a quantidade de fótons que atinge o espectrômetro. O efeito desta diferença é mais pronunciado em espectros com valores menores de tensão aplicada ao tubo de raios $\mathrm{X}$. Para os espectros contendo fótons provenientes somente de fenômenos de espalhamento, sem os primários transmitidos, esta atenuação pela câmara de ionização, embora pequena, é uma fonte de não conformidade no modelo proposto, que por se tratar de feixes de baixa contagem de fótons.

Adicionalmente, o modelo proposto não leva em consideração a eficiência do detector como fonte de alteração na morfologia dos espectros calculados. Esta eficiência, todavia, é considerada na correção dos espectros medidos e, desta forma, esta pode ser uma fonte adicional de diferenças entre os pares de espectros quando avaliados segundo as figuras de mérito adotadas no presente trabalho.

Outro fator que deve ser tratado como limitador na qualidade dos espectros calculados é o fato do modelo prever somente fenômenos de espalhamento simples. Apesar das considerações referentes ao livre caminho médio dos fótons espalhados ter sido feita de forma cuidadosa, tanto na escolha da composição química do material espalhador usado na avaliação comparativa do modelo, quando nas espessuras típicas usadas deste material (PMMA) nos experimentos, a natureza estatística do fenômeno de interação da radiação com a matéria pode influenciar como limitante na consideração de ocorrências de efeitos de espalhamento simples somente. Esta limitação pode ser notada na Figura 38, na qual a qualidade da figura de mérito piora com a espessura do material espalhador, levando à interpretação de que a consideração de espalhamentos únicos diminui sua consistência com o aumento da quantidade de espalhador no caminho dos fótons. Também não foram considerados outros fenômenos de espalhamento, como o coerente, e que podem acarretar em correções necessárias ao modelo, em especial em baixos ângulos.

Uma limitação de origem prática consiste na limitação de tamanho e quantidade das células, ou voxels, considerados no processo de cálculo das contribuições de espalhamento através do modelo proposto. Valores pequenos de células com grandes quantidades das mesmas acarretam em melhores aproximações dos fenômenos considerados nas equações adotadas, porém com 
alto custo computacional. Os padrões de voxels considerados nos cálculos apresentados no presente trabalho tentaram equilibrar tempos computacionais aceitáveis com resultados suficientemente confiáveis para serem comparados com os espectros obtidos empiricamente.

O modelo proposto usou a consideração para cálculo do ângulo sólido, do espectrômetro ser geometricamente um disco. O espectrômetro real, contido, possui um elemento sensível de face quadrada, que é atingido pelo feixe de raios $X$ que atravessa uma janela protetora e passa por um colimador. Neste colimador ocorrem efeitos de atenuação que são variáveis com a geometria do feixe de raios $X$ que incide neste espectrômetro. Devido à natureza geométrica do modelo proposto, não se conseguiu medir numericamente a importância deste efeito. Porém, em diversas medições feitas no mesmo laboratório, foi verificado a existência deste efeito de atenuação pelo colimador, principalmente para energias maiores que $100 \mathrm{kV}$.

Desta forma, como proposta de trabalhos futuros em continuidade aos desenvolvimentos apresentados no presente trabalho, pode-se relacionar:

- a inclusão do efeito anódico na modelagem do feixe de raios $X$ que atinge o material espalhador em condições de feixe largo;

- a adoção da geometria correta do espectrômetro e considerações adicionais como a eficiência de detecção e efeitos de penetração através do sistema de colimação;

- a avaliação de outros materiais espalhadores que atendam as condições de espalhamento único, bem como a utilização de materiais não uniformes, visando o desenvolvimento de modelos mais complexos que possam apoiar pesquisas nas áreas clínicas;

- o aumento da capacidade computacional para teste do modelo, viabilizando a adoção de voxels de menor tamanho e maior quantidade de elementos espalhadores;

- avaliação comparativa utilizando o Método Monte Carlo para validação terciária do modelo matemático. 


\section{Anexo I}

Neste anexo I estão as tabelas com os dados usados para compor figuras apresentadas capítulo de resultados.

Tabela 1 - Dados de kerma no ar medido/ kerma no ar calculado usados na Figura 32

\begin{tabular}{cccc}
\hline Tensão & \multicolumn{3}{c}{ Tamanho de campo } \\
\hline$(\mathrm{kV})$ & $18,2(\mathrm{~cm})$ & $27,5(\mathrm{~cm})$ & $39,5(\mathrm{~cm})$ \\
\hline 50 & 0,78 & 0,81 & 0,79 \\
60 & 0,95 & 0,92 & 0,97 \\
70 & 0,95 & 0,99 & 0,96 \\
80 & 1,04 & 1,08 & 1,05 \\
90 & 0,94 & 0,98 & 0,94 \\
100 & 0,96 & 0,99 & 0,97 \\
110 & 0,89 & 0,92 & 0,89 \\
120 & 0,84 & 0,86 & 0,84 \\
130 & 0,94 & 0,99 & 0,95 \\
140 & 1,03 & 1,07 & 1,04 \\
150 & 1,00 & 1,03 & 1,01 \\
\hline
\end{tabular}

Tabela 2 - Valores da figura de mérito $\boldsymbol{\delta}^{2}$, para variação no tamanho de campo, do feixe P+S. Dados usados na Figura 33.

\begin{tabular}{cccc}
\hline Tensão & \multicolumn{3}{c}{ Tamanho de campo } \\
\hline$(\mathrm{kV})$ & $18,2(\mathrm{~cm})$ & $27,5(\mathrm{~cm})$ & $39,5(\mathrm{~cm})$ \\
\hline 50 & 0,91 & 0,91 & 0,93 \\
60 & 0,97 & 0,97 & 0,98 \\
70 & 0,95 & 0,98 & 0,98 \\
80 & 0,94 & 0,97 & 0,98 \\
90 & 0,93 & 0,96 & 0,97 \\
100 & 0,93 & 0,95 & 0,97 \\
110 & 0,92 & 0,94 & 0,96 \\
120 & 0,91 & 0,93 & 0,94 \\
130 & 0,93 & 0,96 & 0,96 \\
140 & 0,93 & 0,94 & 0,97 \\
150 & 0,71 & 0,93 & 0,95 \\
\hline
\end{tabular}


Tabela 3 - Valores de $\boldsymbol{\delta}^{2}$, para variação no tamanho do campo, apenas para feixe espalhado pela barreira, Dados usados na figura 47.

\begin{tabular}{cccc}
\hline Tensão & \multicolumn{3}{c}{ Tamanho de campo } \\
\hline$(\mathrm{kV})$ & $18,2(\mathrm{~cm})$ & $27,5(\mathrm{~cm})$ & $39,5(\mathrm{~cm})$ \\
\hline 50 & 0.87 & 0.92 & 0.94 \\
60 & 0.91 & 0.95 & 0.94 \\
70 & 0.93 & 0.96 & 0.95 \\
80 & 0.93 & 0.95 & 0.96 \\
90 & 0.94 & 0.94 & 0.96 \\
100 & 0.92 & 0.93 & 0.96 \\
110 & 0.91 & 0.93 & 0.96 \\
120 & 0.90 & 0.92 & 0.96 \\
130 & 0.90 & 0.93 & 0.96 \\
140 & 0.88 & 0.92 & 0.96 \\
150 & 0.87 & 0.91 & 0.95 \\
\hline
\end{tabular}

Tabela 4 - Variação na espessura da barreira, valores de kerma no ar medido dividido por kerma no ar calculado. Feixe P+S. Dados usados na Figura 37.

\begin{tabular}{cccc}
\hline Tensão & \multicolumn{3}{c}{ Espessura da barreira } \\
\hline$(\mathrm{kV})$ & $20(\mathrm{~mm})$ & $24(\mathrm{~mm})$ & $44(\mathrm{~mm})$ \\
\hline 50 & 0,88 & 0,91 & 0,95 \\
60 & 1,07 & 1,11 & 1,16 \\
70 & 1,06 & 1,10 & 1,14 \\
80 & 1,16 & 1,20 & 1,25 \\
90 & 1,04 & 1,07 & 1,16 \\
100 & 1,07 & 1,10 & 1,15 \\
110 & 0,98 & 1,02 & 1,06 \\
120 & 0,92 & 0,95 & 0,99 \\
130 & 1,04 & 1,07 & 1,12 \\
140 & 1,14 & 1,17 & 1,21 \\
150 & 1,11 & 1,14 & 1.17 \\
\hline
\end{tabular}

Tabela 5 - Valores da figura de mérito $\delta^{2}$, para variação na espessura da barreiera, do feixe P+S. Dados usados na

Figura 38.

\begin{tabular}{cccc}
\hline Tensão & \multicolumn{3}{c}{ Espessura da barreira } \\
\hline$(\mathrm{kV})$ & $20(\mathrm{~mm})$ & $24(\mathrm{~mm})$ & $44(\mathrm{~mm})$ \\
\hline 50 & 0,93 & 0,93 & 0,92 \\
60 & 0,98 & 0,98 & 0,99 \\
70 & 0,98 & 0,98 & 0,98 \\
80 & 0,98 & 0,97 & 0,96 \\
90 & 0,97 & 0,97 & 0,94 \\
100 & 0,97 & 0,97 & 0,93 \\
110 & 0,96 & 0,96 & 0,92 \\
120 & 0,94 & 0,94 & 0,91 \\
130 & 0,96 & 0,96 & 0,92 \\
140 & 0,97 & 0,96 & 0,92 \\
150 & 0,96 & 0,96 & 0,92 \\
\hline
\end{tabular}


Tabela 6 - Valores de $\delta^{2}$, para variação na espessura da barreira, apenas para feixe espalhado pela barreira. Dados usados na Figura 51.

\begin{tabular}{cccc}
\hline Tensão & \multicolumn{3}{c}{ Espessura da barreira } \\
\hline$(\mathrm{kV})$ & $20(\mathrm{~mm})$ & $24(\mathrm{~mm})$ & $44(\mathrm{~mm})$ \\
\hline 50 & 0.94 & 0.93 & 0.93 \\
60 & 0.94 & 0.94 & 0.95 \\
70 & 0.95 & 0.95 & 0.96 \\
80 & 0.96 & 0.95 & 0.96 \\
90 & 0.96 & 0.96 & 0.96 \\
100 & 0.96 & 0.96 & 0.95 \\
110 & 0.96 & 0.95 & 0.94 \\
120 & 0.96 & 0.95 & 0.94 \\
130 & 0.96 & 0.95 & 0.93 \\
140 & 0.96 & 0.95 & 0.92 \\
150 & 0.95 & 0.95 & 0.92 \\
\hline
\end{tabular}

Tabela 7 - Variação na distância da barreira, valores de kerma no ar medido dividido por kerma no ar calculado. Feixe P+S. Dados usados na Figura 42.

\begin{tabular}{cccc}
\hline Tensão & \multicolumn{3}{c}{ Distância da barreira } \\
\hline$(\mathrm{kV})$ & $2,0(\mathrm{~m})$ & $2,87(\mathrm{~m})$ & $4,34(\mathrm{~m})$ \\
\hline 50 & 0,80 & 0,85 & 0,70 \\
60 & 0,99 & 1,03 & 0,89 \\
70 & 0,98 & 1,00 & 0,84 \\
80 & 1,08 & 1,10 & 0,92 \\
90 & 1,00 & 0,99 & 0,83 \\
100 & 1,00 & 1,01 & 0,86 \\
110 & 0,92 & 0,93 & 0,79 \\
120 & 0,87 & 0,88 & 0,74 \\
130 & 0,98 & 0,98 & 0,84 \\
140 & 1,06 & 1,07 & 0,91 \\
150 & 1,02 & 1,03 & 0,88 \\
\hline
\end{tabular}

Tabela 8 - Valores da figura de mérito $\delta^{2}$, para variação distância da barreiera. Feixe $\mathrm{P}+\mathrm{S}$. Dados usados na Figura 43.

\begin{tabular}{cccc}
\hline Tensão & \multicolumn{3}{c}{ Distância da barreira } \\
\hline$(\mathrm{kV})$ & $2,0(\mathrm{~m})$ & $2,87(\mathrm{~m})$ & $4,34(\mathrm{~m})$ \\
\hline 50 & 0,92 & 0,94 & 0,90 \\
60 & 0,99 & 0,99 & 0,97 \\
70 & 0,98 & 0,98 & 0,96 \\
80 & 0,96 & 0,96 & 0,95 \\
90 & 0,94 & 0,94 & 0,92 \\
100 & 0,93 & 0,94 & 0,93 \\
110 & 0,92 & 0,92 & 0,92 \\
120 & 0,91 & 0,91 & 0,90 \\
130 & 0,92 & 0,92 & 0,93 \\
140 & 0,92 & 0,92 & 0,95 \\
150 & 0,92 & 0,92 & 0,95 \\
\hline
\end{tabular}


Tabela 9 - Valores de $\delta^{2}$, para variação no distância da barreira, apenas para feixe espalhado pela barreira. Dados usados na Figura 55.

\begin{tabular}{cccc}
\hline Tensão & \multicolumn{3}{c}{ Distância da barreira } \\
\hline$(\mathrm{kV})$ & $2,0(\mathrm{~m})$ & $2,87(\mathrm{~m})$ & $4,34(\mathrm{~m})$ \\
\hline 50 & 0.93 & 0.92 & 0.90 \\
60 & 0.95 & 0.95 & 0.91 \\
70 & 0.96 & 0.96 & 0.93 \\
80 & 0.96 & 0.96 & 0.92 \\
90 & 0.96 & 0.96 & 0.93 \\
100 & 0.95 & 0.95 & 0.90 \\
110 & 0.94 & 0.94 & 0.90 \\
120 & 0.94 & 0.94 & 0.88 \\
130 & 0.93 & 0.93 & 0.85 \\
140 & 0.92 & 0.92 & 0.82 \\
150 & 0.92 & 0.92 & 0.78 \\
\hline
\end{tabular}




\section{REFERÊNCIAS BIBLIOGRÁFICAS}

1 Okuno Yoshimura, E. Física, E.; das Radiações. 1a Edição, São Paulo: Oficina de Textos, 2010. ISBN: 978-85-7975-005-2.

2 Röntgen, W.C. On a new kind of rays. Science, vol. 3, n.59, p. 227-231,1896.

3 Johns,H.E.; Cunningham,J.R. The Physics of Radiology. 3a Edition. Springfield, Illinois, U.S.A.: Thomas Books, 1974. ISBN 0-398-03007-3.

4 Bergstrom, J.R.; Pratt, R.H. An Overview of the theories used in Compton scattering calculations. Radiation Physics and Chemistry. vol. 50, n.1, p. 3-29, 1997.

5 Costa P. R., Yoshimura E. M. - Determinação das propriedades de transmissão de argamassas baritadas. Revista Brasileira de Física Médica.2011;4(3):63-6.

6 Yao W1, Leszczynski KW. An analytical approach to estimating the first order scatter in heterogeneous medium. II. A practical application. Medical Physics vol. 7 n. 36. P. 3157-3169, 2009.

7 Boone, J.M.; Seibert, J.A. An analytical model of the scattered radiation distribution in diagnostic radiology. Medical Physics. vol. 15, n.5, p. 721-725, 1988.

8 McVey G. - The effect of phantom type, beam quality, field size and field position on X-ray scattering simulated using Monte Carlo techniques. Br J Radiol. 2006 Feb;79(938):130-41

9 Yao, W.; Leszczynski, K. W. An analytical approach to estimating the first order xray scatter in heterogeneous medium. Medical Physics. vol. 36, n.7, p. 31453156, 2009

10 Fehrenbacher G., Tesfu K., Panzer W. and Regulla D. - Determination of Diagnostic X Ray Spectra Scattered by a Phantom. Radiation Protection Dosimetry Volume 71, Issue 4Pp. 305-308, 1997

11 Boone, J.M.; Seibert, J.A. Monte Carlo simulation of the scattered radiation distribution in diagnostic radiology. Medical Physics, vol. 15, n.5, p. 713-720, 1988.

12 Tucker, D.; Barnes, G.; Chakraborty, D. Semiempirical model for generating tungsten target x-ray spectra. Medical Physics, v. 18, n.2, p 211-218, 1991.

13 Costa, P. R.; Nersissian, D. Y.; Salvador, F.C.; Rio,P.B.; Caldas, L.V.E. Generation of calibrated tungsten target x-ray spectra: Modified TBC model. Medical Physics, v. 92, n.1, p 24-32, 2007.

14 Oppelt, A. Imaging Systems for Medical Diagnostics. John Wiley \& Sons, 2011.

15 Podgorsak, E.B. Radiation Physics for Medical Physicists. 2nd Edition Springer Science 2010.

16 Oppelt, A. Imaging Systems for Medical Diagnostics. John Wiley \& Sons, 2011. 
17 XCOM, NIST, Disponível em : < http://physics.nist.gov/PhysRefData/Xcom/html/xcom1.html > Acesso em $16 / 06 / 2014$

18 Hubbel, J. H.; et al. Atomic form factors, incoherent scattering functions, and photon scattering cross sections. The Journal of Physical Chemistry, Reference Data, v.4, n. 3, p. 471-538, 1975.

19 Baró, J.; Roteta, M.; Fernández-Varea, J. M.; Salvat, F. Analytical cross sections for monte carlo simulation of photon transport. Radiation Physics and Chemistry. vol. 44, n.5, p. 531-552, 1994.

20 Cromer, D.T.; Mann, J.B. Compton scattering factors for spherically symmetric free atoms. The Journal of Chemical Physics. vol 47, n.6, p. 1892-1893, 1967.

21 Kulenkampff, H. Uber das kontinuierliche Rontgenspektrum. Ann. Phys. Leipzi, v.69, p. 548 - 596, 1922.

22 Kramers, H. A. On the theory of x-ray absorption and of the continuous x-ray spectrum. Philosophical Magazine. v.46, p 836-871, 1923.

23 Soole, B.W. A method of x-ray attenuation analysis for approximating the intensity distribution at its point of bremsstrahlung excite in a thick target by incident electrons of constant medium energy. Physics in Medicine and Biology. v.21, n.3, p. 369-389, 1976.

24 Soole, B.W. A determination by an analysis of $\mathrm{x}$-ray attenuation in aluminum of the intensity distribution at its point of origin in a thick tungsten target of bremsstrahlung excited by a constant potentials of 60-140 kV. Physics in Medicine and Biology. v.22, n.2, p. 187-207, 1977.

25 Birch, R. Marshall, M. Computation of bremsstrahlung x-ray spectra and comparison with spectra measured with a $\mathrm{Ge}(\mathrm{Li})$ detector. Physics in Medicine and Biology, 24(3):505, 1979.

26 Archer, B. R.; Wagner, L. K. Determination of diagnostic x-ray spectra with characteristic radiation using attenuation analysis. Medical Physics, v. 15, n.4, p 637-641, 1988

27 Baird, L. C. X-ray spectra vs attenuation data: A theoretical analysis. Medical Physics, v.8, n.3, p 319-323, 1981

28 Malezan, A.; Antoniassi, M; Poletti, M.E; Tomal, A.; Watanabe, P.C.A.; Albino, L.D. Spectral Reconstruction of Dental X-ray Tubes Using Laplace Inverse Transform of the Attenuation Curve. Radiation Physics and Chemistry, 2015. Aceito para publicação. (doi:10.1016/j.radphyschem.2015.05.008).

29 Whiddington, R. The transmission of cathode rays through matter. Proceeding of the Royal Society. London Ser. v. 89, p. 554-560, 1914.

30 Ay, M. R.; Sarkar, S.; Shahriari, M.; Sardari, D.; Zaidi, H. Assessment of different computational models for generation of $\mathrm{x}$-ray spectra in diagnostic radiology and mammography. Medical Physics, v. 32, n.6, p 1660-1675, 2005 
31 Bissonnette, J. P.; Schreiner, L. J. A comparison of semiempirical models for generating tungsten target x-ray spectra. Medical Physics, v.19, n.3, p. 579-582, 1992.

32 Bhat, M.; Pattison, J.; Bibbo, G.; Caon, M. Diagnostic X-ray spectra: A comparison of spectra generated by different computational methods with a measured spectrum. Medical Physics, v.25, n.1, p 114-120, 1998.

33 Künzel, R.; Herdade, S. B.; Terini, R. A.; Costa, P. R. X-ray spectroscopy in mammography with a silicon PIN photodiode with application to the measurement of tube voltage. Medical Physics, v. 31, n.11, p 2996-3003, 2004.

34 Bhat, M.; Pattison, J.; Bibbo, G.; Caon, M. Off-axis x-ray spectra: A comparison of Monte Carlo simulated and computed x-ray spectra with measured spectra. Medical Physics, v.26, n.2, p 303-309, 1999.

35 Mercier, J. R.; et al. Modification and benchmarking of MCNP for low energy tungsten spectra. Medical Physics, v. 27, n.12, p 2680-2687, 2000.

36 Meyer, P.; et al. Evaluation of the use of six diagnostic X-ray spectra computer codes. The British Journal of Radiology, v. 77, n.915, p 224-230, 2004.

37 Tucker D. M., Barnes G. T. and Wu X. - Molybdenum target x-ray spectra: A semiempirical model. Medical Physics 18, 402,1991.

38 Boone, J.M.; Seibert, J.A. An accurate method for computer-generating tungsten anode x-ray spectra from 30 to 140 kV. Medical Physics, v. 24, n.11, p 16611670, 1997.

39 Silva, M. C.; et al. Determination of the voltage applied to x-ray tubes from the bremsstrahlung spectrum obtained with a silicon PIN photodiode. Medical Physics, v. 27, n.11, p 2617-2623, 2000

40 Terini, R. A.; Pereira, M. A.; Künzel, R.; Costa, P. R.; Herdade, S.B. Comprenhensive analysis of the spectrometric determination of voltage applied to $\mathrm{x}$-ray tubes in the radiography and mammography energy ranges using a silicon PIN photodiode. The British Journal of Radiology, v. 77, p 395-404, 2004.

41 Okunade, A.A. Parameterized algorithms for quantitative differentials in spectrally equivalent medical diagnostic x-ray beams. Medical Physics, v. 32, n.6, p 17851795, 2005.

42 Costa P. R. and Caldas L. V. E. - Evaluation of protective shielding thickness for diagnostic radiology rooms: Theory and computer simulation Medical Physics. 29, 73, 2002.

43 Hoff, G.; e Costa, P. R. Estudo comparativo entre diferentes composições de materiais de blindagem e geometrias de feixe aplicadas a instalações para PET: curvas de transmissão simuladas. Rev. Bras. Eng. Bioméd. [online]. 2013, vol.29, n.1 [cited 2015-07-04], pp. 86-96 . 
44 Gonzales, A.H.L.; Tomal A; Costa P.R. Evaluation of characteristic-to-total spectrum ratio: Comparison between experimental and a semi-empirical model. Appl Radiat Isot. Jun;100:27-31, 2015

45 Bhat, M.; Pattison, J.; Bibbo, G.; Caon, M. Diagnostic X-ray spectra: A comparison of spectra generated by different computational methods with a measured spectrum. Medical Physics, v.25, n.1, p. 114-120, 1998.

46 Poletti JL, McLean D. - The effect of source to image-receptor distance on effective dose for some common X-ray projections. $\mathbf{B r} \boldsymbol{J}$ Radiol. 2005 Sep;78(933):810-5

47 NCRP - National Council on Radiation Protection and Measurement. Structural Shielding Design for Medical X-Ray Imaging Facilities. NCRP Report 147, Bethesda: NCRP, 2004. 125p

48 Archer B. R., Fewell T. R., Conway B. J. and Quinn P. W. Attenuation Properties of diagnostic X-Ray Shielding Materials, Medical Physics, v. 21(9), p. 1499-1507, 1994

49 Tomal, A.; Santos, J.C.; Costa, P.R.; Lopez Gonzales, A.H.; Poletti, M.E. Monte Carlo simulation of the response functions of CdTe detectors to be applied in $\mathrm{x}$ ray spectroscopy. Applied Radiation and Isotopes, v.100, n.3, p. 32-37, 2015.

50 Tomal, A.; Cunha, D.M.; Antoniassi, M.; Poletti, M.E. Response functions of Si(Li), SDD and CdTe detectors for mammographic x-ray spectroscopy. Applied Radiation and Isotopes, v. 70, n.7, p. 1355-1359, 2012.

51 Pfenniger, D. Computational issues connected with 3D N-body simulations. Astronomy and Astrophysics, v. 270, p. 561-572, 1993.

52 Barrett, H.H.; Swindell, W. Radiological Imaging: The Theory of Image Formation, Detection, and Processing.Vol.1. Academic Press, 1996.

53 Gonzales, A.H.L. Estudo experimental das relações entre kerma no ar e equivalente de dose ambiente em barreiras secudárias de salas radiológicas. São Paulo,2014. Dissertação de mestrado, Instituto de Física da Universidade de São Paulo.

54 Mariano, L. Desenvolvimento de materiais equivalentes ao tecido humano. São Paulo, 2015. Monografia para exame de qualificação para Doutorado, Instituto de Física da Universidade de São Paulo.

55 Santos, J. C. 2013. Estudo experimental das relações entre kerma no ar e equivalente de dose ambiente para o cálculo de barreiras primárias em salas radiológicas. Mestrado, Universidade de São Paulo.

56 Di Castro, E.; Pani, R.; Pellegrini, R.; Bacci, C. The use of cadmium telluride detectors for the qualitative analysis of diagnostic x-ray spectra. Physics in Medicine and Biology, v.29, n.9, p. 1117-1131. 1984.

57 Olive, K. A. et al (Particle Data Group), Chin. Phys. C, 38, 090001 ( 2014) 